Shock Initiation of New and Aged PBX 9501

Measured with Embedded Electromagnetic

Particle Velocity Gauges

R. L. Gustavsen

S. A. Sheffield

R. R. Alcon

L. G. Hill 



\section{DISCLAIMER}

This report was prepared as an account of work sponsored by an agency of the United States Government. Neither the United States Government nor any agency thereof, nor any of their employees, make any warranty, express or implied, or assumes any legal liability or responsibility for the accuracy, completeness, or usefulness of any information, apparatus, product, or process disclosed, or represents that its use would not infringe privately owned rights. Reference herein to any specific commercial product, process, or service by trade name, trademark, manufacturer, or otherwise does not necessarily constitute or imply its endorsement, recommendation, or favoring by the United States Government or any agency thereof. The views and opinions of authors expressed herein do not necessarily state or reflect those of the United States Government or any agency thereof. 


\section{DISCLAIMER}

Portions of this document may be illegible in electronic image products. Images are produced from the best available original document. 


\title{
Shock Initiation of New and Aged PBX 9501 Measured with Embedded Electromagnetic Particle Velocity Gauges
}

\author{
R. L. Gustavsen, S. A. Sheffield, R. R. Alcon, and L. G. Hill
}

\begin{abstract}
We have used an embedded electromagnetic particle velocity gauge technique to measure the shock initiation behavior in PBX 9501 explosive. Up to twelve separate particle velocity wave profile measurements have been made at different depths in a single experiment. These detail the growth from an input shock to a detonation. In addition, another gauge element called a "shock tracker" has been used to monitor the progress of the shock front as a function of time and position as it moves through the explosive sample. This provides data similar to that obtained in a traditional explosively driven wedge test and is used to determine the position and time that the wave attains detonation. Run distance-todètonation vs. input pressure (Pop-plot) data and particle velocity wave profile data have been obtained on new PBX 9501 pressed to densities of $1.826,1.830$, and $1.837 \mathrm{~g} / \mathrm{cm}^{3}$. In addition, the same measurements were performed on aged material recovered from dismantled W76 and W78 weapons. The input pressure range covered was 3.0 to $5.2 \mathrm{GPa}$. All results to date show shock sensitivity to be a function only of the initial density and not of age. PBX 9501 shock initiates the same after 17 years in stockpile as it does on the day it is pressed. Particle velocity wave profiles show mixed heterogeneous initiation (growth in the front) and homogeneous initiation (growth behind the front).
\end{abstract}

\section{INTRODUCTION}

During the 1970 's and through the early 1980 's a great deal of effort was expended characterizing the shock initiation behavior of PBX 9404. (PBX 9404 consists of 94 wt.\% HMX, 3 wt.\% nitrocellulose, and $3 \mathrm{wt} . \%$ chloro-ethyl-phosphate as the plasticizer.) Wedge tests were done to measure the run distance-to-detonation as a function of input pressure. ${ }^{1,2}$ In addition, several gas gun studies were done to examine the wave profiles in initiating PBX 9404. These studies included the embedded manganin gauge measurements of Ginsberg et al., 3,4 at Los Alamos and Green et al. ${ }^{5}$ and Vantine et al. ${ }^{6}$ at Lawrence Livermore, the embedded electromagnetic gauge measurements of Vorthman ${ }^{7}$ at Los Alamos, and Vantine et al. ${ }^{6}$ and Erickson et al. ${ }^{8}$, at Livermore, and the quartz gauge and interferometry measurements of Kennedy et al., ${ }^{9,10}$ and Setchell ${ }^{11,12}$ at Sandia. The input shocks were varied and included sustained shocks, ${ }^{1-10}$ double shocks, ${ }^{13,14}$ ramp waves ${ }^{11,14}$ and short shocks. ${ }^{12,14}$ The list above is meant to be representative of the experimental shock wave initiation work on PBX 9404. (We apologize to any authors whose work has been excluded.)

Complementing these experimental developments, a great deal of effort was expended trying to model the PBX 9404 initiation behavior using hydrocodes. Tarver and coworkers ${ }^{5,14}$ from Livermore modeled PBX 9404 initiation using their ignition and growth model. At Los Alamos, Wackerle and co-workers used multiple pressure or particle gauge records and DAGMAR (Direct Analysis of Gauges Modified Arrhenius Rate). ${ }^{3,7,15}$ Later Johnson, Tang, and Forest introduced the JTF model. ${ }^{16,17}$ At Sandia, Nunziato, working with Kennedy introduced yet another initiation model..$^{10,18,19}$ The above list is again meant to be representative rather than comprehensive. It should help to illustrate the notion that PBX 9404 became somewhat of a baseline material for anyone wanting to study the initiation of an explosive, either experimentally or numerically.

When PBX 9404 was found to be susceptible to initiation by sliding friction in the drop/skid test (a test to simulate handling accidents with large pieces of explosives), it was quickly replaced by PBX 9501, which did not exhibit the same handling problems. ${ }^{20}$ (PBX 9501 consists of $95 \mathrm{wt}$ \% HMX, 2.5 wt.\% estane and $2.5 \mathrm{wt} . \%$ nitroplasticizer.) The nitrocellulose was believed to be the reason for the drop/skid sensitivity of the PBX 9404 and this binder material is absent from the PBX 9501 formulation.

A number of experiments were performed on PBX 9501 that indicated that its shock initiation properties were close enough to PBX 9404 that a large number of new tests were unwarranted. About this same time, emphasis shifted to insensitive TATB-based formulations such as PBX 9502 and LX17, so the data on PBX 9501 is minimal.

Researchers verified that the run distance-to-detonation vs. pressure was about the same for PBX 9501 as for PBX $9404 .^{21}$ Vorthman et al. ${ }^{15}$ did a few embedded magnetic gauge experiments which also indicated comparable behavior. Other small scattered tests of a few experiments each were performed, but there was never the comprehensive effort directed toward understanding the initiation behavior of PBX 9501 that had accompanied PBX 9404; PBX 9501 was assumed to behave just like PBX 9404.

Recent interest in the characteristics and shock initiation of PBX 9501 has come from two fronts. First, the problem of 
accidental mechanical insult producing a violent reaction has prompted studies in the low stress regime by Dick et al. ${ }^{22,23}$ using plane impacts, and by Idar et al., ${ }^{24,25}$ and Chidester et al ${ }^{26}$ using spherical impactors. Secondly, it has become advisable (necessary) to leave the nuclear weapons (of which PBX 9501 is a component) in the stockpile for much longer periods than was originally envisioned; thus, the need to know if the properties of PBX 9501 change over long periods of time. Since there was not a large amount of baseline information on PBX 9501, comparisons between new and aged material were impossible. This study resulted from the need for this data.

The remainder of this report details our study of the sustained shock initiation of PBX 9501. To obtain baseline data we studied samples made from one powder lot and pressed to three different densities. These results were compared with data obtained from material recovered from two different weapons that had been in the stockpile for 124 and 201 months, respectively.

\section{EXPERIMENTAL DETAILS}

\section{PBX 9501 Samples}

Three different "new" PBX 9501 sample materials were made at Los Alamos National Laboratory (LANL) S-Site under the supervision of Manny Chavez (ESA-WMM), and two sample materials were recovered from dismantled weapons. These are summarized in Table 1, and discussed in the following paragraphs. Jose Archuleta, of DX-2, measured densities for all samples using the water immersion method. The typical standard deviation was $0.001 \mathrm{~g} / \mathrm{cm}^{3}$ in density for all parts made from a particular pressing. All new sample materials were pressed from Holston PBX 9501 molding powder lot 89C730-010 which was manufactured in 1989. Material pressed from this powder has been used by Idar et al., ${ }^{24,25}$ and Dick et al. $^{22,23}$. We will designate the new materials A, B, and C.

Material A refers to pressing number 96-741319 (hydrostatically pressed in a $13.5 \times 13.5 \times 3.5$ inch block) and has a nominal density of $1.826 \mathrm{~g} / \mathrm{cm}^{3}$. This is the same pressing used by Jerry Dick et al. for their recent experiments. ${ }^{22,23}$

Material B designates pressing number 97-525099 (hydrostatically pressed into a 9 inch diameter by 11 inch high cylinder) which has a nominal density of $1.830 \mathrm{~g} / \mathrm{cm}^{3}$.
Material $\mathrm{C}$ designates material that was pressed in a multi264 steel die (S-site term) measuring 3-inch diameter by $21 / 8$ inch thick. It had a nominal density of $1.837 \mathrm{~g} / \mathrm{cm}^{3}$. As usual, there was concern that the ram or die pressing could result in variations in density throughout the sample. For our experiments, the pressings were machined into 3 or more parts, each with $\mathrm{cm}$ scale dimensions. The density variation among parts was less than $0.001 \mathrm{~g} / \mathrm{cm}^{3}$, alleviating this concern. There is also a concern that the die pressing modifies the particle size distribution or morphology in a way different than the hydrostatic pressing. Particle size distribution or morphology is thought to be an important factor in shock initiation. As will be discussed later, our results show no measurable difference.

The material we designate "W76" was recovered from a dismantled W76 nuclear weapon. The piece number is 761100830 , and it was pressed from powder lot 730-006. The weapon spent 124 months in stockpile before it was dismantled. Nominal density for this material was $1.838 \mathrm{~g} / \mathrm{cm}^{3}$.

The material designated "W78" was recovered from a dismantled W78 nuclear weapon. The piece number is 781020331 and powder lot $685-006$ was used to make the pressing. The weapon spent 201 months in stockpile before it was dismantled. Nominal density for this material was 1.838 $\mathrm{g} / \mathrm{cm}^{3}$.

\section{Overall Experimental Configuration}

The overall configuration for the initiation experiments is shown in Figure 1. This is the same configuration used by Vorthman.,15 A projectile made of Lexan, or with a Lexan nose, is faced with a non metallic impactor disk and launched in a 72-mm bore single-stage gas gun. When the impactor strikes the explosive sample, a planar shock wave is generated which begins the initiation process. For the experiments discussed here, the impactors were $2^{1 / 4}$ inch $(57 \mathrm{~mm})$ diameter by 0.43 inch $(11 \mathrm{~mm})$ thick, and the explosive sample (or target) was 2 inch $(51 \mathrm{~mm})$ diameter by $\approx 1$ inch $(25 \mathrm{~mm})$ thick.

Gauges embedded in the sample at various depths from the impact plane measured the particle velocity, as well as the position of the shock front with time. The construction and operation of these gauges will be discussed in a following section.

Table 1. Summary of Materials

\begin{tabular}{|c|c|c|c|c|}
\hline $\begin{array}{c}\text { Mat- } \\
\text { erial }\end{array}$ & $\begin{array}{c}\text { Powder } \\
\text { Lot }\end{array}$ & Piece No. & $\begin{array}{c}\text { Pressing } \\
\text { Method* }\end{array}$ & Density $\left(\mathrm{g} / \mathrm{cm}^{3}\right)$ \\
\hline \hline A & $730-010$ & $96-741319$ & Hydrostatic & $1.826 \pm 0.001$ \\
\hline B & $730-010$ & $97-525099$ & Hydrostatic & $1.830 \pm 0.001$ \\
\hline C & $730-010$ & $97-264309 \mathrm{x}$ & Ram & $1.837 \pm 0.001$ \\
\hline W76 & $730-006$ & $76-1100830$ & Hydro/Mandrel & $1.838 \pm 0.001$ \\
\hline W78 & $685-006$ & $78-1020331$ & Hydro/Mandrel & $1.838 \pm 0.001$ \\
\hline
\end{tabular}

* All pressings were made at $100^{\circ} \mathrm{C}$. 


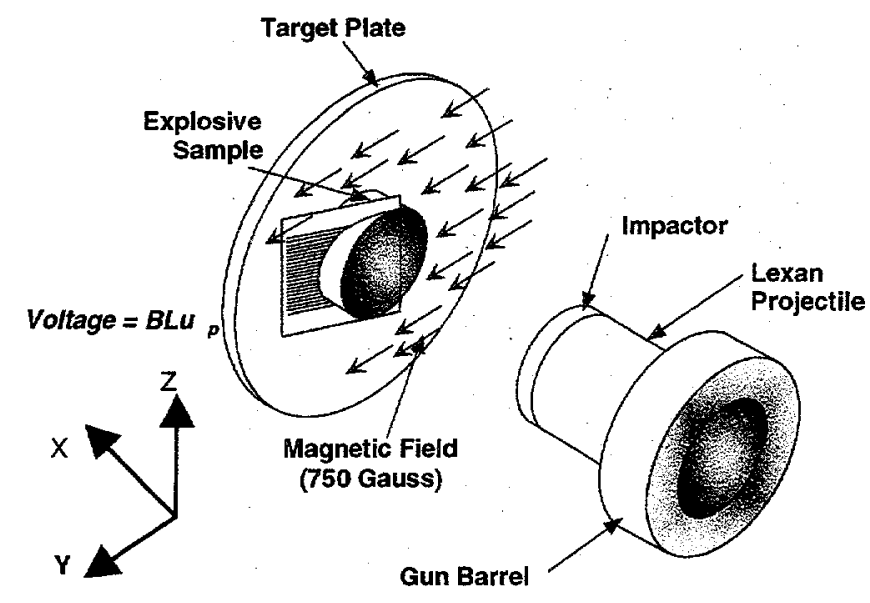

Figure 1. Overall experimental configuration. Explosive sample installed in gun target chamber and magnetic field.

The projectile impact velocity and the choice of impactor material determine pressure input to the sample. With gas guns the impact velocity can be precisely controlled by varying the combination of the gas pressure used to drive the projectile and the projectile mass. The projectile velocity is measured to $0.1 \%$ using precisely spaced electrical shorting pins.

Impactors used for the present experiments were either of Vistal (a high-density aluminum oxide ceramic sold by Coors), $\mathrm{z}$-cut alpha quartz, or $\mathrm{z}$-cut sapphire. Impact velocities of $0.55-0.82 \mathrm{~km} / \mathrm{s}$ produced stresses of $3.1-5.2 \mathrm{GPa}$ in the PBX 9501 samples.

In order to produce very planar impacts, the impactor disk is aligned to the projectile axis to less than 0.25 milliradian (mrad). ( 1 degree is $17.6 \mathrm{mrad}$ ). The target face is aligned perpendicular to the barrel axis to better than $0.5 \mathrm{mrad}$ using an auto-collimating telescope. With this gun, we typically get impactor target misalignments of less than 2 mrad at impact. Additional tilt can be due to such factors as the projectile wearing as it travels down the barrel, etc.

\section{Calculation of Impact Stresses}

Our goal in this study was to carefully compare run distance(time)-to-detonation versus input stress or pressure for various densities and ages of PBX 9501 . Our measurements of particle velocity $\left(u_{p}\right)$ and shock velocity $\left(U_{s}\right)$ have uncertainties of $2-3 \%$ each. If these measurements are considered independent, this implies the pressure is known with an absolute accuracy of about $4 \%$. For comparisons, we would like a better measure of the pressure than this.

Because they are elastic at stresses less than $9 \mathrm{GPa}$, we know the Hugoniots of the impactors to an accuracy of about $1 \%{ }^{27,28,29}$ Linear $U_{S}-u_{p}$ Hugoniot (Equation 1) parameters for these materials are given in Table 2. Further, we can measure impact velocities very accurately, to $0.1 \%$. This suggests that if we carefully construct a Hugoniot for the PBX 9501, we
Table 2. Impactor material Hugoniots

\begin{tabular}{|c|c|c|c|c|}
\hline Material & $\rho_{0}\left(\mathrm{~g} / \mathrm{cm}^{3}\right)$ & $C(\mathrm{~km} / \mathrm{s})$ & $S$ & Ref. \\
\hline Vistal & 3.966 & 10.75 & 0.00 & 27 \\
\hline z-cut $\alpha$ quartz & 2.65 & 6.32 & 1.38 & 28 \\
\hline z-cut sapphire & 3.985 & 11.19 & 1.00 & 29 \\
\hline
\end{tabular}

should be able to get impact pressures, at least for comparison purposes, with an accuracy of $1 \%$.

Previous experience suggests that even small $1.5-2.0 \%$ porosities can have an effect on the Hugoniot. This level of porosity is characteristic of PBX 9501 and other pressed high explosives. We will account for this porosity by using the "Snow-Plow" model. Because all of the porosity is surely removed by a $3 \mathrm{GPa}$ shock, this ought to be valid in the $3 \mathrm{GPa}+$ pressure range of the present experiments.

Using formalism presented in McQueen et $\mathrm{al}^{30}{ }^{30}$, the Hugoniot of a porous material can be determined. Porous materials are comprised of solid material and void. Formalism for constructing equations of state (EOS) for porous materials involve knowing or constructing an EOS for the solid material and then properly accounting for the voids. We make the assumption that the solid material has a linear $U_{s}-u_{P}$ Hugoniot,

$$
U_{S}=C+S u_{p}
$$

where $C$ and $S$ are constants, and use the conservation of mass jump condition and the definition

$$
X=1-V / V_{0} .
$$

In Equation (2), $V$ is the specific volume or $1 / \rho$, where $\rho$ is the density. $V_{0}$ is the specific volume of the solid at ambient conditions. This is $1 / \mathrm{TMD}$, where TMD stands for the theoretical maximum density. Then, the pressure on the Hugoniot, $P_{H}$, is

$$
P_{H}=\frac{1}{V_{0}} \frac{C^{2} X}{(1-S X)^{2}} .
$$

If we make the usual assumption regarding the Gruneisen's parameter, $\Gamma$, that

$$
\rho \Gamma=\frac{\Gamma}{V}=G=\text { const },
$$

then the formalism of McQueen et al. ${ }^{30}$ results in the following form for the Hugoniot of the porous material, 


$$
P=\frac{\frac{C^{2} X}{(1-S X)^{2}}\left(\frac{1}{V_{0}}-\frac{G X}{2}\right)}{1-\frac{G}{2}\left(V_{00}-V_{0}(1-X)\right)}
$$

The only as yet unidentified symbol in equation 5 is $V_{00}$, the initial specific volume of the porous material.

Particle velocity and shock velocity for the porous material at a specific $P, V$ state are calculated using the usual equations:

$$
\begin{aligned}
& u_{P}=\sqrt{P\left(V_{00}-V\right)} \\
& U_{s}=V_{00} \sqrt{\frac{P}{V_{00}-V}} .
\end{aligned}
$$

In order to get Hugoniot's for various densities, we first establish a Hugoniot for the solid material at TMD, $\rho_{0}=1.860 \mathrm{~g} / \mathrm{cm}^{3}$. Then we adjust parameters $(C$ and $S)$ for this Hugoniot so as to match the Hugoniot which is available for the porous material. We did this as follows.

Jerry Dick et al. ${ }^{22,23}$ have made Hugoniot measurements on $1.826 \mathrm{~g} / \mathrm{cm}^{3}$ PBX 9501 . Combining their measurements with the 1.832 and $1.844 \mathrm{~g} / \mathrm{cm}^{3}$ measurements reported in Gibbs and Popolato, ${ }^{21}$ they suggested a Hugoniot of

$$
U_{S}=2.40 \pm 0.03+2.39 \pm 0.07 u_{P} \quad \mathrm{~km} / \mathrm{s}
$$

for these three data sets. Based on these measurements, we adjusted the constants $C$ and $S$ for the solid Hugoniot so as to get $U_{S}=2.4+2.4 u_{P}$ for $V_{00}=1 / 1.834 \mathrm{~g} / \mathrm{cm}^{3} .\left(1.834 \mathrm{~g} / \mathrm{cm}^{3}\right.$ is the average of the three densities used by Dick. ${ }^{22,23}$ ) $\rho \Gamma=G=2.1$ was used, as suggested by the work of Olinger et al. ${ }^{31}$, and $V_{0}$ was based on the theoretical maximum density of $1.860 \mathrm{~g} / \mathrm{cm}^{3} .{ }^{21} C=2.65 \mathrm{~km} / \mathrm{s}$ and $S=2.3$ provided a good fit in the range $0.3-0.9 \mathrm{~km} / \mathrm{s}$.

Figure 2 presents Hugoniots for PBX 9501 at TMD, $1.837,1.830,1.826,1.800$, and $1.700 \mathrm{~g} / \mathrm{cm}^{3}$. The straight red line represents the nominal $U_{s}=2.4+2.4 u_{P}$ fit. Note that the Hugoniots for 1.830 and $1.837 \mathrm{~g} / \mathrm{cm}^{3}$ densities cluster very well around the $U_{S}=2.4+2.4 u_{P}$ line. Note also that there is about $0.1 \mathrm{~km} / \mathrm{s}$ variation in Hugoniots for densities of 1.826$1.837 \mathrm{~g} / \mathrm{cm}^{3}$. Purely by coincidence, this is equivalent to the uncertainty in the measured shock velocity, and to the RMS scatter in the Hugoniot data reported by Dick. ${ }^{22}$ Further, there is a substantial difference of about $0.18 \mathrm{~km} / \mathrm{s}$ between the calculated Hugoniots for PBX 9501 at typical densities and at TMD.

Input states, pressure and particle velocity, were calculated for each experiment using the impedance matching technique.

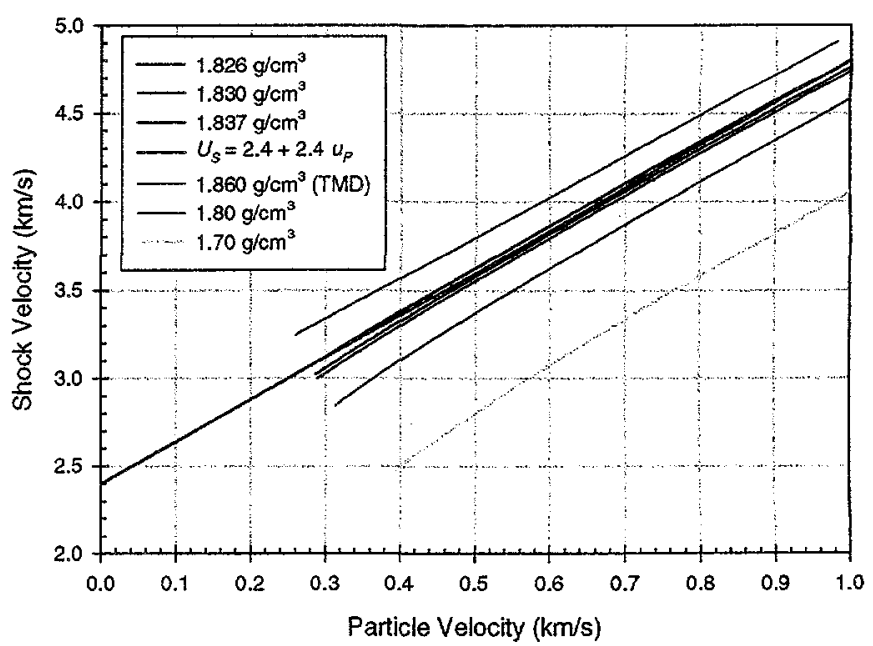

Figure 2. Calculated Hugoniots for PBX 9501 with various initial densities. The solid red line represents the nominal Hugoniot for $1.834 \mathrm{~g} / \mathrm{cm}^{3}$ PBX 9501 .

A Hugoniot for PBX 9501, appropriate for the initial density, was constructed in the pressure-particle velocity plane. Likewise, a Hugoniot appropriate for the impactor and the impact velocity was constructed. The impact pressure-particle velocity state was, as usual, defined as the point where these two Hugoniots cross. As we stated earlier, we believe that this method gives impact conditions that are internally consistent to about $1 \%$.

\section{Electromagnetic Particle Velocity Gauging}

Electromagnetic particle velocity gauging is based on Faraday's law of induction. For a conductor of length $\mathbf{L}$ moving with velocity $\mathbf{u}$ in a steady uniform magnetic field of strength $\mathbf{B}$, the induced voltage $V$ is,

$$
V=\mathbf{L} \bullet \mathbf{u} \times \mathbf{B}
$$

In Equation (9), all quantities but the induced voltage are vector quantities. If the experiment is designed so that the vectors $\mathbf{L}, \mathbf{u}$, and $\mathbf{B}$ are everywhere mutually orthogonal, this reduces to the scalar equation,

$$
V=L u B
$$

With reference to Figure 1, the projectile and thus velocity $\mathbf{u}$ is directed along the $\mathbf{x}$-axis, and the magnetic field $\mathbf{B}$ along the $\mathbf{y}$ axis. The active gauge length $\mathbf{L}$ must then lie along the $\mathbf{z}$ axis. In this configuration, leads which sense the voltage in the active element $\mathbf{L}$, can be made to have zero induced voltage by placing them in any orientation such that they are perpendicular to the active element $\mathbf{L}$. This gives a great deal of flexibility in lead placement.

In the experiments $B$ and $L$ are measured before the experiment and $V$, as a function of time, is recorded during the experiment. From this the conductor velocity $(u)$ as a function 
of time can be determined. If one assumes that the conductor moves with the material it is embedded in, then $u$ is the mass or particle velocity of the material at the particular Lagrangian position of the gauge.

Magnetic gauging was used first in Russia during the late 1940's and described in 1960 by Zaitzev et al. ${ }^{32}$ They used a loop gauge to measure particle velocity in explosively driven shock experiments. Dremin et al. report using these gauges in explosives in the $1960 \mathrm{~s}^{33,34}$

Although a number of researchers in the U. S. tried this method, it was not used extensively until the technique was developed further on gas guns at Physics International and Washington State University, largely under the direction of Fowles and coworkers ${ }^{35,36}$ during the 1970's. The first published reports of magnetic gauges being used in explosives by Americans were from Jacobs and Edwards ${ }^{37}$ in 1970 and Cowperthwaite and Rosenberg ${ }^{38}$ in 1976.

The magnetic gauge technique in use at LANL was developed by Vorthman and coworkers in the early 1980s. ${ }^{7,15,39}$ The pattern of conducting elements in a typical gauge configuration is shown in Figure 3. It includes 10 particle velocity gauges and a shock tracker ${ }^{40}$ in the center of the package. (Vorthman first conceived the idea of a shock tracker during the 1980s. ${ }^{7,15,39}$ However, it was not used at that time due to recording difficulties which have now been overcome.)

The active elements, $\mathbf{L}$, for particle velocity measurements are the horizontal segments. The longest active elements are $\approx$ $10 \mathrm{~mm}$ long, and are spaced $\approx 2 \mathrm{~mm}$ apart vertically. The sensing leads are the vertical segments, and as stated earlier, are perpendicular to the active element $\mathbf{L}$. The shock tracker is the center element with the square wave pattern.

The gauge membrane containing the conductors shown in Figure 3 is constructed as follows; first, a $5 \mu \mathrm{m}$ thick sheet of aluminum foil is glued onto a $25 \mu \mathrm{m}$ thick sheet of FEP Teflon. The aluminum is then etched leaving the gauge pattern shown in Figure 3. A $25 \mu \mathrm{m}$ thick sheet of FEP Teflon is glued on top of the etched aluminum, resulting in a robust membrane or

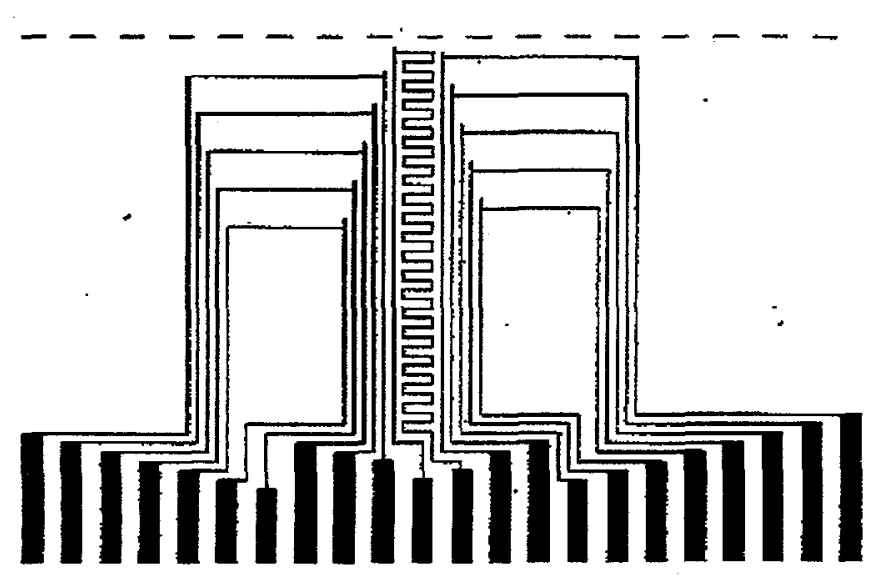

Figure 3. Pattern of conductors used for electromagnetic particle velocity gauging in explosives. package $\approx 60 \mu \mathrm{m}$ thick. We call this the Vorthman gauge after its originator. Frank Hines and Scott Sahlen at RdF Corporation, Hudson, New Hampshire developed the gluing and etching process and make these gauge packages for us. The gauge design can be easily changed by supplying $\mathrm{RdF}$ with a new etching mask.

\section{Mounting the Vorthman Gauge in Explosives}

Figure 4 shows how the Vorthman gauge is installed in the high explosive sample. Wedge shaped pieces that fit together are machined from right circular cylinders of explosive. The angle in these experiments was 30 degrees. The gauge membrane is glued to the bottom wedge, typically with a two-part glue called aralhex, a Los Alamos urethane based adhesive found to be compatible with most explosives. Care is taken to align the active gauge elements with the top surface of the wedge, and the depths of the elements from this surface are measured. Because of the 30-degree angle of the wedge, elements spaced $\approx 2 \mathrm{~mm}$ apart on the membrane will be spaced $\approx$ $1 \mathrm{~mm}$ apart in depth. Staggering the elements on two sides results in the 10 active elements being located at depths of approximately 0.5 through $5.0 \mathrm{~mm}$ on $0.5 \mathrm{~mm}$ intervals.

When the glue under the gauge package has hardened, the top wedge is glued on. Typically the top surfaces of the two wedges do not match up and there is a glue ridge at the joint. To clean up this surface, a light machine cut is made; just enough to clean up the surface.

This method of having the gauges in a membrane and inserting the membrane on an angle into the explosive has sev-
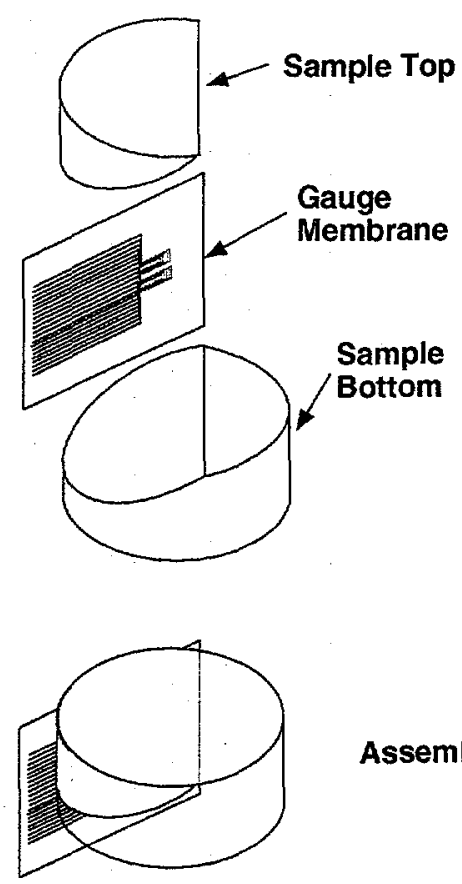

Assembly

Figure 4. Details of the explosive sample and the magnetic gauge package installation. 
eral advantages. First, many gauges can be put in, each at a different depth. Secondly, like the method of Cowperthwaite and Rosenberg, ${ }^{38}$ the gauges are staggered so they do not "shadow" each other, i.e., the particular part of the shock front that crosses a gauge does not cross any of the other gauges deeper in the flow. (If the gauges do shadow each other, ${ }^{8}$ mechanical cross talk caused by shock reflections can occur between the gauges.) Third, this method requires much less machining than the other methods. ${ }^{8,38}$. Finally, like the method of Cowperthwaite and Rosenberg ${ }^{38}$ (where the sensing leads are brought out the back of the sample) Vorthman's method minimizes lead spreading and the accompanying errors by angling the leads out the side/back.

The center element with the square wave pattern shown in Figure 3 is the shock tracker. When mounted in the wedge shaped sample shown in Figure 4, the gauge will have a periodically varying effective length with depth. As the shock sweeps through the sample, the effective length, and thus the output voltage, changes with the position of the shock front. The voltage output is high when the shock front is at a wide part of the gauge and low when the shock front is at a narrow part of the gauge. A time varying voltage trace is thus recorded. The time of a voltage change can be correlated with the shock position and an $x-t$ plot of the shock front can be obtained. ${ }^{40}$

The $x-t$ plots obtained using shock trackers are similar to those obtained in optical or pinned wedge tests. If a transition to detonation occurs within the depth spanned by the shock tracker, the shock-to-detonation transition can be determined.

Very often in the experiments described in this report, a 3$6 \mathrm{~mm}$ thick disk of explosive was glued on top of the completed assembly shown at the bottom of Figure 4. (The disk is not shown in Figure 4.) This allowed the point where detonation was achieved to be placed at a depth covered by the shock tracker elements.

"Stirrup" gauges are single element particle velocity gauges sandwiched between FEP Teflon sheets in a manner similar to the multi-element Vorthman gauge described previously. They are mounted in a plane parallel to the impact surface with the leads coming out the side and parallel to the magnetic field vector. They provide a particle velocity measurement at that plane. For example a stirrup gauge would be mounted on the top surface of the assembly shown in Figure 4. When disks were mounted on top of this assembly, as described above, an additional stirrup gauge would be mounted on top of the disk. Thus, a single experiment could have up to 12 particle velocity gauges.

As shown in Figure 1, the explosive sample is eventually mounted to a target plate. The target plate is placed in the gun target chamber between the poles of the electromagnet and positioned so the active elements of the gauges are perpendicular to the magnetic field.

\section{Tilt}

If the projectile impactor and target faces are not perfectly aligned at impact, a tilted shock will be introduced into the sample. Because the embedded gauges are spatially distributed in the sample, a tilted shock will have several effects. First, wave arrival times at the gauges will not be time correlated as they would be if the shock was not tilted. Second, the shock and/or detonation velocity will not be measured correctly because the phase velocity of the shock/detonation running along the shock tracker varies with angle. It is possible to over or under estimate these velocities depending on the magnitude of the tilt (up to 5\% errors). Lastly, shock tilt will increase the rise times of the particle velocity wave profiles.

Figure 5 shows schematically a typical sample with the gauges embedded; both the top and side views are shown. Active gauge elements are shown as blue, green, and red bars or spots, depending on the view. The red bar/spot is the stirrup gauge that sits on the impact surface. The blue and green bars/spots represent the active gauge elements located on the top and bottom of the sample, respectively. Coordinate systems for locating the gauge positions are also indicated. If the projectile face is tilted with respect to the target face, a contact line (red line with arrow) will sweep across the sample face and a tilted shock will be set up inside the material.

Using Figure 5, the position of each gauge element can be described by its $(x, y, z)$ coordinates. If the shock is not tilted, the arrival time of the shock at a gauge element will be given by

$$
t=\frac{z}{U_{s}}
$$

where $U_{s}$ is the shock velocity, and $z$ is the distance of the gauge below the impact surface. If the shock is tilted, but planar, the $x$ and $y$ positions of the gauge element are needed to predict the arrival time. For a shock tilted by a small angle $\alpha$
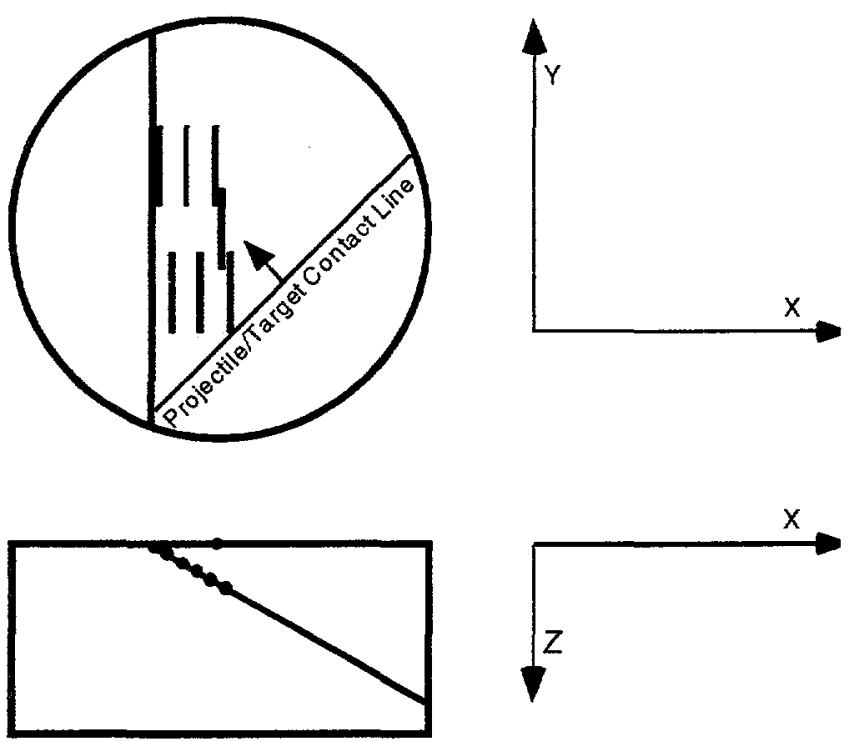

Figure 5 Schematic of the embedded gauge target shown in top and side views. 
from the $x$-axis and a small angle $\beta$ from the $y$-axis, the arrival time of the shock at a gauge element located at the position $(x, y, z)$ is given by

$$
t=\frac{z}{U_{S}}+\frac{\alpha x}{U_{S}}+\frac{\beta y}{U_{S}} .
$$

Tilt along the $\mathbf{x}$-axis affects primarily the apparent shock and detonation velocity. Tilt along the $y$-axis results in the grouping of top and bottom gauge signals in pairs.

Using the measured shock arrival times and $(x, y, z)$ positions of 5 or more gauge elements, one can perform a nonlinear least squares fit to Equation (12). The parameters $U_{s}, \alpha$ and $\beta$ are determined from the fit. It should be noted that if the arrival time and the position of the stirrup gauge are omitted from the fit, all the other elements are co-planar and the fit is indeterminate, i.e. the stirrup gauge in a different plane is necessary to do the analysis.

Once $\alpha$ and $\beta$ are determined from the fit, the total magnitude of the tilt can be determined

$$
\delta=\sqrt{\alpha^{2}+\beta^{2}} .
$$

The orientation of the tilt is

$$
\phi=\tan \left(\frac{\beta}{\alpha}\right)
$$

and describes the direction the contact line is moving with respect to the $\mathbf{x}$-axis of Figure 5 .

Equations (12) and (13) describe the tilt of the shock in the sample. Because of an analog to Snell's law of refraction, the impact tilt will be

$$
\delta_{\text {impact }}=\delta \frac{U_{\text {projectile }}}{U_{S}},
$$

where $U_{\text {projectile }}$ is the projectile velocity. Because the shock/detonation velocity is much higher than the projectile velocity, a small amount of impact tilt can result in a larger amount of shock tilt. For instance, if $\delta_{\text {impact }}=0.001$ (1 mrad), the projectile velocity is $0.5 \mathrm{~km} / \mathrm{s}$ and the shock velocity is 4 $\mathrm{km} / \mathrm{s}$, the shock tilt will be $\delta=0.008(8 \mathrm{mrad})$.

Once the tilt for an experiment has been determined, the data can be corrected to a no tilt condition using the following equation for the corrected time.

$$
t_{\text {corrected }}=t-\frac{\alpha x}{U_{S}}-\frac{\beta y}{U_{S}} .
$$

The correction of Eq. (16) must be applied to each gauge element including the shock tracker elements.
The caveat to the tilt measurement and correction program outlined above is that small misalignments of the gauges in the samples can produce the same effects with the same magnitudes. For example, if the right hand gauge of Figure 3 is misaligned relative to the left-hand gauge by 0.003 inch $(0.076$ $\mathrm{mm}$ ), or roughly the thickness of a sheet of paper, this will produce results equivalent to a shock tilt of $5 \mathrm{mrad}$. At the present time there is no way to differentiate between shock tilt and small gauge misalignments.

\section{EXPERIMENTAL RESULTS AND DISCUSSION}

Wave profiles of particle velocity vs. time and $x$ - $t$ plots of the shock trajectories were obtained at impact stresses of about 3.1, 3.9, and 5.2 GPa for each of the five PBX 9501 materials described previously in Table 1 . Table 3 (following page) summarizes data for all of the experiments described in this report. Data are grouped by pressure. That is, there is a $\approx 5.2$ $\mathrm{GPa}$ group, $\mathrm{a} \approx 3.9 \mathrm{GPa}$ group and $\mathrm{a} \approx 3.1 \mathrm{GPa}$ group. Within each group, shots are ordered by increasing density. Presented in the table are the material identification, the sample density, the projectile impact velocity and impactor material, the calculated impact conditions (based on the projectile velocity, and known Hugoniot of the impactor; see Table 3 for explanation), the measured Hugoniot conditions, parameters for the fit to determine run distance (discussed in a later section), and the measured run distance and time-to-detonation. Also listed is the tilt magnitude. For experiments with tilts of less than 0.3 mrad, no tilt correction was made. The remainder of this section will cover first, an example of the wave profiles, including how density and age affect them, and second, an example of the shock tracker data and its interpretation. Particle velocity wave profiles and shock tracker data from each experiment in this study are presented in Appendix A. 
Table 3. Summary of PBX 9501 Experiments (See Appendix A for additional data.)

\begin{tabular}{|c|c|c|c|c|c|c|c|c|c|c|c|c|c|c|c|}
\hline \multirow[b]{2}{*}{ Shot \# } & \multicolumn{2}{|c|}{$\begin{array}{l}\text { PBX 9501 } \\
\text { Description }\end{array}$} & \multicolumn{2}{|c|}{$\begin{array}{c}\text { Impact } \\
\text { Parameters }\end{array}$} & \multicolumn{2}{|c|}{$\begin{array}{c}\text { Calculated Impact } \\
\text { Conditions }\end{array}$} & \multicolumn{2}{|c|}{$\begin{array}{c}\text { Measured } \\
\text { Hugoniot State } \\
\end{array}$} & \multicolumn{3}{|c|}{$\begin{array}{l}\text { Equation } 17 \\
\text { Parameters } \\
\end{array}$} & \multicolumn{2}{|c|}{$\begin{array}{c}\text { Measured Run } \\
\text { to Detonation }\end{array}$} & \multirow{2}{*}{$\begin{array}{l}\text { Tilt } \\
\text { mrad }\end{array}$} & \multirow[b]{2}{*}{ Comment } \\
\hline & Type & $\rho_{0}$ & Material & $u_{I}$ & $P_{I}$ & $u_{P}$ & $u_{P}$ & $U_{S}$ & $a$ & $b$ & $x_{0}$ & $x^{*}$ & $t^{*}$ & & \\
\hline 1133 & A & 1.825 & Vistal & 0.817 & 5.12 & 0.697 & 0.69 & 4.00 & 0.1 & 2.379 & 0.04 & 5.1 & 1.13 & $<0.3$ & \\
\hline 1134 & B & 1.830 & Vistal & 0.814 & 5.13 & 0.694 & 0.68 & 4.02 & 0.1 & 2.307 & 0.02 & 5.8 & 1.27 & $<0.3$ & \\
\hline 1144 & $\mathrm{C}$ & 1.837 & Vistal & 0.816 & 5.21 & 0.694 & 0.68 & 4.04 & 0.1 & 2.302 & 0.03 & 5.6 & 1.23 & $<0.3$ & \\
\hline 1145 & $\mathrm{C}$ & 1.837 & Vistal & 0.811 & 5.17 & 0.690 & 0.68 & 4.03 & 0.1 & 2.292 & 0.03 & 5.9 & 1.28 & $<0.3$ & \\
\hline 1154 & W76 & 1.838 & Vistal & 0.819 & 5.24 & 0.696 & 0.68 & 4.03 & 0.1 & 2.314 & 0.03 & 5.6 & 1.22 & 1.1 & \\
\hline 1156 & W78 & 1.838 & Vistal & 0.817 & 5.22 & 0.694 & 0.68 & 4.00 & 0.1 & 2.364 & 0.00 & 5.3 & 1.17 & $<0.3$ & \\
\hline 1162 & $A$ & 1.826 & Vistal & 0.663 & 3.89 & 0.572 & 0.56 & 3.75 & 0.1 & 2.487 & 0.03 & 7.2 & 1.71 & 0.5 & \\
\hline 1161 & A & 1.826 & z-quartz & 0.798 & 3.92 & 0.575 & 0.56 & 3.73 & 0.1 & & 0.07 & & & 1.5 & Tracker broke \\
\hline 1164 & B & 1.830 & Vistal & 0.667 & 3.95 & 0.574 & 0.56 & 3.75 & 0.1 & 2.412 & 0.06 & 8.4 & 1.99 & 1.4 & \\
\hline 1155 & $\bar{B}$ & 1.830 & Vistal & 0.663 & 3.92 & 0.571 & 0.56 & 3.68 & 0.1 & & 0.09 & & & 0.3 & Tracker broke \\
\hline 1150 & C & 1.837 & Vistal & 0.653 & 3.90 & 0.562 & 0.55 & 3.71 & 0.1 & 2.435 & 0.05 & 8.8 & 2.12 & 2.5 & \\
\hline 1179 & W76 & 1.838 & sapphire & 0.620 & 3.68 & 0.538 & 0.54 & 3.67 & 0.1 & 2.395 & 0.03 & 10.5 & 2.57 & $\mathrm{NA}$ & $\begin{array}{l}\text { Only tracker } \\
\text { gauge worked }\end{array}$ \\
\hline 1178 & W78 & 1.837 & sapphire & 0.638 & 3.82 & 0.553 & 0.55 & 3.69 & 0.1 & 2.416 & -0.03 & 9.6 & 2.33 & 1.0 & \\
\hline 1075 & $\mathrm{~A}$ & 1.826 & Vistal & 0.586 & 3.32 & 0.508 & 0.51 & 3.64 & 0.1 & & 0.02 & & & $<0.3$ & Tracker broke \\
\hline 1163 & $\bar{A}$ & 1.825 & Vistal & 0.552 & 3.07 & 0.480 & 0.47 & 3.49 & 0.1 & 2.674 & -0.05 & 10.58 & 2.76 & $<0.3$ & \\
\hline 1171 & B & 1.830 & z-quartz & 0.656 & 3.09 & 0.478 & 0.47 & 3.51 & 0.1 & 2.556 & 0.20 & 12.2 & 3.14 & 2.0 & \\
\hline 1146 & $\mathrm{C}$ & 1.837 & z-quartz & 0.652 & 3.10 & 0.474 & 0.47 & 3.49 & 0.1 & 2.522 & 0.15 & 13.7 & 3.56 & 0.0 & \\
\hline 1147 & $\mathrm{C}$ & 1.837 & z-quartz & 0.651 & 3.10 & 0.473 & 0.47 & 3.49 & 0.1 & & 0.05 & & & 0.0 & Off tracker end \\
\hline 1165 & W76 & 1.838 & Vistal & 0.550 & 3.13 & 0.476 & 0.47 & 3.53 & 0.1 & 2.461 & 0.00 & 13.6 & 3.47 & 1.5 & \\
\hline 1177 & W78 & 1.837 & Vistal & 0.552 & 3.14 & 0.478 & 0.46 & 3.50 & 0.1 & 2.554 & 0.10 & 12.6 & 3.26 & 0.0 & \\
\hline
\end{tabular}

$\rho_{0}:$ Initial density $\left(\mathrm{g} / \mathrm{cm}^{3}\right)$

$u_{I}:$ Impact velocity $(\mathrm{km} / \mathrm{s})$

$P_{I}$ : Impact stress or pressure (GPa). This is calculated by impedance matching the impactor Hugoniot with the 'snow plow' Hugoniot for the PBX 9501.

$u_{P}:$ Impact particle velocity $(\mathrm{km} / \mathrm{s})$. This is calculated by impedance matching the impactor Hugoniot with the 'snow plow' Hugoniot for the PBX 9501 .

The measured particle velocity is obtained from the first gauge element.

$U_{S}:$ Shock velocity $(\mathrm{km} / \mathrm{s})$. This was measured through fitting $x-t$ data to Equation 17.

$a$ : Initial acceleration parameter from Equation 17.

$b$ : Parameter from Equation 17 which controls run to detonation.

$x_{0}$ : Initial offset $(\mathrm{mm})$. This is also used in Equation 17. It should indicate how accurately gauge positions are known.

$x^{*}$ : Run distance to detonation (mm). Obtained through fit to Equation 17.

$t^{*}$ : Time to detonation $(\mu \mathrm{s})$. Also obtained through the fit to Equation 17. 
Table 4. Summary of Gauge Positions (See Appendix A for additional data.)

\begin{tabular}{|c|c|c|c|c|c|c|c|c|c|c|c|c|c|}
\hline \multirow{3}{*}{ Shot \# } & \multicolumn{13}{|c|}{ Cap* Thickness (mm) } \\
\hline & \multicolumn{13}{|c|}{ Gauge Positions (mm from impact surface) } \\
\hline & & $1^{\text {st }} \mathrm{St}$. & $2^{\text {nd }} \mathrm{St}$. & $\mathrm{G} 1$ & $\mathrm{G} 2$ & G3 & $\mathrm{G} 4$ & G5 & G6 & G7 & G8 & G9 & G10 \\
\hline 1133 & NA & & 0.00 & 0.51 & 1.01 & 1.50 & 2.02 & 2.49 & 3.00 & 3.48 & 3.99 & 4.47 & 4.98 \\
\hline 1134 & NA & & 0.00 & 0.43 & 0.92 & 1.42 & 1.93 & 2.41 & 2.92 & 3.40 & 3.91 & 4.38 & 4.90 \\
\hline 1144 & NA & & 0.00 & 0.91 & 1.41 & 1.90 & 2.42 & 2.89 & 3.41 & 3.88 & 4.40 & 4.86 & 5.39 \\
\hline 1145 & NA & & 0.00 & 0.43 & 0.93 & 1.41 & 1.94 & 2.41 & 2.93 & 3.40 & 3.92 & 4.38 & 4.91 \\
\hline 1154 & NA & & 0.00 & 0.43 & 0.92 & 1.42 & 1.93 & 2.40 & 2.91 & 3.39 & 3.90 & 4.37 & 4.88 \\
\hline 1156 & NA & & 0.00 & 0.46 & 0.95 & 1.45 & 1.96 & 2.43 & 2.95 & 3.42 & 3.94 & 4.41 & 4.92 \\
\hline 1162 & 3 & 0.00 & 3.07 & 3.57 & 4.07 & 4.56 & 5.07 & 5.55 & 6.06 & 6.53 & 7.05 & 7.52 & 8.03 \\
\hline 1161 & NA & & 0.00 & 0.44 & 1.17 & 1.91 & 2.64 & 3.38 & 4.12 & 4.85 & 5.59 & 6.33 & 7.07 \\
\hline 1164 & 3 & 0.00 & 3.08 & 3.47 & 3.97 & 4.46 & 4.98 & 5.44 & 5.96 & 6.43 & 6.95 & 7.42 & 7.94 \\
\hline 1155 & NA & & 0.00 & 0.38 & 1.12 & 1.86 & 2.60 & 3.33 & 4.07 & 4.80 & 5.54 & 6.28 & 7.02 \\
\hline 1150 & 3 & 0.00 & 3.03 & 3.41 & 3.90 & 4.40 & 4.91 & 5.39 & 5.90 & 6.38 & 6.89 & 7.37 & 7.88 \\
\hline 1179 & 3 & 0.00 & 3.08 & 3.55 & 4.04 & 4.54 & 5.06 & 5.54 & 6.05 & 6.53 & 7.05 & 7.52 & 8.04 \\
\hline 1178 & 3 & 0.00 & 3.11 & 3.63 & 4.12 & 4.62 & 5.13 & 5.60 & 6.12 & 6.59 & 7.10 & 7.58 & 8.09 \\
\hline 1075 & NA & & 0.00 & 0.45 & 0.93 & 1.44 & 1.94 & 2.43 & 2.93 & 3.41 & 3.92 & 4.41 & 4.91 \\
\hline 1163 & 6 & 0.00 & 6.08 & 6.59 & 7.08 & 7.57 & 8.08 & 8.56 & 9.07 & 9.55 & 10.06 & 10.53 & 11.04 \\
\hline 1171 & 6 & 0.00 & 6.04 & 6.50 & 7.01 & 7.50 & 8.02 & 8.49 & 9.01 & 9.46 & 10.00 & 10.44 & 10.98 \\
\hline 1146 & 6 & 0.00 & 6.01 & 6.93 & 7.43 & 7.92 & 8.43 & 8.91 & 9.42 & 9.90 & 10.41 & 10.89 & 11.40 \\
\hline 1147 & 3 & 0.00 & 3.01 & & 3.92 & & 4.91 & & 5.90 & & 6.88 & & 7.88 \\
\hline 1165 & 6 & 0.00 & 6.08 & 6.49 & 6.98 & 7.48 & 7.99 & 8.47 & 8.98 & 9.45 & 9.97 & 10.44 & 10.95 \\
\hline 1177 & 6 & 0.00 & 6.12 & 6.59 & 7.09 & 7.58 & 8.10 & 8.58 & 9.10 & 9.57 & 10.09 & 10.56 & 11.08 \\
\hline
\end{tabular}

* The cap is a disk of explosive placed on top of the assembly shown in Fig. 4. 


\section{Particle Velocity Wave Profiles}

Figures $6 \mathrm{a}$ and $6 \mathrm{~b}$ show wave-profiles from Shot 1133 where PBX 9501 of type A (see Table 1) was impacted with a Vistal impactor at a velocity of $0.817 \mathrm{~km} / \mathrm{s}$, producing an input of $5.12 \mathrm{GPa}$. There are eleven wave profiles at depths from 0 to $5 \mathrm{~mm}$ into the explosive. Profiles from different gauges are given different colors for ease of reading. Positions for the gauges are given in Table 4 . The first profile is from the stirrup gauge on the front of the sample and the remaining ten are from the embedded gauges. The input particle velocity is about $0.7 \mathrm{~km} / \mathrm{s}$ and this grows to over $2 \mathrm{~km} / \mathrm{s}$, very near a full detonation, by the time the wave reaches the last gauge at 5 $\mathrm{mm}$ into the sample. The gauges measure reliably even under these harsh conditions.

Figure $6 \mathrm{a}$ shows the profiles in a 3-D time-gauge depthparticle velocity plot that provides a good picture of the wave as it evolves. Figure $6 \mathrm{~b}$ shows the same data in 2-D, making it easier to see the magnitude of each of the profiles.

The input wave is flat-topped early on, as shown by the first wave profile. After about $0.25 \mu \mathrm{s}$, the particle velocity at this position begins to gradually decrease, indicating reaction is occurring and decelerating the impact interface. The other wave profile:; show some increase in amplitude at the shock front and a lirge following wave which builds with depth and eventually overtakes the shock front. By the time the wave has reached the last gauge, the following wave has overtaken the shock front. These features, a small amount of growth in the shock front and a large amplitude following wave, are common to all our experiments in PBX 9501 and have been seen in all other HMX based explosives. We usually refer to the character of growth purely in the shock front as having to do with heterogeneous initiation and the growth purely behind the shock front as being influenced by homogeneous initiation. Clearly the initiation of PBX 9501 is a mixed homogeneousheterogeneous initiation. (a)

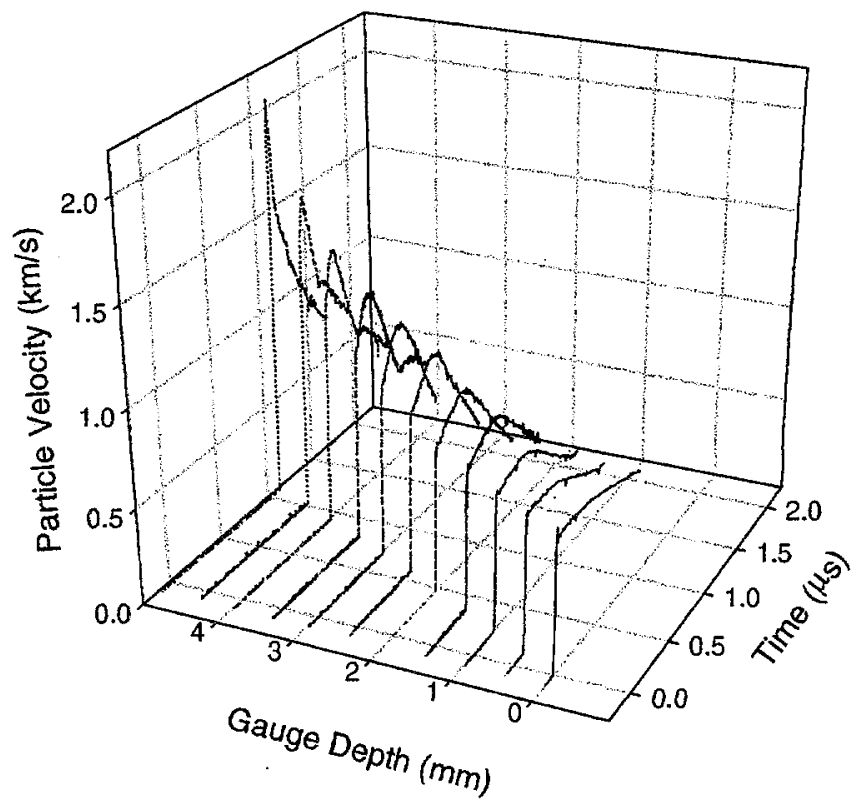

(b)

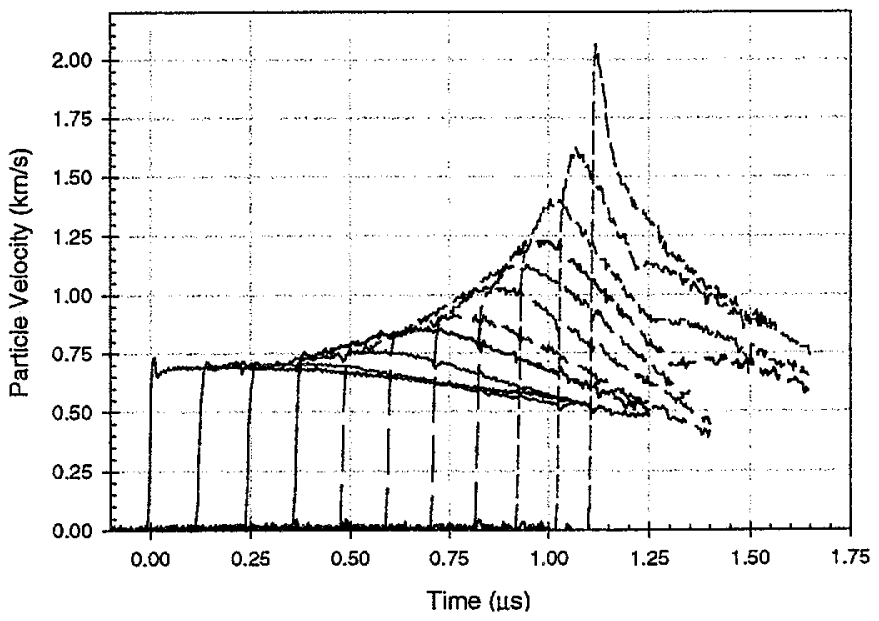

Figure 6. Particle velocity wave profiles from Shot 1133. The input is 5.15 GPa and was created by impacting Vistal on the PBX 9501 at $0.817 \mathrm{~km} / \mathrm{s}$. The PBX is of type A. 


\section{Effect of density on wave profiles}

Figure 7 shows the effect of initial density on the particle velocity wave profiles. Two experiments are shown in Figures $7 \mathrm{a}$, and $7 \mathrm{~b}$. In both experiments a Vistal disk impacted a PBX 9501 sample at $0.665 \pm 0.002 \mathrm{~km} / \mathrm{s}$ producing an input stress of $\approx 3.9 \mathrm{GPa}$. Both experiments had gauges located at 0 and 3 through $8 \mathrm{~mm}$ depths. Figure 7 a shows particle velocity wave profiles from Shot 1162 which used material A with initial density $1.826 \mathrm{~g} / \mathrm{cm}^{3}$ and Figure $7 \mathrm{~b}$ shows wave profiles obtained from Shot 1164 which used material B with initial density $1.830 \mathrm{~g} / \mathrm{cm}^{3}$. The input stress in Shot 1162 (Figure 7a) was $0.06 \mathrm{GPa}$ lower than in Shot 1164 (Figure 7b) because of the density difference.

(a)

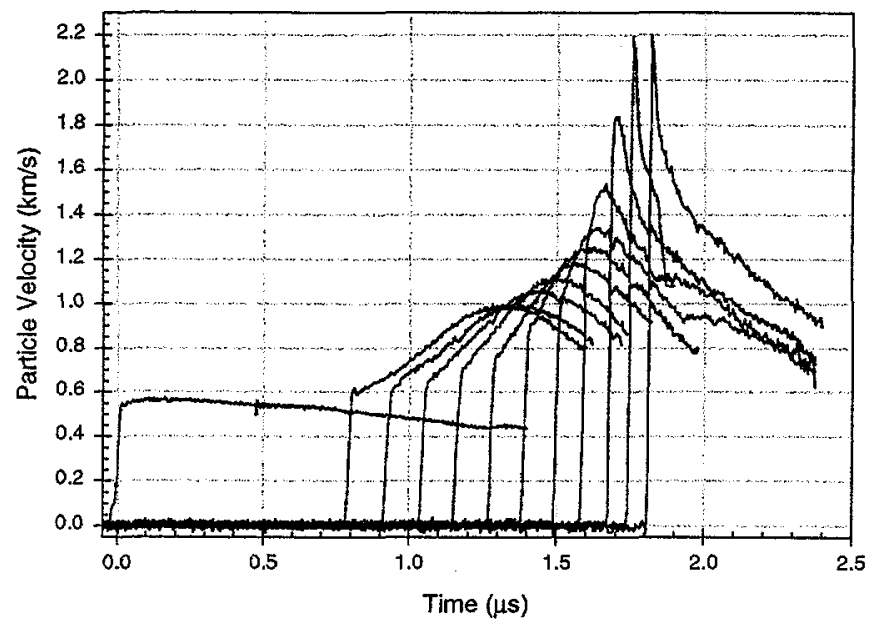

(b)

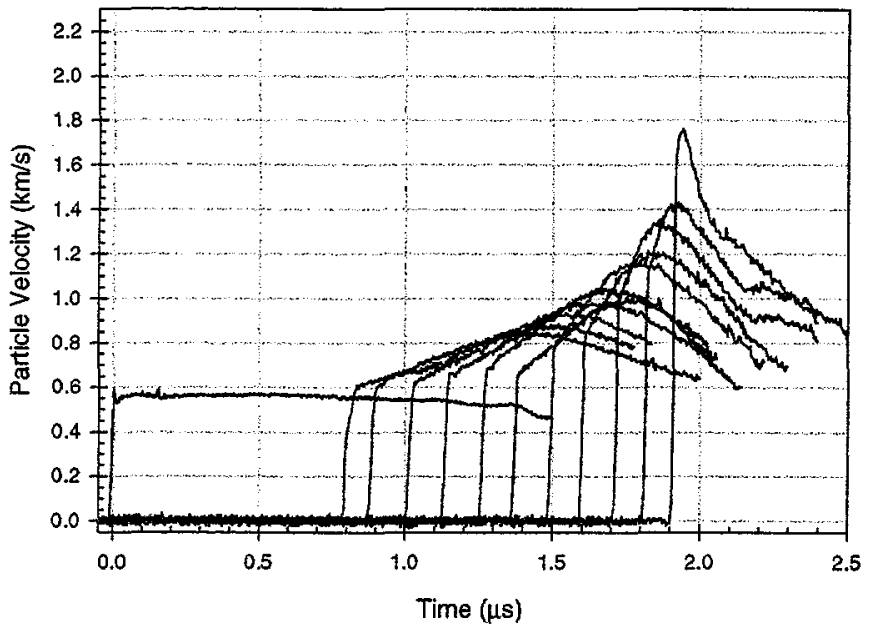

Figure 7. Effect of density on wave profiles. Particle velocity wave profiles for Shot 1162 (a) (material A, $1.826 \mathrm{~g} / \mathrm{cm}^{3}$ ) and Shot 1164 (b) (material B, 1.830 $\mathrm{g} / \mathrm{cm}^{3}$ ). Both experiments had Vistal impacting on the PBX 9501 at $0.665 \pm$ $0.002 \mathrm{~km} / \mathrm{s}$. This produced a stress of $3.92 \mathrm{GPa}$ in Shot 1164 and $3.86 \mathrm{GPa}$ in Shot 1162.
In the $1.826 \mathrm{~g} / \mathrm{cm}^{3}$ sample, detonation was achieved at 7.2 $\mathrm{mm}$, near the second to last gauge. This is quite apparent in Figure 7a, as C-J particle velocity of $2.2 \mathrm{~km} / \mathrm{s}$ (Ref. 41) is reached at the second to last gauge. In the $1.830 \mathrm{~g} / \mathrm{cm}^{3}$ sample, detonation was not achieved until $8.8 \mathrm{~mm}$, well beyond the last gauge. The last wave profiles do not even begin to approach the C-J condition. These figures clearly show that small changes in initial density significantly affect the wave profiles in the buildup to detonation. As expected, higher density materials do not build to detonation as quickly as low-density materials.

\section{Effect of age on wave profiles}

Figure 8 shows the effect of sample age on the particle velocity wave profiles. Wave profiles are presented from three experiments using the same input, the same sample density, but varying the age of the explosive. In all three experiments the input stress of $5.22 \pm 0.02 \mathrm{GPa}$ was produced by impacting Vistal on the 9501 with a velocity of $0.817 \pm 0.002 \mathrm{~km} / \mathrm{s}$. The red trace is from newly pressed material, the blue trace is from the W76 material that was aged 124 months in stockpile, and the green trace is from the W78 material that was aged 201 months in stockpile. Gauges were located at roughly, but not exactly, the same positions, and spanned depths of 0 through roughly $5 \mathrm{~mm}$.

Wave profiles clearly show very good repeatability from one experiment to the next, i.e., corresponding profiles from all three experiments fall almost exactly on top of one another. The slight differences in wave arrival times are caused by slight differences in the depths of individual gauges. At the last gauge, where one would expect differences to be greatest, profiles from all three experiments are very nearly the same.

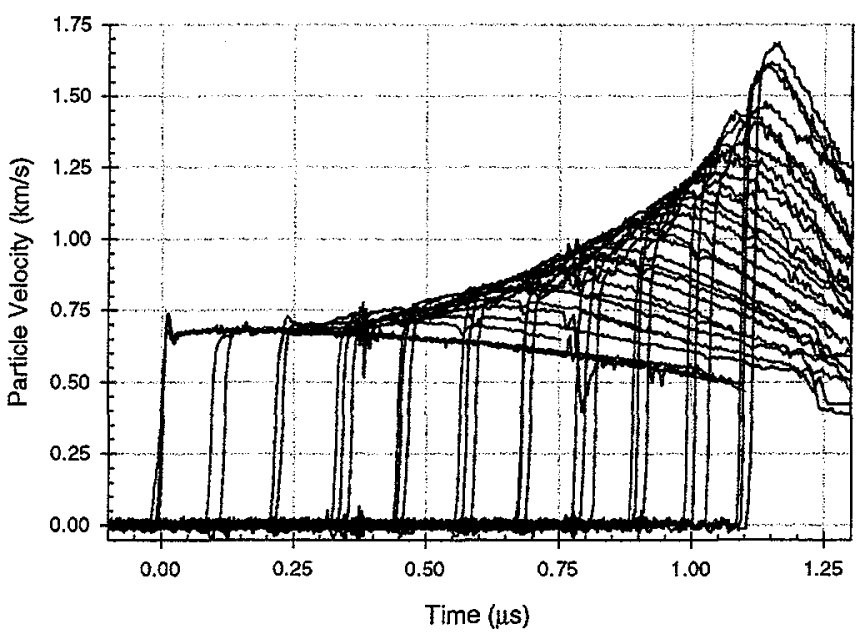

Figure 8. Effect of age on wave profiles. Particle velocity wave profiles for Shot 1144 (red curve, material C, $1.837 \mathrm{~g} / \mathrm{cm}^{3}$, new) Shot 1154 (blue curve, material W76, $1.838 \mathrm{~g} / \mathrm{cm}^{3}, 124$ months), and Shot 1156 (green curve, material W78, $1.838 \mathrm{~g} / \mathrm{cm}^{3}, 201$ months). All experiments had impact stresses of $5.22 \pm$ 0.02 GPa produced by impacting Vistal on the PBX 9501 at $0.817 \pm 0.002$ $\mathrm{km} / \mathrm{s}$. 
Clearly, the age of the sample affects the wave profiles, and therefore the shock initiation process, very little.

Comparison of the wave profiles shown in Figure 8 with those of Figure $6 \mathrm{~b}$, also clearly illustrates the effect of density on the wave profiles. All four of these experiments had inputs that were within $0.1 \mathrm{GPa}$ in pressure. The $1.826 \mathrm{~g} / \mathrm{cm}^{3}$ (low density material) shown in Figure $6 \mathrm{~b}$ has almost reached detonation by the last gauge position of $5 \mathrm{~mm}$. Clearly none of the higher density materials shown in Figure 8 have advanced the reaction to the same level, because the particle velocity peaks are significantly lower at the same positions. Thus, the wave profiles show that density affects the shock initiation process but sample age does not.

\section{Shock Tracker Data}

Figure 9 presents the raw output data from the shock tracker. These results are from Shot 1133, the $5.12 \mathrm{GPa}$ input experiment described previously with wave profiles shown in Fig. 6. As discussed earlier, the shock tracker output is high when the shock is at a wide part of the gauge and low when it is at a narrow part. Correlating the time when the gauge output changes from low to high (or vice versa) with the position of a width change is generally straightforward. There are a total of about 40 width changes with this gauge. They are spaced every $1 / 4 \mathrm{~mm}$, and cover about $10 \mathrm{~mm}$ in sample depth. The large change in amplitude occurs at about the time the shock wave transitions to a detonation wave. Even in this area, we have been able to correlate voltage changes with the position of a width change. The shock tracker position-time data are given in Appendix A for each experiment in this study.

The $x$ - $t$ plot showing the position of the shock front with time for Shot 1133 is shown in Figure 10. Red points were obtained from the shock tracker. Green points were obtained from the wave arrival times and initial gauge positions of the particle velocity gauges. The black points indicate

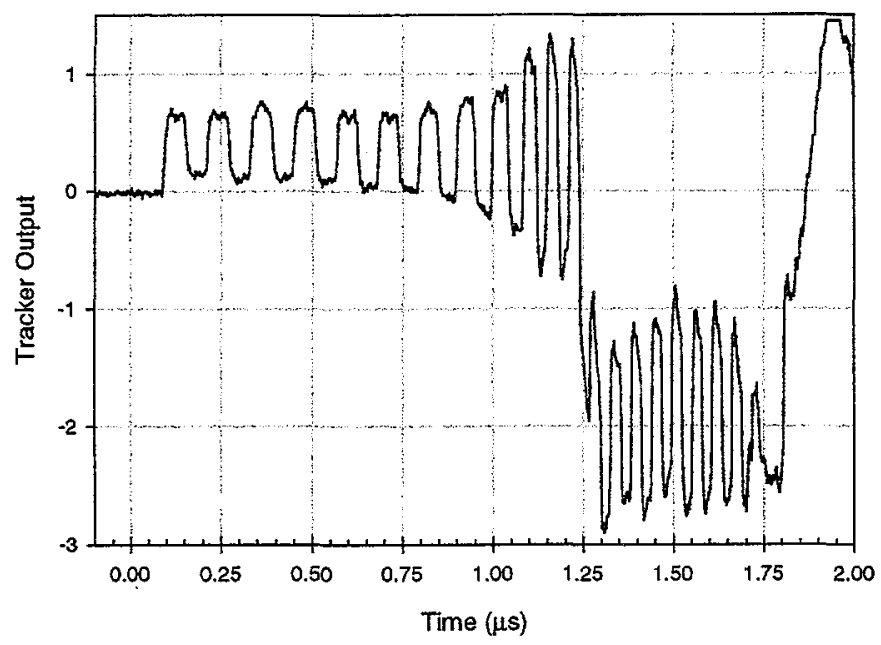

Figure 9. Shock tracker output for Shot 1133. The input is 5.12 GPa and was created by impacting Vistal on the PBX 9501 at $0.817 \mathrm{~km} / \mathrm{s}$. The PBX is of twne. A times/positions where the explosive is fully detonating. Lines through the data indicate shock velocity (initial slope) and detonation velocity (final slope). As discussed earlier, a small amount of impact tilt can cause detonation front tilts and thus errors in the apparent or measured detonation velocity (up to $5 \%$ error).

\section{Analysis of $x-t$ Shock Trajectories}

From plots such as those shown in Figure 10, there are a number of ways to determine the run distance (time)-todetonation. One can pick the point by eye or use the point where the lines (whose slopes indicate the detonation velocity and shock velocity) cross. The line crossing method is shown in Figure 10. We have found both of these methods, as well as several others, to be unreliable.

The method we have found most reliable is to choose a differential equation which mimics the shock front behavior in the position-time $(x-t)$ plane (like that shown in Figure 10) and which also behaves appropriately in every other plane which can be reached by integration or differentiation. Recent work by one of us (Larry Hill) indicates that by starting with an appropriately behaved differential equation in the shock velocityshock acceleration $(\dot{x}-\ddot{x})$ plane, these goals can be realized. (In this analysis, dots indicate differentiation with respect to time.)

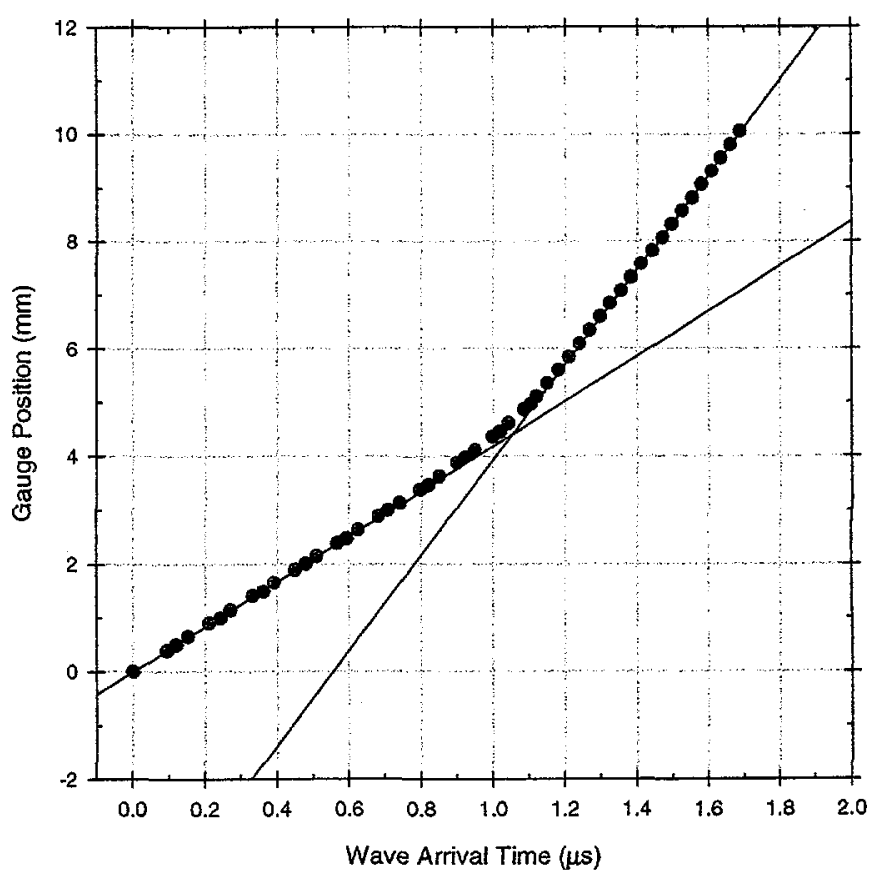

Figure 10. $x$ - $t$ plot for Shot 1133 obtained from shock arrival at shock tracker elements (red) and particle velocity gauge elements (green). 
The differential equation suggested by Hill is;

$$
\ddot{x}=\frac{\left(\frac{a}{100}\right) \dot{x}^{b+2}(\dot{x}-C)^{b+1}\left(D_{C J}-\dot{x}\right)}{(2 \dot{x}-C)\left(D_{C J}-0.99 \dot{x}\right)} .
$$

In Equation (17) the symbols and parameters have the following meanings: $a$ controls the initial acceleration of the wave; $b$, when other parameters are held constant, controls where turnover to detonation occurs; $C$ is the intercept of the explosive's Hugoniot in the shock velocity particle velocity or $U_{S}-u_{P}$ plane (Equation (1)); $D_{C J}$ is the Chapman Jouguet detonation velocity. $D_{C J}$ is usually obtained as a fit to the last few points of the measured $x-t$ trajectory. Equation (17) is solved numerically to find $x(t)$ with the constraint $\dot{x}(t=0)=U_{S}$, the initial shock velocity, and $x(t=0)=x_{0}$ the initial position (nominally 0.0 ).

We initially used "machine" fits in which Mathematica varied the parameters $a, b$, and $U_{s}$ over a limited range in an attempt to find the best fit according to a least squares criterion. We also tried hand/eye fits in which the best parameters were selected by trial and error. Both methods work well but give slightly different results. In the end we chose to use hand/eye fits with the parameter $a$ fixed at 0.1 . This resulted in very consistent values for $U_{s}$ from one experiment to the next. Allowing all parameters to vary resulted in less consistent values for $U_{S}$, although good fits.

Figure 11 shows the data of Fig. 10, the fit using Equation (17), and the residuals multiplied by 10 for Shot 1133 . Note that the residuals for the fit are typically $0.05 \mathrm{~mm}$, and all are under $0.1 \mathrm{~mm}$. From the fit we obtain the following information: the run distance-to-detonation, $x^{*}$, is $5.1 \mathrm{~mm}$; and the run time-to-detonation, $t^{*}$, is $1.13 \mu \mathrm{s}$. The point where detonation is achieved is arbitrarily defined to be the point where $99 \%$ of $D_{C I}$ is reached in the fit. We have arbitrarily set the error in run distance to be $0.4 \mathrm{~mm}$, or 1.5 times the spacing between shock tracker elements.

From Fig. 11 and the fit using Equation (17), the initial shock velocity, $U_{s}$, is determined to be $4.0 \mathrm{~km} / \mathrm{s}$, consistent with the predicted shock velocity of $4.0 \mathrm{~km} / \mathrm{s}$. The detonation velocity was determined to be $8.74 \mathrm{~km} / \mathrm{s}$, in good agreement with the predicted value of $8.75 \mathrm{~km} / \mathrm{s}$ for $1.826 \mathrm{~g} / \mathrm{cm}^{3}$ PBX 9501 based on Richard Catanach's ${ }^{42}$ empirical relation for the variation of $\mathrm{PBX} 9501$ detonation velocity with density,

$$
D_{C J}=1.88+3.76 \rho_{0} \text {. }
$$

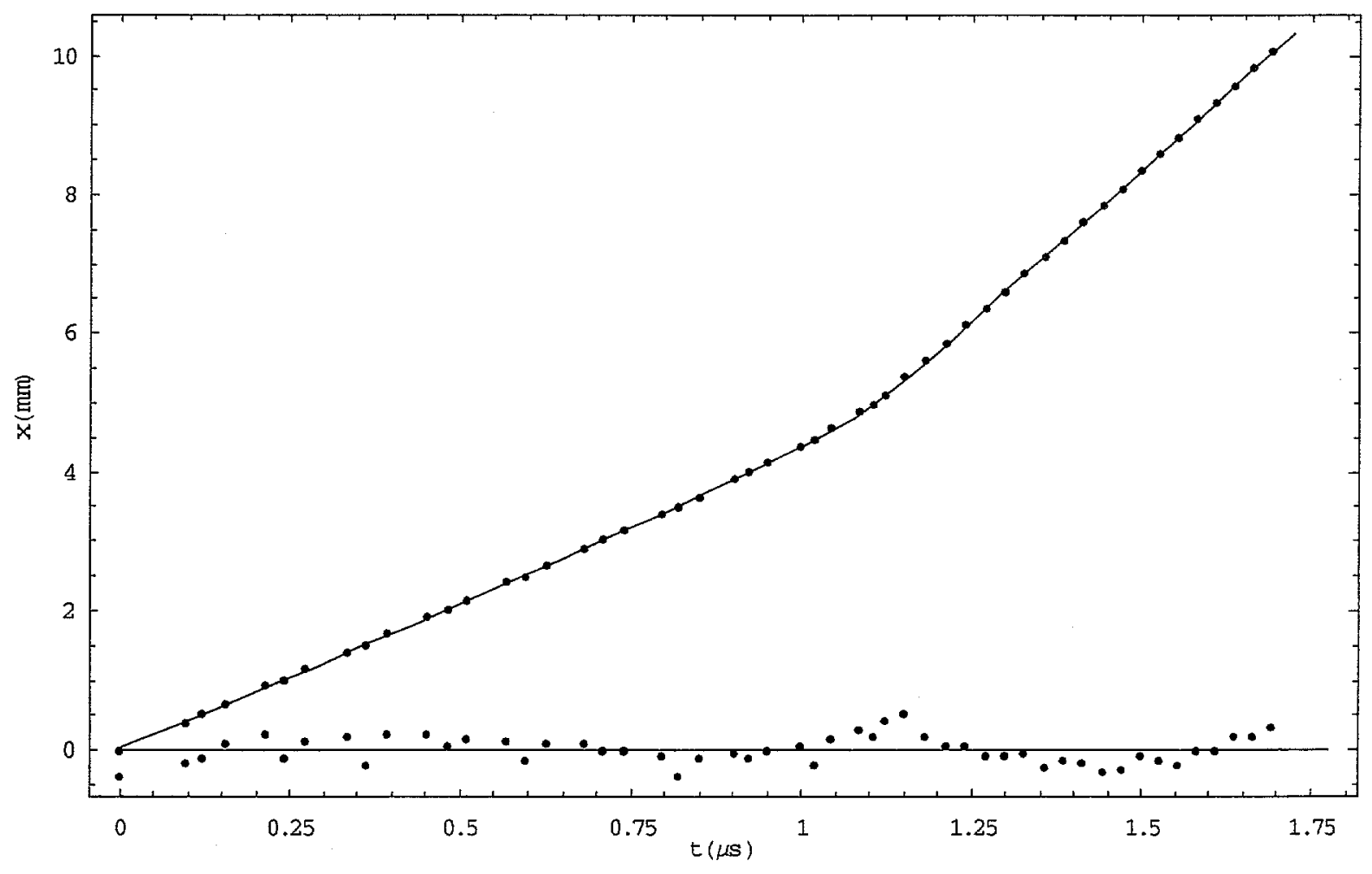

Figure 11. $x$ - $t$ data (dots along upper solid curve), fit (upper solid curve) and $10 \mathrm{x}$ residuals (dots about lower straight line) for Shot 1133 . 


\section{Pop-plots}

The Pop-plot, named after one of its originators, Alphonse Popolato, ${ }^{1}$ plots the run distance (time)-to-detonation as a function of the input stress (pressure). Most commonly it is plotted as a Log-Log plot. ${ }^{1}$ It has been found to be a very useful tool for measuring and ranking the shock sensitivity of explosives. The run distance-to-detonation is usually denoted by the symbol $x^{*}$, and the run time-to-detonation by the symbol $t^{*}$.

Figure 12 presents historical and new Pop-plots for PBX 9501. Table 5 summarizes straight-line fits to these data sets. The historical data sets were obtained from the compilation of Gibbs and Popolato. ${ }^{21}$ Both the $1.833 \mathrm{~g} / \mathrm{cm}^{3}$ and $1.844 \mathrm{~g} / \mathrm{cm}^{3}$ materials of Ref. 21 were die pressed in steel cups. This is the same method used to press our $1.837 \mathrm{~g} / \mathrm{cm}^{3}$ material $C$ whose points are also shown. Figure 12 shows large differences in the Pop-plots for the two materials. With a given input stress, the

(a)

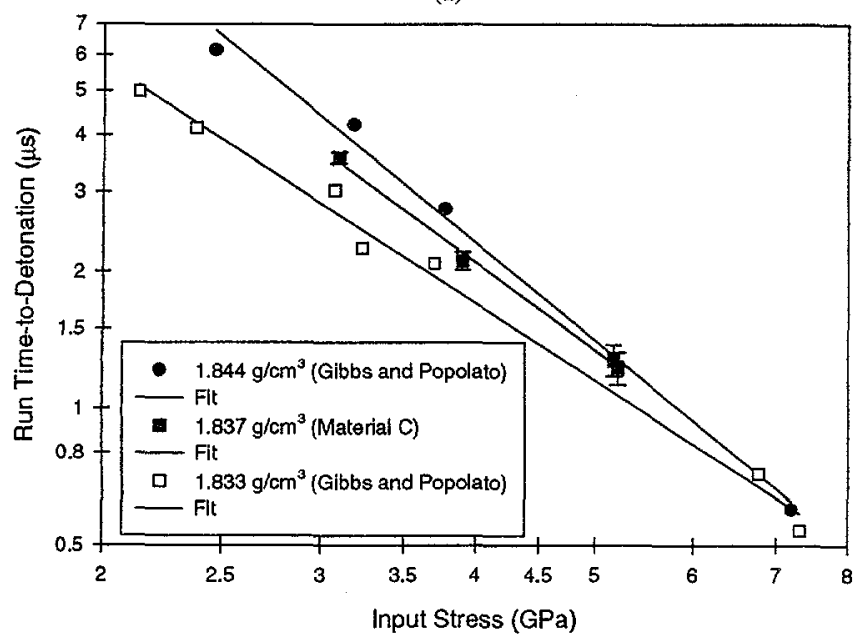

(b)

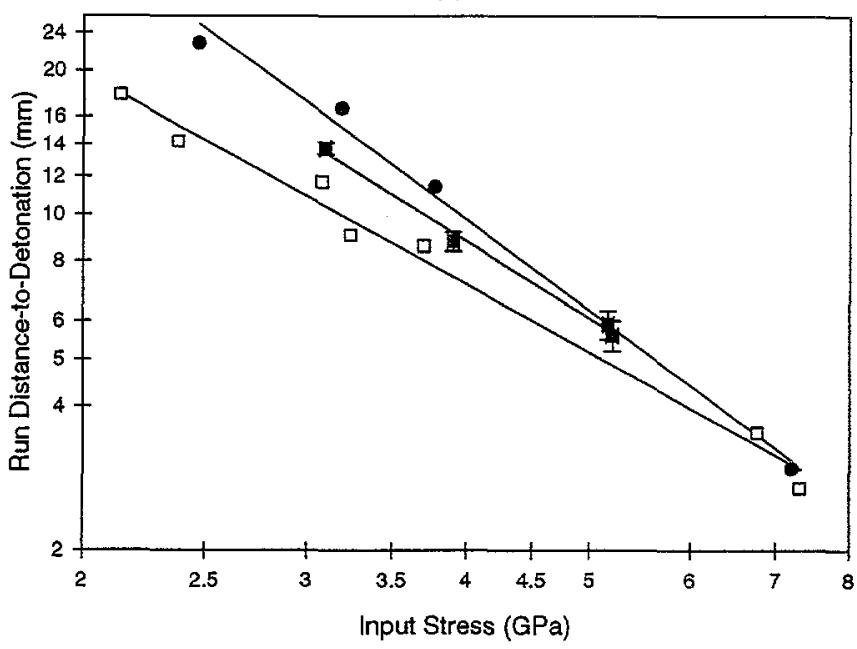

Figure 12. PBX 9501 Pop-plots for historical data sets and the present data set for $1.837 \mathrm{~g} / \mathrm{cm}^{3}$ material C. run distance/time is less for the $1.833 \mathrm{~g} / \mathrm{cm}^{3}$ material than for the $1.844 \mathrm{~g} / \mathrm{cm}^{3}$ material. This indicates that the lower density material is more sensitive, presumably due to more porosity, i.e., more hot spots. In general, the Pop-plot of a more sensitive material will lie below and/or to the left of the Pop-plot for a less sensitive material. The differences in the two materials run distance/time are most apparent at lower pressures, and rather small at higher pressures. The fitted lines appear to cross near $7 \mathrm{GPa}$, although the run distance is so small that experiments above this pressure are difficult.

The red points lying about the central red line are data from newly pressed PBX 9501 which has a density of 1.837 $\mathrm{g} / \mathrm{cm}^{3}$ (material C, see Table 1). Note first that data from our study falls between the two other curves. This is consistent with this material having a density intermediate between the densities of the other two materials, coupled with the common finding that increases in density result in decreases in sensitivity. It further demonstrates that our technique provides results consistent with explosively driven wedge experiments. ${ }^{21}$

Our error bars for $x^{*}$ were set at $11 / 2$ times the $0.25 \mathrm{~mm}$ spacing between shock tracker elements or $0.4 \mathrm{~mm}$. Error bars of $100 \mathrm{~ns}$ for $t^{*}$ were determined by dividing the $0.4 \mathrm{~mm} x^{*}$ error bar by the shock velocity of about $4 \mathrm{~mm} / \mu \mathrm{s}$. These are shown in Figure 12 for the data from this study.

Note that even with these generous error bars, there is much less scatter in our data than in the historical data. This could be due to a number of factors such as: (1) gas guns provide a better supported pressure pulse than explosive drivers; (2) the pressure is more accurately known because of the precisely measured impact velocity and the use of elastic impactors; and (3) our analysis technique for finding the run distance (time)-to-detonation is more consistent than what has been previously used.

Table 5. Pop-plot Fits

\begin{tabular}{|c|c|c|}
\hline Material & $\begin{array}{c}\text { Density } \\
\left(\mathrm{g} / \mathrm{cm}^{3}\right)\end{array}$ & Fits by Authors \\
\hline $\mathrm{A}$ & 1.826 & $\begin{array}{l}\log \left(x^{*}\right)=1.71-1.43 \log (P) \\
\log \left(t^{*}\right)=1.28-1.74 \log (P)\end{array}$ \\
\hline B & 1.830 & $\begin{array}{l}\log \left(x^{*}\right)=1.80-1.47 \log (P) \\
\log \left(t^{*}\right)=1.37-1.78 \log (P)\end{array}$ \\
\hline $\begin{array}{c}\text { C, } \\
\text { W76, }\end{array}$ & 1.837 & $\begin{array}{l}\log \left(x^{*}\right)=1.94-1.66 \log (P) \\
\log \left(t^{*}\right)=1.52-2.00 \log (P)\end{array}$ \\
\hline Ref. 21 & 1.833 & $\begin{array}{l}\log \left(x^{*}\right)=1.74-1.46 \log (P) \\
\log \left(t^{*}\right)=1.29-1.76 \log (P)\end{array}$ \\
\hline Ref. 21 & 1.844 & $\begin{array}{l}\log \left(x^{*}\right)=2.17-1.96 \log (P) \\
\log \left(t^{*}\right)=1.70-2.23 \log (P)\end{array}$ \\
\hline
\end{tabular}


Figure 13 presents Pop-plots for the 3 different density new PBX 9501 materials used in the present study; material $\mathrm{A}-1.826 \mathrm{~g} / \mathrm{cm}^{3}$, material $\mathrm{B}-1.830 \mathrm{~g} / \mathrm{cm}^{3}$, and material C-1.837 $\mathrm{g} / \mathrm{cm}^{3}$. As was noted earlier for the historical data sets ${ }^{21}$ we see an increase in sensitivity with decreasing density. For a given input stress, run distances (times)-to-detonation are shorter for lower density materials than those for higher density materials. Again differences are most distinct at low pressures and less distinct at high pressures. This result parallels the differences in wave profiles for different density materials which were seen in Figures 7 and $6 \mathrm{~b}$ vs. Figure 8. Those results also showed much faster buildup to detonation for lower density materials.

Data has just been presented which indicates that density differences of only 0.004 and $0.007 \mathrm{~g} / \mathrm{cm}^{3}$ affect the buildup to detonation, i.e., the Pop-plot. The fact that this technique can consistently make this discrimination is impressive. These kinds of experiments should prove to be a powerful discrimi-

(a)

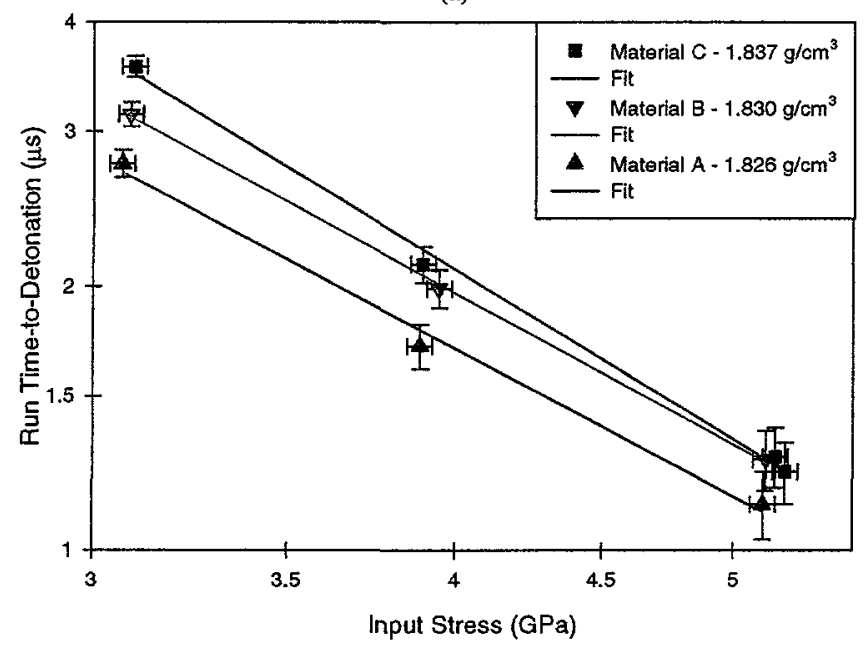

(b)

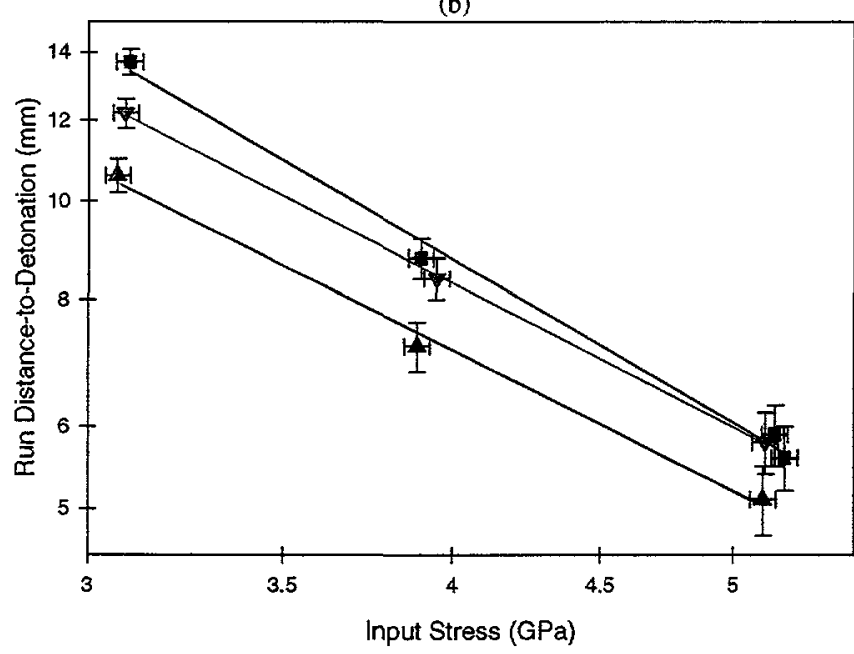

Figure 13. Pop-plots for the three different density new PBX 9501 materials of the present study. nator for small changes in material parameters which may take place in material formulation or aging.

Figure 14 presents Pop-plots for the two stockpile aged PBX 9501 materials; the 124 month old W76 material, and the 201 month old W78 material. These two materials had nominal densities of $1.838 \mathrm{~g} / \mathrm{cm}^{3}$. For comparison, the run distances/times and the linear fit for the new $1.837 \mathrm{~g} / \mathrm{cm}^{3}$ material (material $\mathrm{C}$ ) is also shown. This data and fit provide a baseline so that we can make comparisons and see if age significantly affects the run distance (time)-to-detonation.

While there is some scatter about the material C or baseline data fit, there is no definitive trend. All of the data from the aged explosives lie about as far from the baseline fit as do the baseline data. In addition, the stress and distance/time error bars are such that the baseline fit goes through all the points if error bars are included. The lack of difference in the Popplots for new and stockpile aged materials clearly indicates that (a)

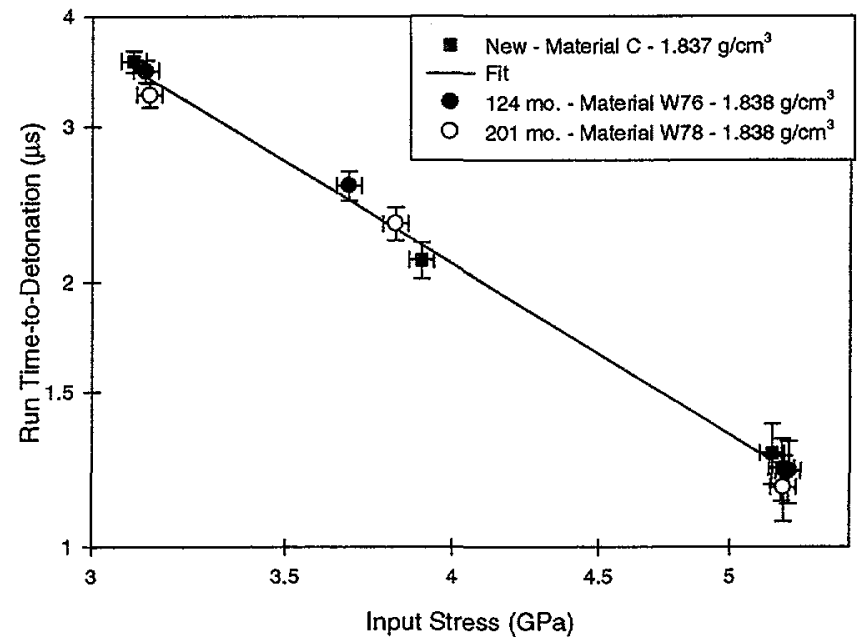

(b)

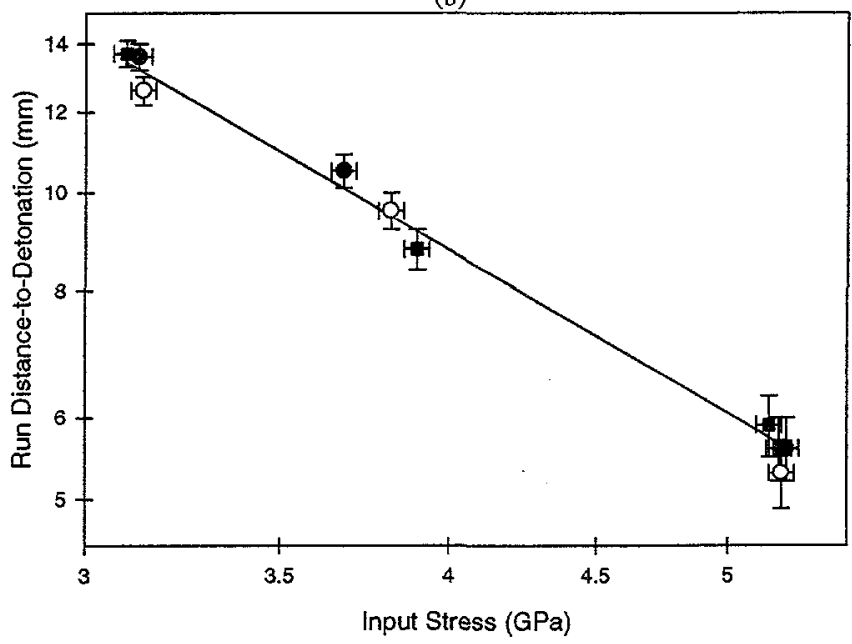

Figure 14. Pop-plots for new baseline and stockpile aged PBX 9501 materials. 
aging is not affecting the shock initiation properties of PBX 9501 . Figure 8 , which showed particle velocity wave profiles for these materials, also showed no effects. Thus, in two ways we have demonstrated that stockpile aging does not affect the shock initiation properties of $P B X 9501$.

It is also interesting that material $C$ was ram pressed while the weapons material was hydrostatically pressed. It has been assumed that ram pressing causes much more particle breakage than hydrostatic pressing. Our initiation data, discussed above, does not indicate significant differences in behavior. This suggests that the pressed materials may not be much different, since a significant difference in particle size would be expected to produce different initiation results.

\section{CONCLUSIONS/SUMMARY}

The present set of twenty experiments provides a comprehensive set of baseline shock initiation experiments on PBX 9501. This baseline was previously unavailable and, considering that PBX 9501 is used in many nuclear weapons, it is extremely important. In total, five different PBX 9501 materials were studied; three newly pressed materials with three slightly different initial densities and two stockpile aged materials.

For each of the twenty experiments, particle velocity wave profiles of the initiation process were measured in-material at 10-12 different depths. These profiles were obtained with unprecedented fidelity. They should prove to be extremely valuable for either Lagrange analysis or for comparison to direct numerical simulations using reactive rate models.

In addition, we have measured $x$ - $t$ trajectories of the shock front using a relatively new gauge called a shock tracker. Trajectories provided by these gauges are similar to the data obtained in explosively driven/optically recorded wedge tests, but this set of experiments shows less data scatter indicating improved accuracy. From these measurements and a new companion analysis, we have accurately determined the run distance (time)-to-detonation, the shock velocity, and the detonation velocity. The results (Pop-plots and Hugoniots) show far less data scatter than those obtained using explosive driven/optically recorded wedge tests.

The present results demonstrate an increase in shock sensitivity with decreasing density. This result is seen in the both the particle velocity wave profiles and also in the Pop-plots. It is not a new result but we think it is noteworthy that we have been able to measure sensitivity changes correlated to density differences as small as $0.005 \mathrm{~g} / \mathrm{cm}^{3}$. Measuring sensitivity changes for density differences this small has never been demonstrated before.

Lastly, we have an important result for those studying the aging of explosives in nuclear weapons. We find, both through particle velocity wave profile measurements and also through run distance (time)-to-detonation measurements, that age alone does not increase or decrease the shock sensitivity of PBX 9501. If the PBX 9501 density is held constant, we see no difference in the initiation of aged explosives when compared to new explosives.

For those concerned with safety issues this is important because it means that PBX 9501 is not becoming less or more safe, in reference to shock initiation, with age. Further, it means that safety models should not have to change the explosives shock initiation parameters to compensate for changing behavior with the explosive's age. Finally, it means that initiability for design purposes does not change with age. The $P B X$ 9501 will initiate the same after 17 years in stockpile as it did on the day it was pressed.

\section{ACKNOWLEDGEMENTS}

Bob Medina operated the gas gun for all of the shots. Jose Archuleta measured the densities of all the samples (we have found no one else who can make such consistently accurate density measurements). George Harper machined all the explosive parts, and Nancy Tessmar measured all of the relevant dimensional parameters of the electromagnetic gauges. We had useful discussions regarding initiation and PBX 9501 with Jerry Dick, Craig Tarver, Langdon Bennet, Jerry Forbes and Frank Garcia. The High Explosive Science program administered by Phil Howe, and the Enhanced Surveillance Program administered by Greg Buntain and Deanne Idar provided financial support.

\section{REFERENCES}

1. J. B. Ramsay and A. Popolato, "Analysis of Shock Wave and Initiation Data for Solid Explosives" in Proceedings of the Fourth Symposium (International) on Detonation, Office of Naval Research Report ACR-126, Washington, D.C., 1965, p. 233.

2. Los Alamos data compiled in LASL Explosive Property Data, edited by T. R. Gibbs and A. Popolato (University of California Press, Berkeley, 1980), pp. $359-366$.

3. J. Wackerle, R. L. Rabie, M. J. Ginsberg, and A. B. Anderson, "A Shock Initiation Study of PBX 9404," in Proceedings of the Symposium on High Dynamic Pressures, (Comisariat a l'Energie Atomique, Paris, France, 1978), p. 127.

4. M. J. Ginsberg is the author responsible for the Manganin gauge work in Reference 3.

5. L. Green, E. Nidick, E. Lee, and C. Tarver, "Reactions in PBX 9404 from Low Amplitude Shock Waves," in Proceedings of the Symposium on High Dynamic Pressures, (Comisariat a l'Energie Atomique, Paris, France, 1978) p. 115.

6. H. C. Vantine, W. D. Curtis, L.M. Erickson, and R.S. Lee, "A Comparison of Stress and Velocity Measurements in PBX 9404 Explosive," in Proceedings of the Eighteenth Symposium (International) on Combustion, The Combustion Institute, Pittsburgh, PA 1981, p. 1631.

7. J. E. Vorthman, "Facilities for the Study of Shock Induced Decomposition of High Explosives", in Shock Waves in Condensed Matter - 1981, edited by W. J. Nellis, L. Seaman, and R. A. Graham, AIP Conference Proceedings No. 78, American Institute of Physics, New York, 1982, p. 680.

8. L. M. Erickson, C. B. Johnson, N. L. Parker, H. C. Vantine, R. C. Weingart, and R. S. Lee, "The Electromagnetic Velocity Gauge: Use of Multiple Gauges, Time Response, and Flow Perturbations" in Proceedings of the Seventh Symposium (International) on Detonation, Office of Naval Research, Report NSWC MP-82-334, p. 1062, 1982. 
9. J. E. Kennedy, in Proceedings of the Fourteenth Symposium (International) on Combustion, The Combustion Institute, Pittsburgh, PA 1973, p. 1251.

10. J. E. Kennedy and J. W. Nunziato, J. Mech. Phys. Solids, 24, 107 (1976).

11. R. E. Setchell, "Ramp Wave Initiation of Granular Explosives," Combustion and Flame 43, 255 - 264, (1981).

12. R. E. Setchell, "Short-Pulse Shock Initiation of Granular Explosives" in Proceedings of the Seventh Symposium (International) on Detonation, Office of Naval Research, Report NSWC MP-82-334, p. 857, 1982.

13. A. W. Campbell and J. R. Travis, "The Shock Desensitization of PBX 9404 and Composition B-3" in Proceedings of the Eighth Symposium (International) on Detonation, Office of Naval Research, Report NSWC MP-86-194, p. 1057, 1986.

14. C. M. Tarver, J. O. Hallquist, and L. M. Erickson, "Modeling Short Pulse Duration Shock Initiation of Solid Explosives" in Proceedings of the Eighth Symposium (International) on Detonation, Office of Naval Research, Report NSWC MP-86-194, p. 951, 1986.

15. J. E. Vorthman, G. Andrews, and J. Wackerle "Reaction Rates from Electromagnetic Gauge Data" in Proceedings of the Eighth Symposium (International) on Detonation, Office of Naval Research, Report NSWC MP-86-194, p. 99, 1986.

16. J. N. Johnson, P. K. Tang, and C. A. Forest, "Shock Wave Initiation of Heterogeneous Reactive Solids," J. Appl. Phys., 57, 4323, 1985.

17. P. K. Tang, J. N. Johnson, and C. A. Forest, "Modeling Heterogeneous High Explosive Burn with an Explicit Hot-Spot Process" in Proceedings of the Eighth Symposium (International) on Detonation, Office of Naval Research, Report NSWC MP-86-194, p. 52, 1986.

18. J. W. Nunziato, E. K. Walsh, and J. E. Kennedy "A Continuum Model for Hot Spot Initiation of Granular Explosives," in Proceedings of the Symposium on High Dynamic Pressures, (Comisariat a l'Energie Atomique, Paris, France, 1978) p. 139.

19. M. E. Kipp, J. W. Nunziato, R. E. Setchell, and E. K. Walsh "Hot Spot Initiation of Heterogeneous Explosives" in Proceedings of the Seventh Symposium (International) on Detonation, Office of Naval Research, Report NSWC MP-82-334, p. 394, 1982.

20. Los Alamos data compiled in LASL Explosive Property Data, edited by $\mathrm{T}$. R. Gibbs and A. Popolato (University of California Press, Berkeley, 1980), pp. $94-95$, and pp. $116-117$. A good example of the sensitivity difference is the large scale drop test; PBX 9404 exploded when dropped from a height of less than 50 feet, while PBX 9501 did not start to react until dropped from a height of 150 feet.

21. Los Alamos data compiled in LASL Explosive Property Data, edited by $\mathrm{T}$. R. Gibbs and A. Popolato (University of California Press, Berkeley, 1980), pp. $353-358$.

22. J. J. Dick, A. R. Martinez, and R. S. Hixson, "Plane Impact Response of PBX 9501 and its Components below $2 \mathrm{GPa}$," Los Alamos National Laboratory Report \# LA-13426-MS, April 1998.

23. J. J. Dick, A. R. Martinez, and R. S. Hixson, "Plane Impact Response of PBX 9501 below $2 \mathrm{GPa}$ in Proceedings of the Eleventh Symposium (International) on Detonation, Snowmass, Colorado, 1998. Until proceedings are published, this paper can be accessed from the Detonation Symposium page at http://www.sainc.com/onr/detsymp/financcmt.html

24. D. J. Idar, R. A. Lucht, J. W. Straight, R. J. Scammon, R. V. Browning, J. Middleditch, J. K. Diennes, C. B. Skidmore, and G. A. Buntain, "Low Amplitude Insult Project: PBX 9501 Explosive Violent Reaction Experiments" in Proceedings of the Eleventh Symposium (International) on Detonation, Snowmass, Colorado, 1998. Until proceedings are published, this paper can be accessed from the Detonation Symposium page at http://www.sainc.com/onr/detsymp/financemt.html

25. D. J. Idar R. A. Lucht, R. J. Scammon, J. W. Straight, and C. B. Skidmore. "PBX 9501 High Explosive Violent Response/Low Amplitude Insult Project: Phase I," Los Alamos National Laboratory Report \# LA-13164MS January 1997.
26. S. K. Chidester, C. M. Tarver, and R. G. Garza, "Low Amplitude Impact Testing and Analysis of Pristine and Aged Solid High Explosives" in Proceedings of the Eleventh Symposium (International) on Detonation, Snowmass, Colorado, 1998. Until proceedings are published, this paper can be accessed from the Detonation Symposium page at http://www.sainc.com/onr/detsymp/financcmt.html

27. J. J. Dick, Private communication. (Vistal Hugoniot)

28. M. D. Knudson. "Use of Pico-Second Electronic Spectroscopy to Understand Phase Transitions in Shocked Cadmium Sulfide", Ph.D. Thesis, Washington State University, 1998. (Z - cut quartz Hugoniot)

29. L. M. Barker and R. E. Hollenbach, "Shock Wave Studies of PMMA, Fused Silica and Sapphire," J. Appl. Phys., 41, 4208, 1970.

30. R. G. McQueen, S. P. Marsh, J. W. Taylor, J. N. Fritz, and W. J. Carter, "The Equation of State of Solids from Shock Wave Studies," in High Velocity Impact Phenomena, edited by Ray Kinslow, Academic Press, New York, p. 328. (1970)

31. B. Olinger, B. Roof, and $\mathbf{H}$ Cady in "The Linear and Volume Compression of $\beta$-HMX and RDX to $9 \mathrm{GPa"}$ in Proceedings of the Symposium on High Dynamic Pressures, (Comisariat a l'Energie Atomique, Paris, France, 1978) p. 3, (1978).

32. V. M. Zaitzev, P. F. Pokhil, and K. K. Shvevdov, DAN SSSR, 132, p. 1339, (1960).

33. A. N. Dremin and S. A. Koldunov, "Shock Initiation of Detonation in Cast and Pressed TNT," Vzrimoe Delo, No. 63/20, p. 37, Moscow, Nedra, 1967:

34. A. N. Dremin, V. M. Zaitzev, V. S. Ilyukhin, and P. F. Pokhil, "Detonation Parameters" in Proceedings of the Eighth Symposium (International) on Combustion, The Combustion Institute, 1962, p. 610.

35. C. Young, R. Fowles, and R. P. Swift, in Shock Waves and the Mechanical Properties of Solids, edited by J.J. Burke and V. Weiss, Syracuse University Press, p. 203 (1981).

36. L. R. Koller, "Generation and Measurement of Simuitaneous Compression-Shear Waves in Arkansas Novaculite," Ph.D. Thesis, Washington State University, (1978). This thesis work was performed under the direction of R. Fowles.

37. S. J. Jacobs and D. J. Edwards "Experimental Study of the Electromagnetic Velocity Gauge Technique" in Proceedings of the Fifth Symposium (International) on Detonation, Office of Naval Research, Report ACR184, p. $413,1970$.

38. M. Cowperthwaite and J. T. Rosenberg, "A Multiple Lagrange Gauge Study of Shock Initiation Process in Cast TNT", in Proceedings of the Sixth Symposium (International) on Detonation, Office of Naval Research, Report ACR-221, p. 786, 1976.

39. J. E. Vorthman and J. Wackerle, "Multiple Wave Effects on Explosive Decomposition Rates", in Shock Waves in Condensed Matter-1983, edited by J. R. Asay, R. A. Graham, and G. K. Straub, Elsevier Science Publishers, p. 613, 1984.

40. R. R. Alcon and R. N. Mulford, "Shock Tracker Configuration of InMaterial Gauge", in Shock Compression of Condensed Matter-1995, edited by S.C. Schmidt and W.C. Tao, American Institute of Physics (AIP) Conference Proceedings 370, AIP Press, p. 1057, 1996.

41. J. N. Fritz, R. S. Hixson, M. S. Shaw, C. E. Morris, and R. G. McQueen, J. Appl. Phys. 80, 6129 (1996)

42. Richard Catanach, Private Communication Los Alamos National Laboratory Memo, "Variation in PBX 9501 Detonation Velocity with Density," DX-1 memo DX-1-98-036, March 12, 1998, unpublished. 


\section{APPENDIX A}

This appendix presents wave profiles, $x$ - $t$ trajectory plots and $x-t$ data for all 20 experiments. Profiles are grouped by input pressure and ordered in the same way as they were in Table 3. Gauge positions are listed in Table 4. These are also in the same order as in Table 3.

\section{Shot 1133}

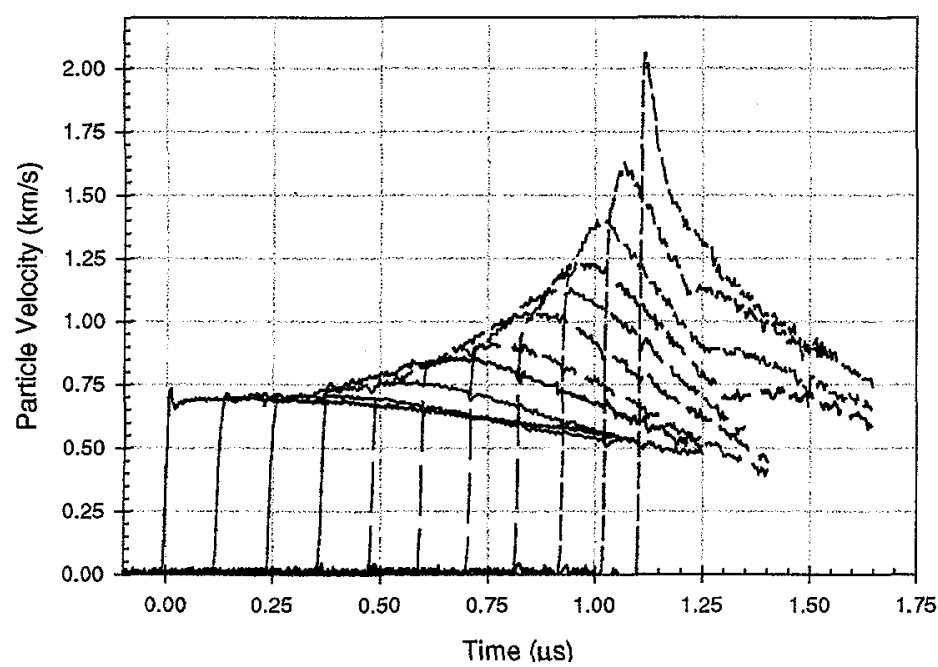

Figure A1. Particle velocity wave profiles from Shot 1133. The input is $5.12 \mathrm{GPa}$ and was created by impacting Vistal on the PBX 9501 at $0.817 \mathrm{~km} / \mathrm{s}$. The PBX is of type A.

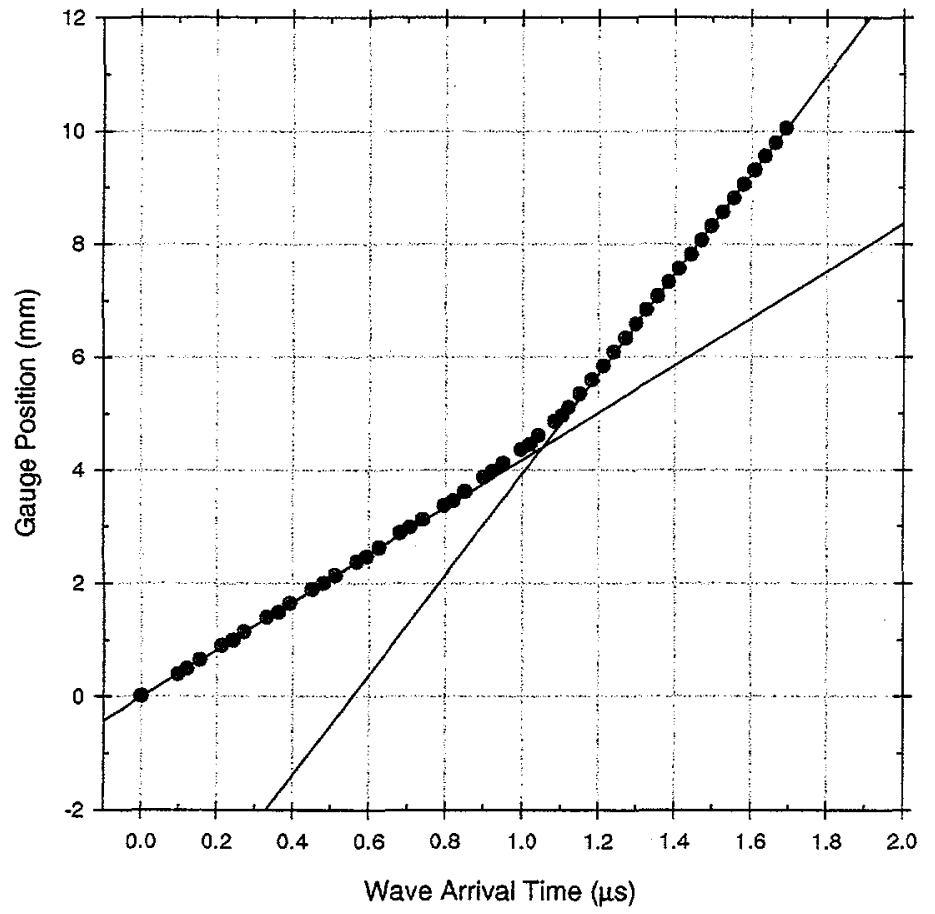

Figure A2. $x$ - $t$ plot for Shot 1133 obtained from shock arrival at shock tracker elements (red) and particle velocity gauge elements (green).
Table A1. $t-x$ data for Shot 1133

\begin{tabular}{lr}
$t-\mu \mathrm{s}$ & $x-\mathrm{mm}$ \\
\hline 0.000 & 0.000 \\
0.120 & 0.490 \\
0.242 & 0.987 \\
0.362 & 1.477 \\
0.480 & 1.997 \\
0.594 & 2.468 \\
0.708 & 2.985 \\
0.820 & 3.456 \\
0.924 & 3.973 \\
1.020 & 4.445 \\
1.104 & 4.960 \\
0.096 & 0.386 \\
0.154 & 0.649 \\
0.212 & 0.900 \\
0.272 & 1.137 \\
0.332 & 1.391 \\
0.392 & 1.643 \\
0.450 & 1.889 \\
0.510 & 2.137 \\
0.568 & 2.382 \\
0.626 & 2.631 \\
0.682 & 2.878 \\
0.740 & 3.125 \\
0.796 & 3.373 \\
0.850 & 3.619 \\
0.900 & 3.865 \\
0.950 & 4.112 \\
0.998 & 4.360 \\
1.043 & 4.607 \\
1.085 & 4.856 \\
1.122 & 5.102 \\
1.150 & 5.349 \\
1.182 & 5.596 \\
1.212 & 5.842 \\
1.240 & 6.091 \\
1.270 & 6.338 \\
1.298 & 6.583 \\
1.326 & 6.832 \\
1.356 & 7.075 \\
1.384 & 7.328 \\
1.412 & 7.571 \\
1.442 & 7.819 \\
1.470 & 8.067 \\
1.496 & 8.317 \\
1.525 & 8.562 \\
1.554 & 8.810 \\
1.580 & 9.057 \\
1.608 & 9.302 \\
1.634 & 9.550 \\
1.662 & 9.794 \\
1.689 & 10.045
\end{tabular}


Shot 1134

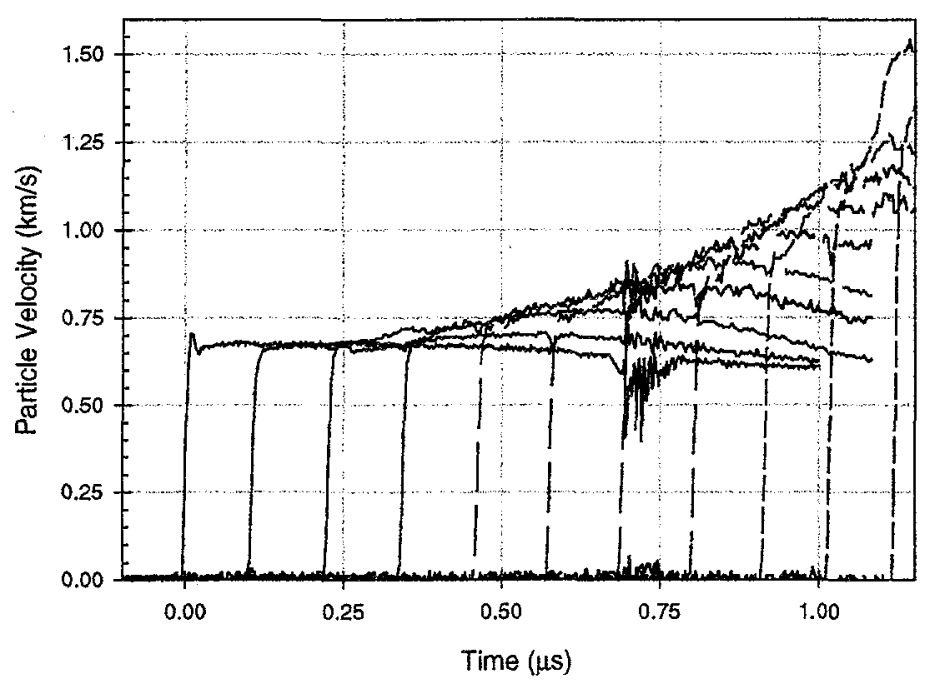

Figure A3. Particle velocity wave profiles from Shot 1134. The input is $5.13 \mathrm{GPa}$ and was created by impacting Vistal on the PBX 9501 at $0.814 \mathrm{~km} / \mathrm{s}$. The PBX is of type B.

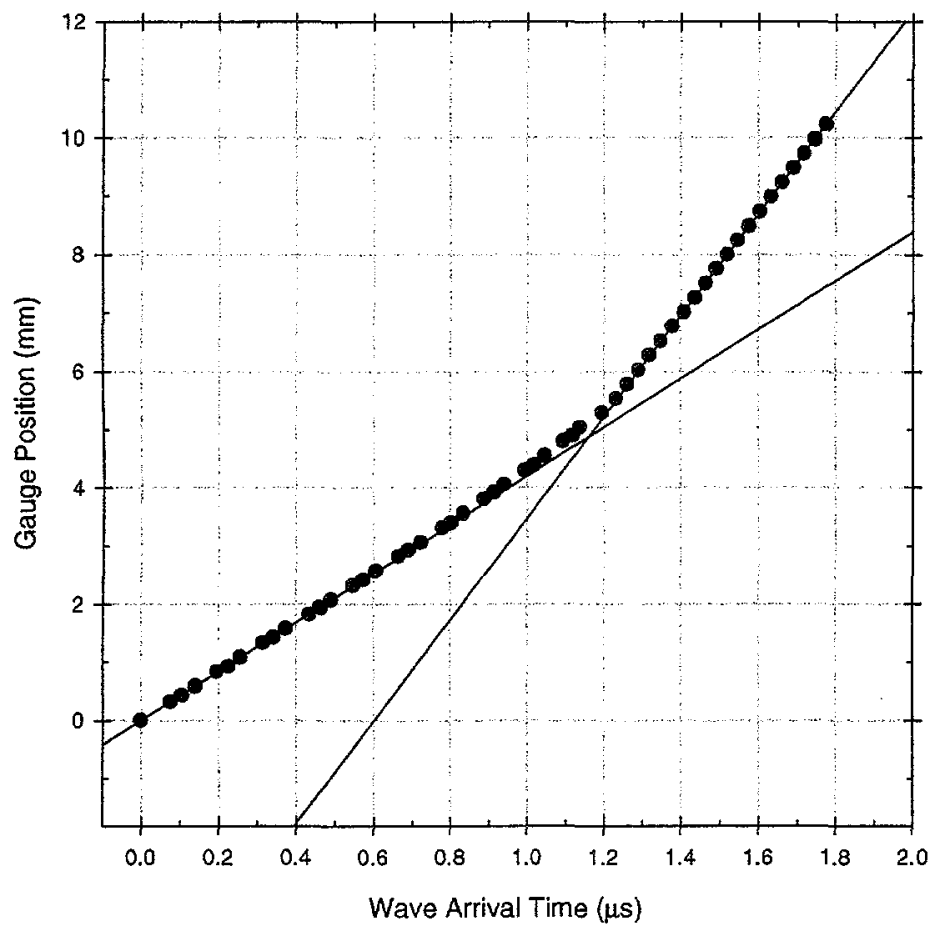

Figure A4. $x$ - $t$ plot for Shot 1134 obtained from shock arrival at shock tracker elements (red) and particle velocity gauge elements (green).
Table A2. $t-x$ data for Shot 1134

\begin{tabular}{ll}
$t-\mu \mathrm{s}$ & $x-\mathrm{mm}$ \\
\hline 0.000 & 0.000 \\
0.160 & 0.429 \\
0.226 & 0.924 \\
0.342 & 1.418 \\
0.462 & 1.931 \\
0.574 & 2.407 \\
0.690 & 2.921 \\
0.802 & 3.396 \\
0.914 & 3.911 \\
1.018 & 4.381 \\
1.118 & 4.898 \\
0.076 & 0.324 \\
0.141 & 0.589 \\
0.196 & 0.835 \\
0.256 & 1.082 \\
0.315 & 1.332 \\
0.374 & 1.577 \\
0.434 & 1.824 \\
0.491 & 2.074 \\
0.548 & 2.319 \\
0.606 & 2.568 \\
0.664 & 2.816 \\
0.722 & 3.061 \\
0.778 & 3.310 \\
0.832 & 3.557 \\
0.887 & 3.805 \\
0.940 & 4.053 \\
0.994 & 4.298 \\
1.046 & 4.542 \\
1.094 & 4.795 \\
1.138 & 5.041 \\
1.196 & 5.286 \\
1.232 & 5.535 \\
1.261 & 5.782 \\
1.291 & 6.029 \\
1.319 & 6.276 \\
1.349 & 6.520 \\
1.379 & 6.770 \\
1.407 & 7.016 \\
1.435 & 7.262 \\
1.463 & 7.508 \\
1.491 & 7.759 \\
1.519 & 8.004 \\
1.546 & 8.251 \\
1.575 & 8.497 \\
1.603 & 8.743 \\
1.632 & 8.994 \\
1.661 & 9.242 \\
1.690 & 9.486 \\
1.718 & 9.735 \\
1.776 & 9.976 \\
& 10.229 \\
& \\
\hline
\end{tabular}


Shot 1144

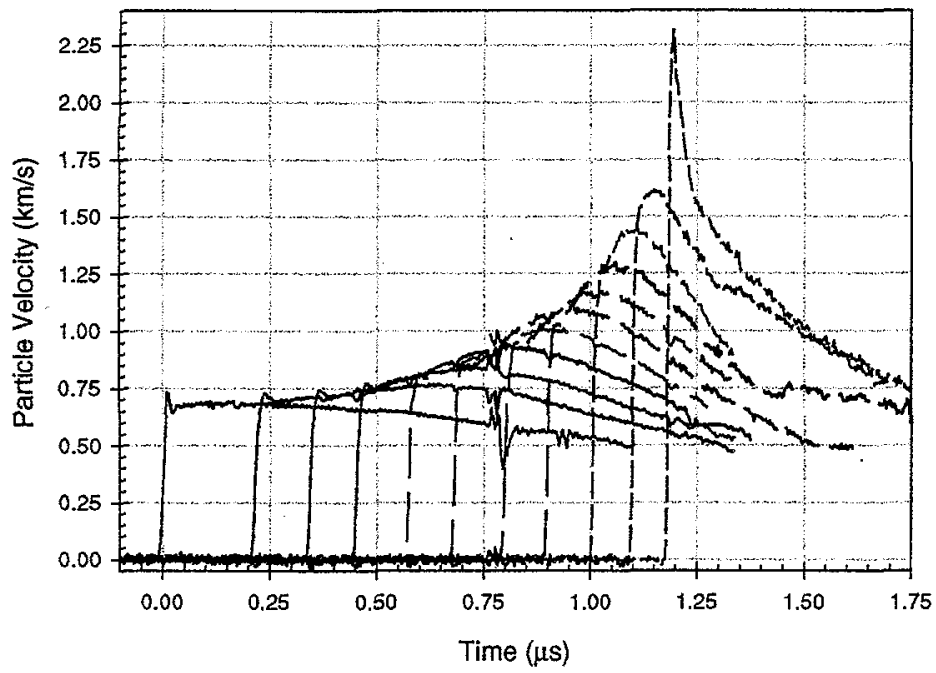

Figure A5. Particle velocity wave profiles from Shot 1144 . The input is $5.21 \mathrm{GPa}$ and was created by impacting Vistal on the PBX 9501 at $0.816 \mathrm{~km} / \mathrm{s}$. The PBX is of type C.

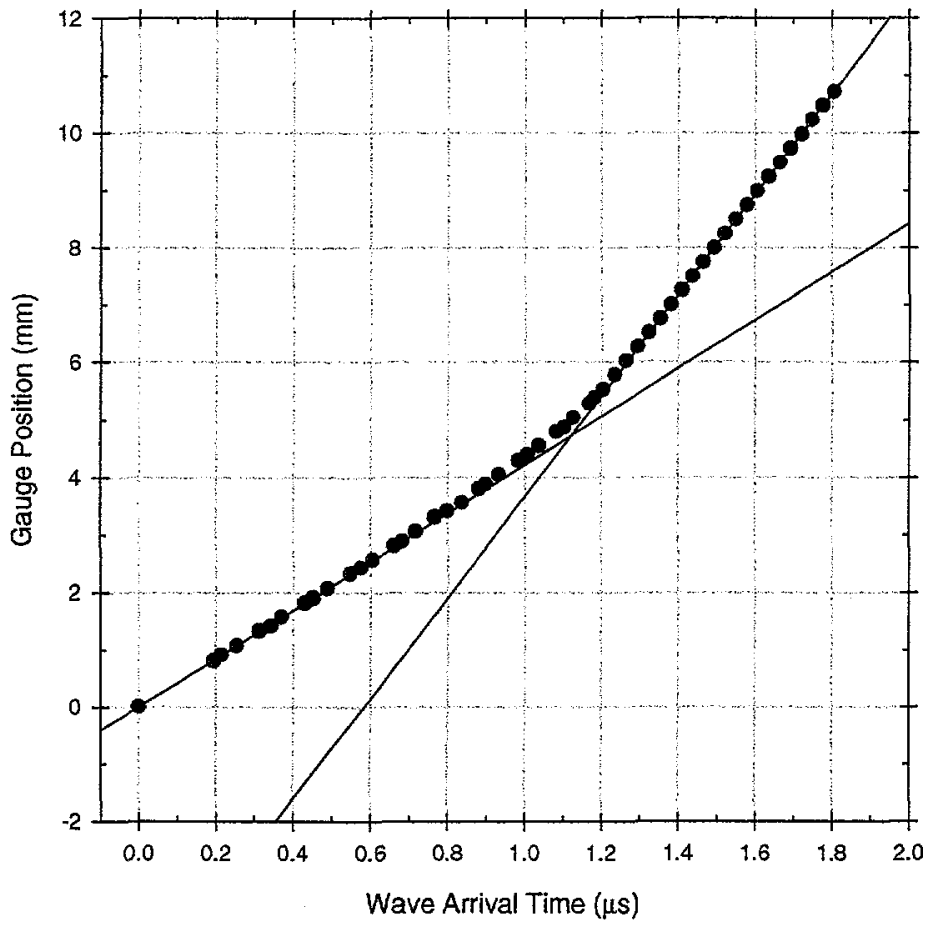

Figure A6. $x$ - $t$ plot for Shot 1144 obtained from shock arrival at shock tracker elements (red) and particle velocity gauge elements (green).
Table A3, $t-x$ data for Shot 1144

\begin{tabular}{rr}
$t-\mu \mathrm{s}$ & $x-\mathrm{mm}$ \\
\hline 0.000 & 0.000 \\
0.214 & 0.907 \\
0.342 & 1.411 \\
0.450 & 1.901 \\
0.574 & 2.420 \\
0.682 & 2.890 \\
0.798 & 3.408 \\
0.898 & 3.876 \\
1.006 & 4.398 \\
1.102 & 4.863 \\
1.182 & 5.385 \\
0.194 & 0.809 \\
0.254 & 1.077 \\
0.312 & 1.327 \\
0.370 & 1.574 \\
0.430 & 1.819 \\
0.488 & 2.068 \\
0.546 & 2.315 \\
0.604 & 2.562 \\
0.660 & 2.808 \\
0.716 & 3.056 \\
0.766 & 3.306 \\
0.836 & 3.553 \\
0.880 & 3.798 \\
0.932 & 4.048 \\
0.984 & 4.291 \\
1.036 & 4.544 \\
1.082 & 4.790 \\
1.126 & 5.034 \\
1.168 & 5.282 \\
1.204 & 5.527 \\
1.234 & 5.777 \\
1.264 & 6.021 \\
1.294 & 6.270 \\
1.324 & 6.518 \\
1.804 & 10.718 \\
1.353 & 6.763 \\
1.381 & 7.010 \\
1.410 & 7.260 \\
1.438 & 7.504 \\
1.466 & 7.748 \\
1.494 & 7.997 \\
1.522 & 8.243 \\
1.550 & 8.491 \\
1.578 & 8.740 \\
& \\
1.606 & 8.989 \\
1.720 & 9.235 \\
\hline
\end{tabular}


Shot 1145

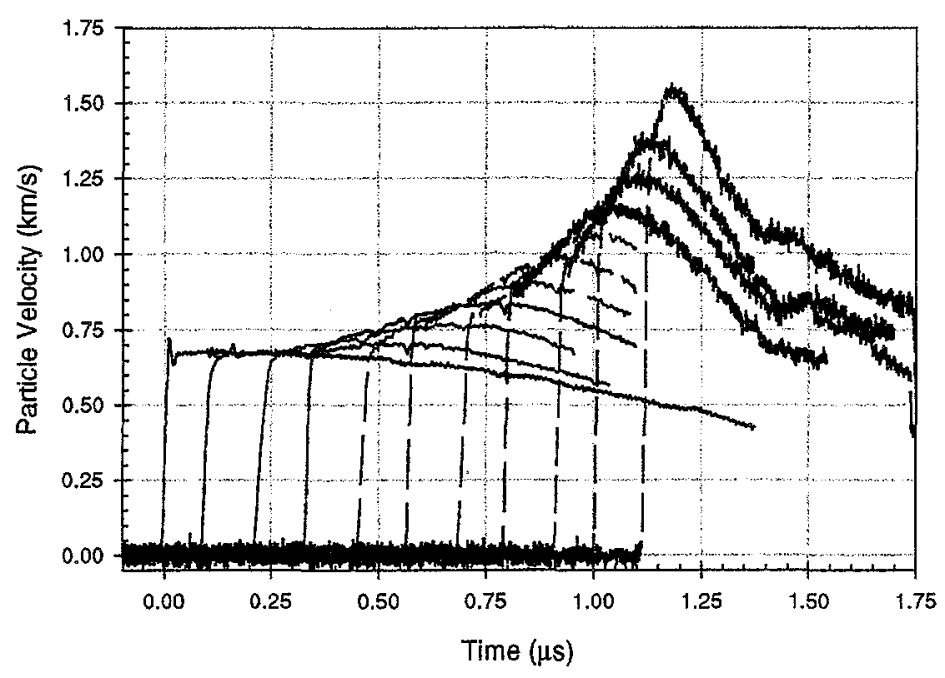

Figure A7. Particle velocity wave profiles from Shot 1145 . The input is $5.17 \mathrm{GPa}$ and was created by impacting Vistal on the PBX 9501 at $0.811 \mathrm{~km} / \mathrm{s}$. The PBX is of type $C$.

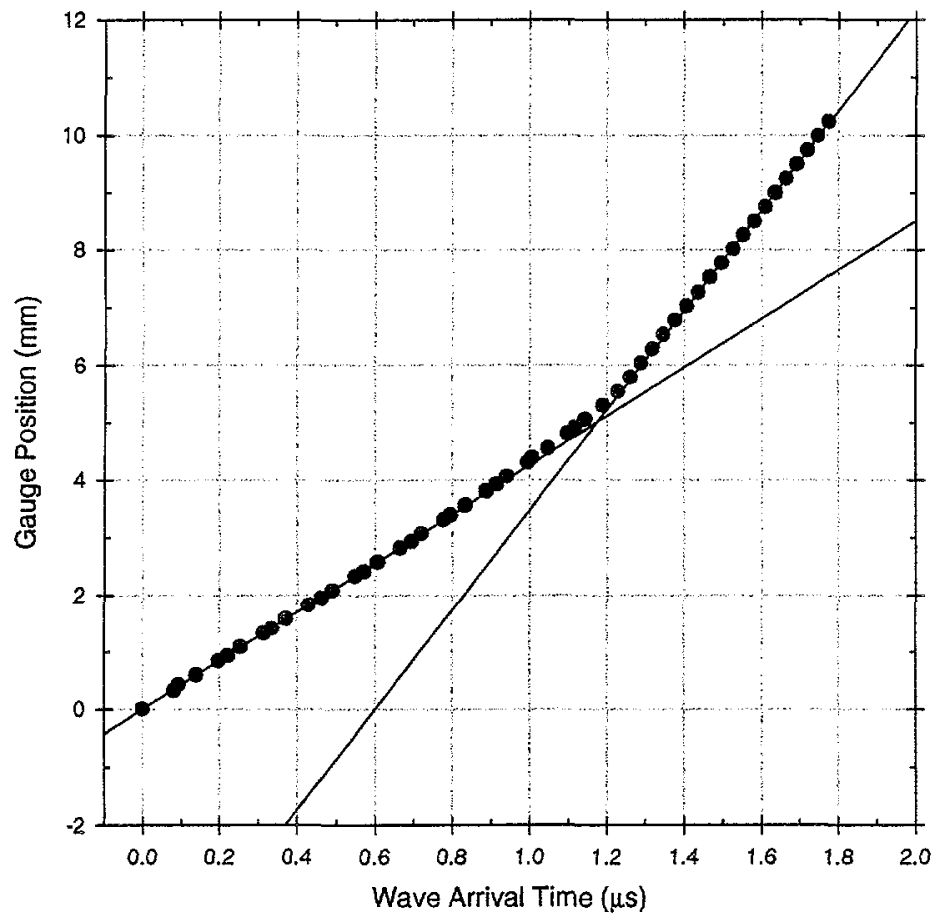

Figure A8. $x-t$ plot for Shot 1145 obtained from shock arrival at shock tracker elements (red) and particle velocity gauge elements (green).
Table A4. $t-x$ data for Shot 1145

\begin{tabular}{rr}
$t-\mu \mathrm{s}$ & $x-\mathrm{mm}$ \\
\hline 0.000 & 0.000 \\
0.094 & 0.427 \\
0.222 & 0.931 \\
0.334 & 1.413 \\
0.462 & 1.942 \\
0.570 & 2.405 \\
0.694 & 2.931 \\
0.795 & 3.395 \\
0.915 & 3.920 \\
1.006 & 4.383 \\
1.118 & 4.908 \\
0.082 & 0.325 \\
0.140 & 0.598 \\
0.198 & 0.841 \\
0.254 & 1.090 \\
0.314 & 1.335 \\
0.372 & 1.584 \\
0.430 & 1.830 \\
0.490 & 2.078 \\
0.548 & 2.325 \\
0.606 & 2.575 \\
0.664 & 2.820 \\
0.720 & 3.068 \\
0.777 & 3.311 \\
0.834 & 3.562 \\
0.888 & 3.809 \\
0.942 & 4.057 \\
0.996 & 4.305 \\
1.048 & 4.551 \\
1.097 & 4.799 \\
1.144 & 5.045 \\
1.190 & 5.290 \\
1.229 & 5.540 \\
1.262 & 5.791 \\
1.290 & 6.037 \\
1.318 & 6.281 \\
1.346 & 6.529 \\
1.376 & 6.779 \\
1.406 & 7.028 \\
1.436 & 7.268 \\
1.466 & 7.521 \\
1.496 & 7.764 \\
1.526 & 8.009 \\
1.553 & 8.260 \\
1.581 & 8.502 \\
1.610 & 8.747 \\
1.636 & 8.992 \\
1.664 & 9.244 \\
1.692 & 9.491 \\
& 9.740 \\
& \\
1.720 & \\
\hline
\end{tabular}


Shot 1154

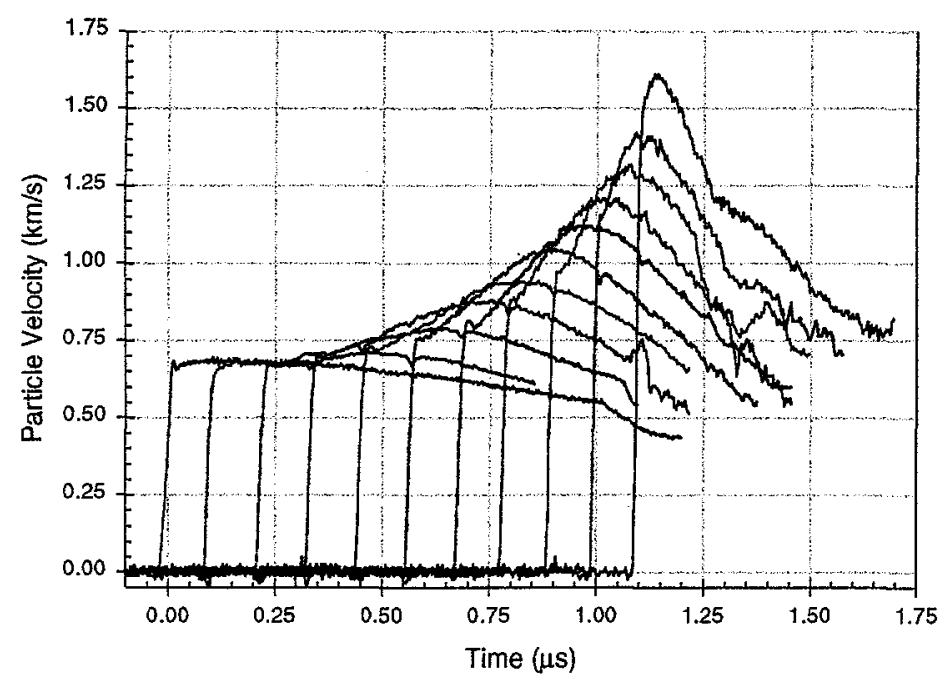

Figure A9. Particle velocity wave profiles from Shot 1154 . The input is $5.24 \mathrm{GPa}$ and was created by impacting Vistal on the PBX 9501 at $0.819 \mathrm{~km} / \mathrm{s}$. The PBX is of type W76.

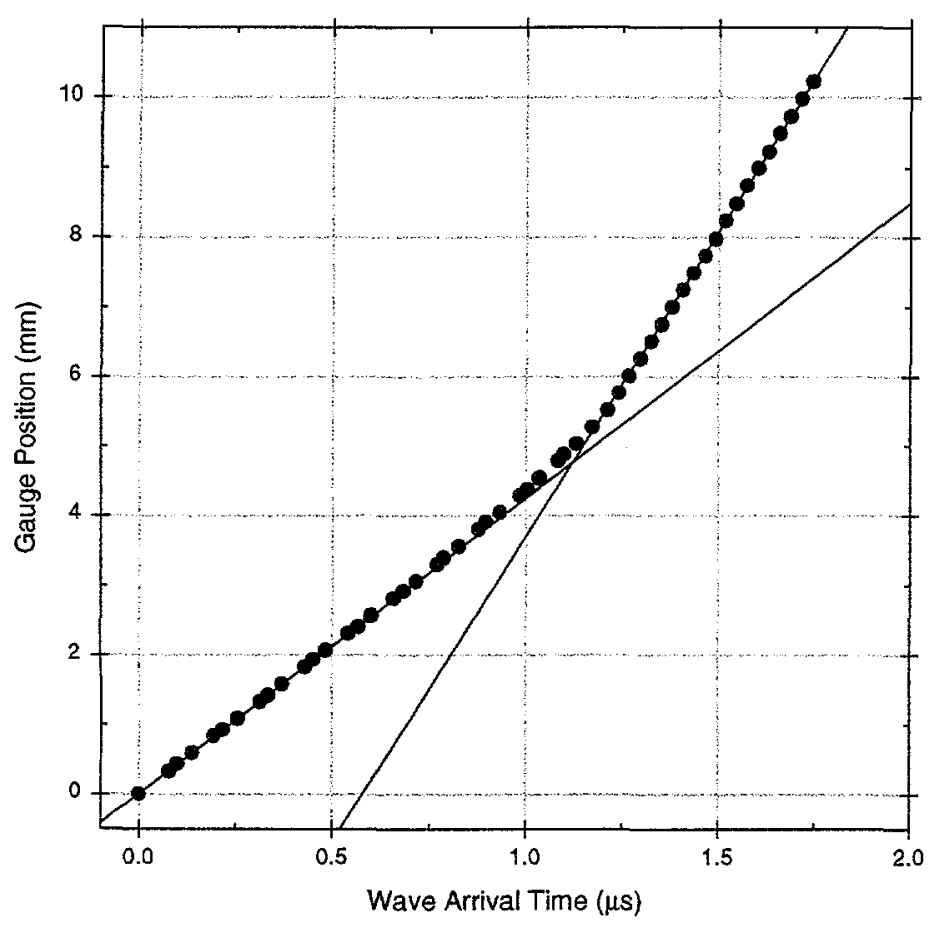

Figure A10. $x-t$ plot for Shot 1154 obtained from shock arrival at shock tracker elements (red) and particle velocity gauge elements (green).
Table A5. $t-x$ data for Shot 1154

\begin{tabular}{rr}
$t-\mu \mathrm{s}$ & $x-\mathrm{mm}$ \\
\hline 0.000 & 0.000 \\
0.100 & 0.430 \\
0.218 & 0.923 \\
0.334 & 1.417 \\
0.452 & 1.927 \\
0.568 & 2.402 \\
0.682 & 2.911 \\
0.787 & 3.387 \\
0.897 & 3.900 \\
1.005 & 4.374 \\
1.099 & 4.884 \\
0.079 & 0.327 \\
0.139 & 0.590 \\
0.194 & 0.838 \\
0.256 & 1.086 \\
0.314 & 1.327 \\
0.371 & 1.578 \\
0.431 & 1.825 \\
0.484 & 2.067 \\
0.542 & 2.314 \\
0.599 & 2.562 \\
0.657 & 2.808 \\
0.715 & 3.055 \\
0.770 & 3.299 \\
0.826 & 3.549 \\
0.877 & 3.796 \\
0.933 & 4.043 \\
0.984 & 4.288 \\
1.036 & 4.536 \\
1.084 & 4.783 \\
1.131 & 5.028 \\
1.173 & 5.274 \\
1.212 & 5.519 \\
1.242 & 5.766 \\
1.270 & 6.013 \\
1.297 & 6.258 \\
1.325 & 6.507 \\
1.352 & 6.750 \\
1.380 & 7.000 \\
1.407 & 7.242 \\
1.435 & 7.489 \\
1.465 & 7.738 \\
1.492 & 7.972 \\
1.518 & 8.232 \\
1.545 & 8.479 \\
1.573 & 8.743 \\
1.602 & 8.987 \\
1.630 & 9.215 \\
& 9.480 \\
1.687 & 9.727 \\
\hline
\end{tabular}


Shot 1156

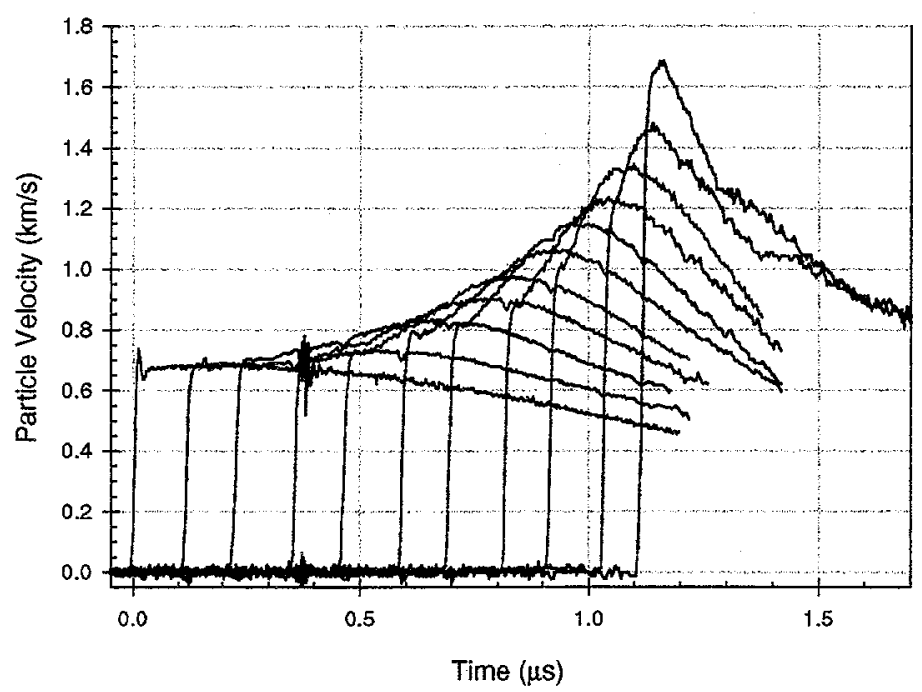

Figure A11. Particle velocity wave profiles from Shot 1156 . The input is 5.22 $\mathrm{GPa}$ and was created by impacting Vistal on the PBX 9501 at $0.817 \mathrm{~km} / \mathrm{s}$. The $\mathrm{PBX}$ is of type W78.

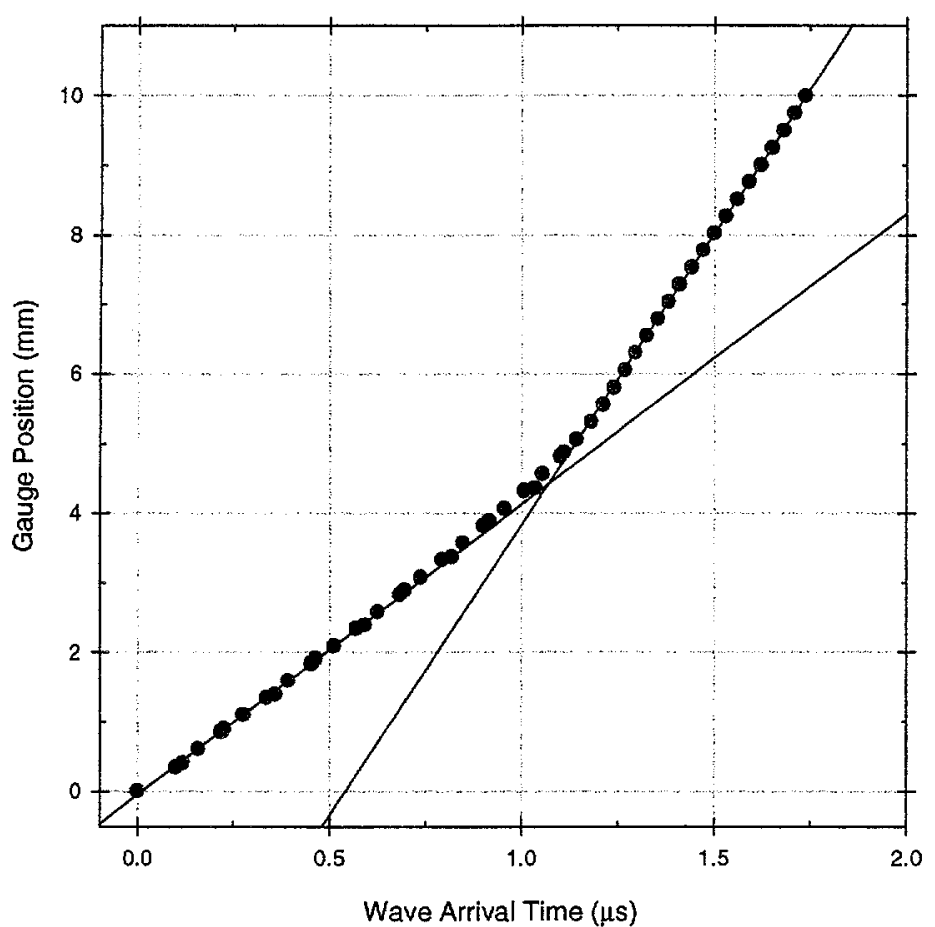

Figure A12. $x$ - $t$ plot for Shot 1156 obtained from shock arrival at shock tracker elements (red) and particle velocity gauge elements (green).
Table A6. $t-x$ data for Shot 1156

\begin{tabular}{rr}
$t-\mu \mathrm{s}$ & $x-\mathrm{mm}$ \\
\hline 0.000 & 0.000 \\
0.118 & 0.458 \\
0.226 & 0.951 \\
0.358 & 1.447 \\
0.462 & 1.958 \\
0.590 & 2.434 \\
0.694 & 2.949 \\
0.818 & 3.424 \\
0.914 & 3.937 \\
1.034 & 4.407 \\
1.110 & 4.924 \\
0.100 & 0.361 \\
0.158 & 0.628 \\
0.218 & 0.876 \\
0.276 & 1.123 \\
0.336 & 1.371 \\
0.392 & 1.617 \\
0.452 & 1.865 \\
0.510 & 2.112 \\
0.568 & 2.358 \\
0.624 & 2.601 \\
0.682 & 2.853 \\
0.736 & 3.102 \\
0.792 & 3.350 \\
0.846 & 3.595 \\
0.900 & 3.842 \\
0.954 & 4.087 \\
1.006 & 4.338 \\
1.054 & 4.584 \\
1.100 & 4.829 \\
1.142 & 5.078 \\
1.180 & 5.323 \\
1.212 & 5.572 \\
1.240 & 5.819 \\
1.268 & 6.066 \\
1.296 & 6.311 \\
1.324 & 6.558 \\
1.354 & 6.806 \\
1.382 & 7.051 \\
1.410 & 7.298 \\
1.442 & 7.545 \\
1.472 & 7.796 \\
1.500 & 8.041 \\
1.530 & 8.283 \\
1.560 & 8.533 \\
1.590 & 8.779 \\
1.620 & 9.026 \\
1.650 & 9.270 \\
1.680 & 9.519 \\
1.7368 & 9.766 \\
& 10.011
\end{tabular}


Shot 1162

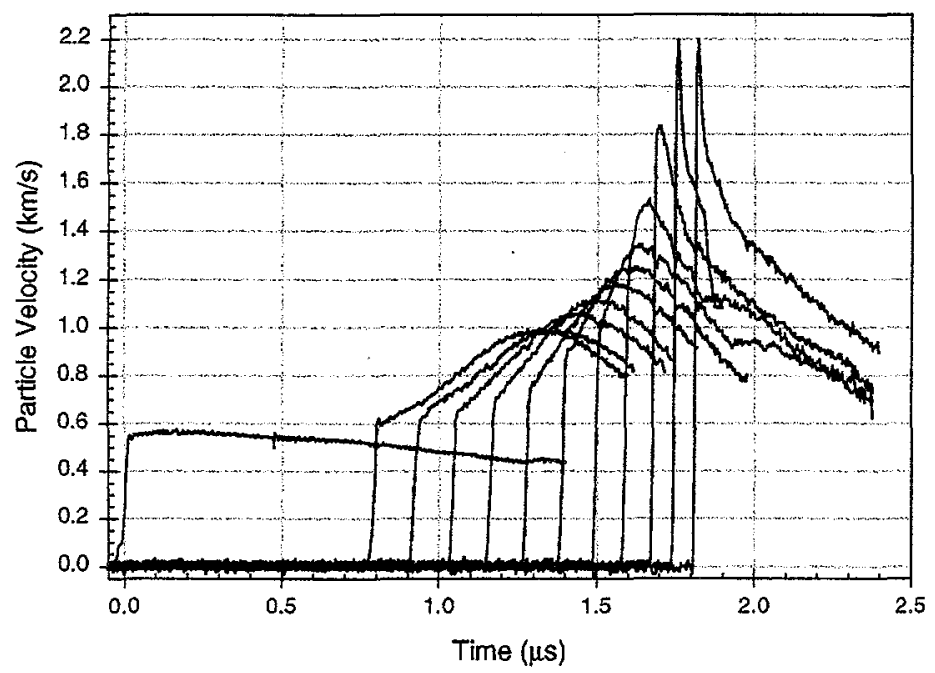

Figure A13. Particle velocity wave profiles from Shot 1162 . The input is 3.89 $\mathrm{GPa}$ and was created by impacting Vistal on the PBX 9501 at $0.663 \mathrm{~km} / \mathrm{s}$. The PBX is of type A.

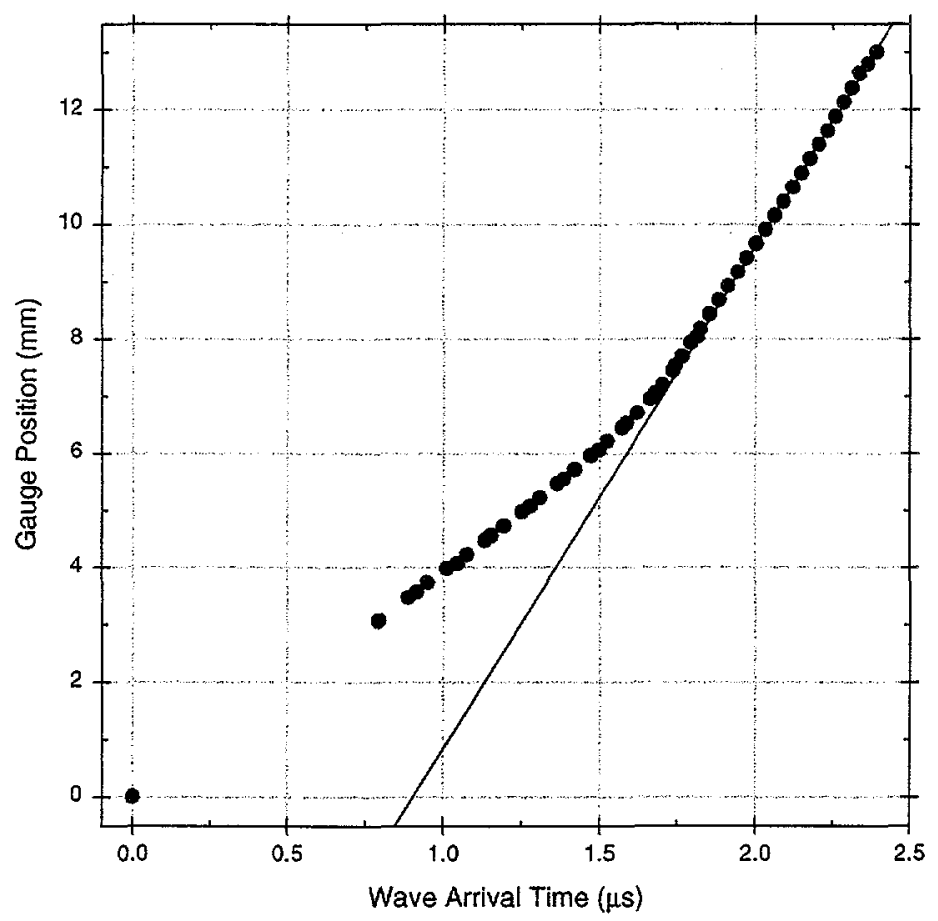

Figure A14. $x$-t plot for Shot 1162 obtained from shock arrival at shock tracker elements (red) and particle velocity gauge elements (green). The first two black points are from the stirrup gauges.
Table A7. $t-x$ data for Shot 1162

\begin{tabular}{rr}
$t-\mu \mathrm{s}$ & $x-\mathrm{mm}$ \\
\hline 0.000 & 0.000 \\
0.792 & 3.071 \\
0.914 & 3.574 \\
1.046 & 4.070 \\
1.156 & 4.563 \\
1.278 & 5.074 \\
1.387 & 5.546 \\
1.498 & 6.060 \\
1.587 & 6.533 \\
1.678 & 7.048 \\
1.743 & 7.522 \\
1.810 & 8.033 \\
0.886 & 3.475 \\
0.948 & 3.739 \\
1.012 & 3.984 \\
1.076 & 4.230 \\
1.134 & 4.479 \\
1.194 & 4.727 \\
1.252 & 4.972 \\
1.308 & 5.219 \\
1.364 & 5.467 \\
1.420 & 5.714 \\
1.472 & 5.959 \\
1.524 & 6.207 \\
1.572 & 6.451 \\
1.620 & 6.698 \\
1.662 & 6.947 \\
1.702 & 7.191 \\
1.734 & 7.437 \\
1.764 & 7.685 \\
1.792 & 7.932 \\
1.824 & 8.178 \\
1.854 & 8.424 \\
1.884 & 8.674 \\
1.912 & 8.918 \\
1.944 & 9.165 \\
1.972 & 9.412 \\
2.002 & 9.659 \\
2.032 & 9.904 \\
2.062 & 10.151 \\
2.090 & 10.394 \\
2.120 & 10.644 \\
2.148 & 10.886 \\
2.176 & 11.136 \\
2.2334 & 11.384 \\
& 11.627 \\
2.38 & 11.876 \\
& 12.124 \\
2.372 \\
\hline
\end{tabular}


Shot 1161

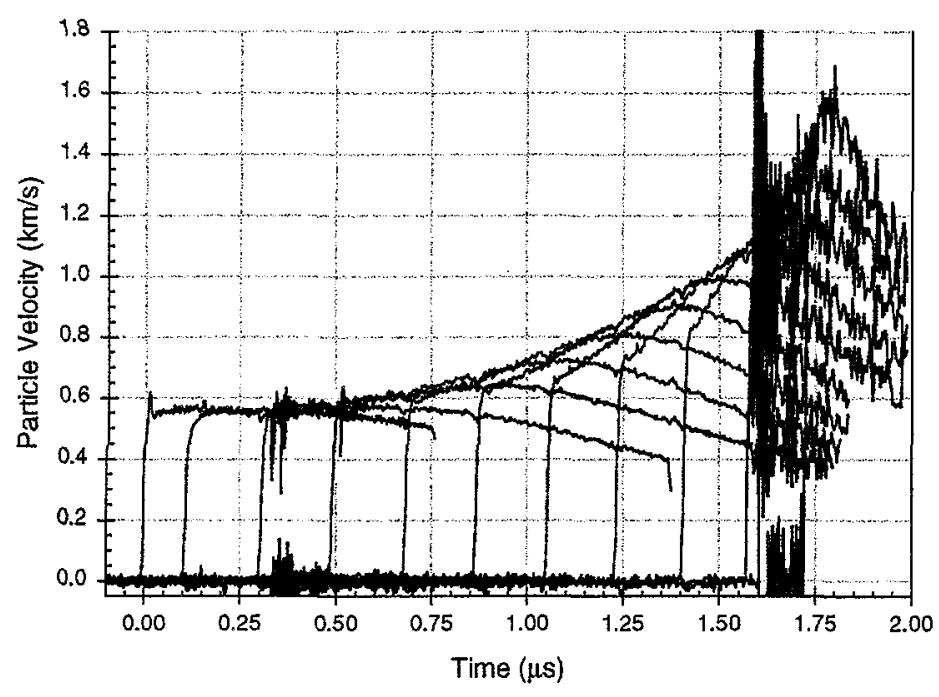

Figure A15. Particle velocity wave profiles from Shot 1161. The input is 3.92 GPa and was created by impacting z-cut quartz on the PBX 9501 at $0.798 \mathrm{~km} / \mathrm{s}$. The PBX 9501 is of type A. The burst of noise at about $1.6 \mathrm{~ms}$ is likely due to fracture of the quartz when the shock reaches the free surface.

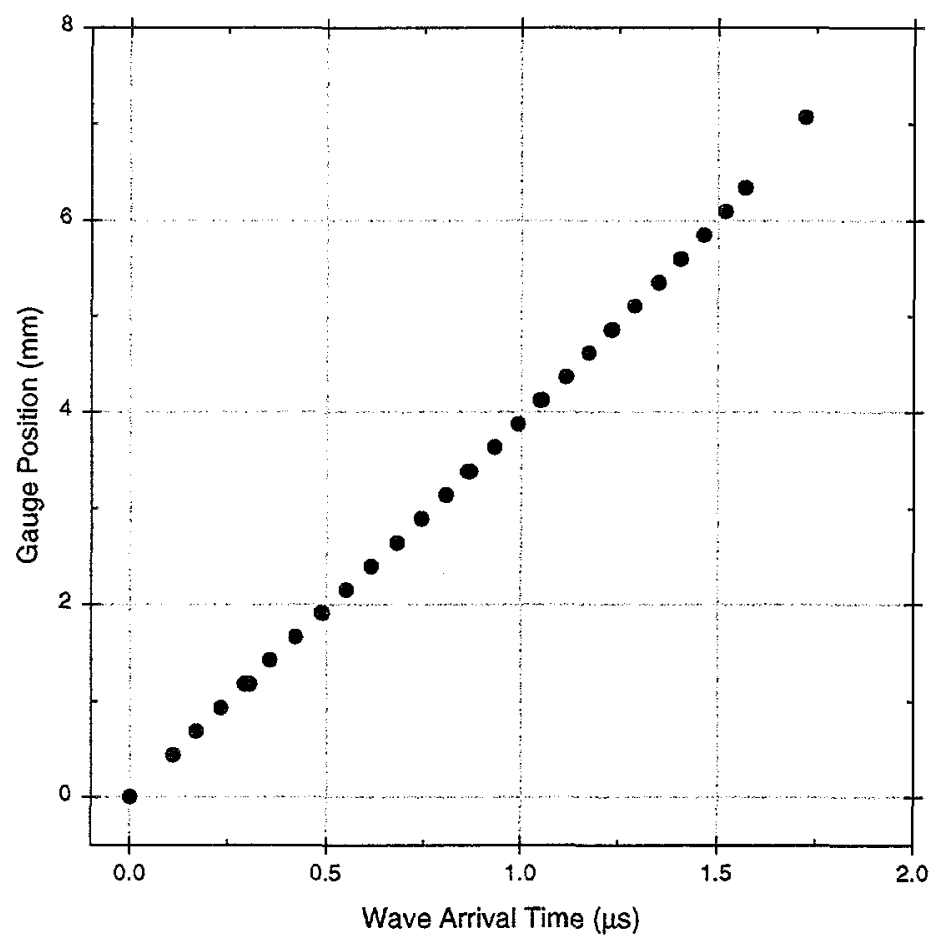

Table A8. $t-x$ data for Shot 1161

\begin{tabular}{cc}
$t-\mu \mathrm{s}$ & $x-\mathrm{mm}$ \\
\hline 0.000 & 0.000 \\
0.110 & 0.436 \\
0.304 & 1.174 \\
0.491 & 1.909 \\
0.681 & 2.645 \\
0.863 & 3.381 \\
1.049 & 4.118 \\
1.231 & 4.850 \\
1.405 & 5.590 \\
1.571 & 6.328 \\
1.725 & 7.065 \\
0.169 & 0.681 \\
0.232 & 0.925 \\
0.292 & 1.172 \\
0.357 & 1.418 \\
0.422 & 1.662 \\
0.489 & 1.909 \\
0.551 & 2.153 \\
0.616 & 2.400 \\
0.681 & 2.644 \\
0.743 & 2.892 \\
0.806 & 3.136 \\
0.869 & 3.382 \\
0.931 & 3.629 \\
0.992 & 3.873 \\
1.053 & 4.119 \\
1.115 & 4.365 \\
1.174 & 4.612 \\
1.235 & 4.857 \\
1.291 & 5.101 \\
1.350 & 5.348 \\
1.407 & 5.593 \\
1.465 & 5.840 \\
1.520 & 6.085 \\
1.571 & 6.331 \\
& \\
\hline
\end{tabular}

Figure A16. $x-t$ plot for Shot 1161 obtained from shock arrival at shock tracker elements (blue) and particle velocity gauge elements (green). The black point is from the stirrup gauge. 
Shot 1164

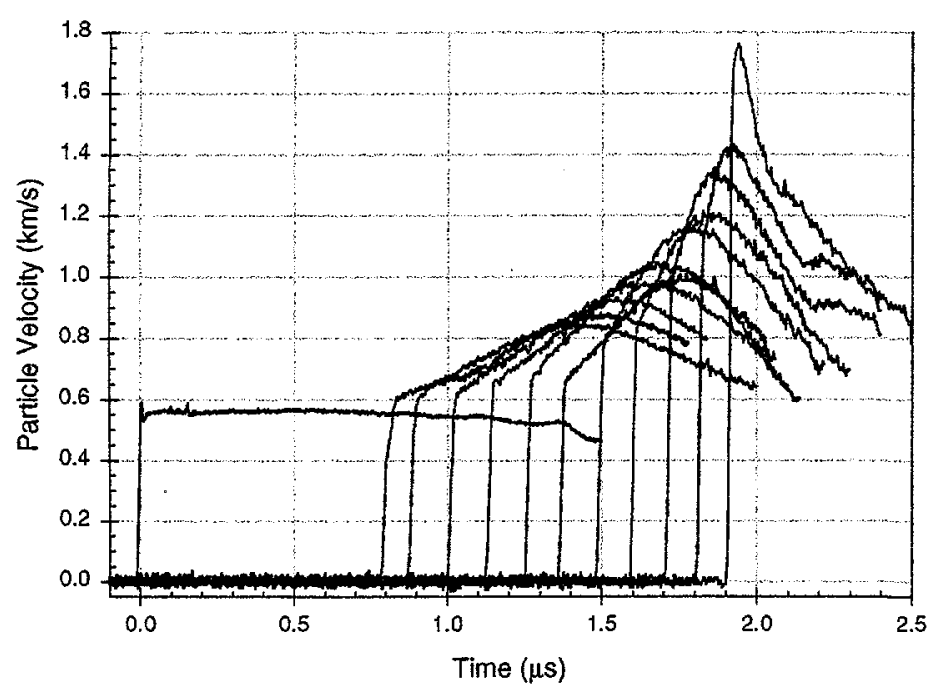

Figure A17. Particle velocity wave profiles from Shot 1164 . The input is 3.95 $\mathrm{GPa}$ and was created by impacting Vistal on the PBX 9501 at $0.667 \mathrm{~km} / \mathrm{s}$. The PBX 9501 is of type B.

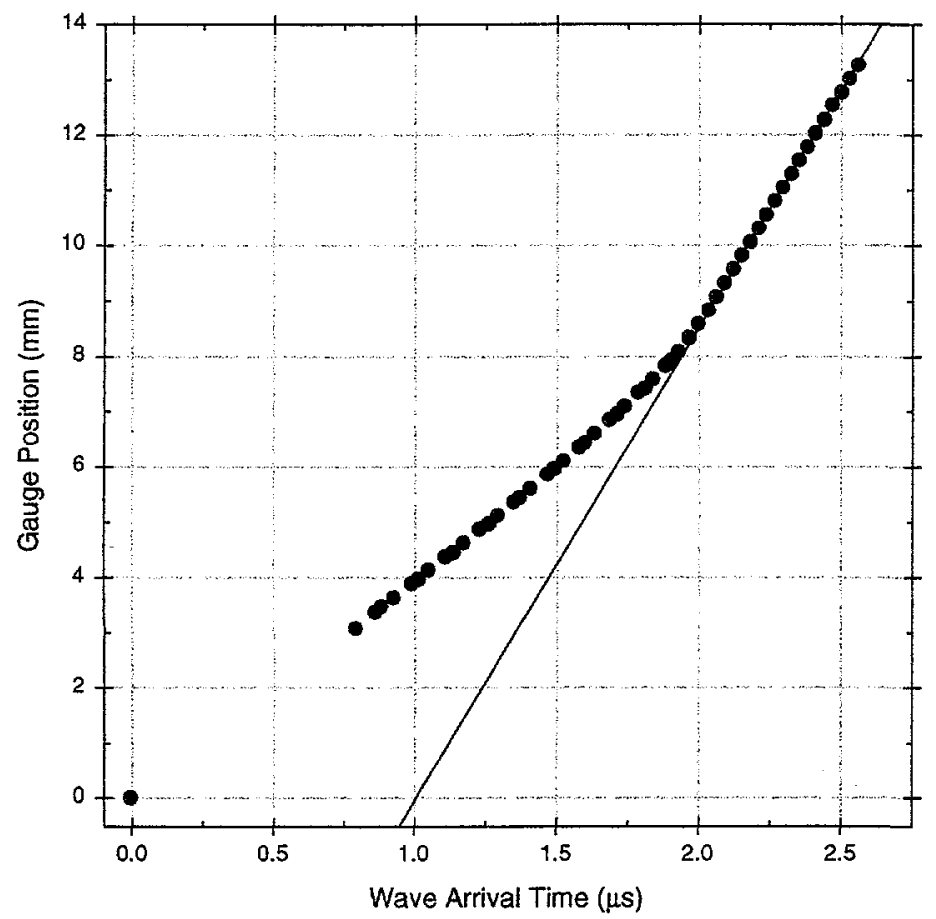

Figure A18. $x$ - $t$ plot for Shot 1164. Blue, green, and the first two black points were obtained from shock arrival particle velocity and stirrup gauge elements. Red points are from the shock tracker elements. The black points were used to determine the detonation velocity.
Table A9. $t$ - $x$ data for Shot 1164

\begin{tabular}{rr}
$t-\mu s$ & $x-\mathrm{mm}$ \\
\hline 0.000 & 0.000 \\
0.790 & 3.075 \\
0.881 & 3.471 \\
1.012 & 3.968 \\
1.134 & 4.457 \\
1.261 & 4.977 \\
1.368 & 5.444 \\
1.491 & 5.964 \\
1.598 & 6.434 \\
1.713 & 6.950 \\
1.811 & 7.421 \\
1.906 & 7.938 \\
0.859 & 3.374 \\
0.925 & 3.634 \\
0.986 & 3.886 \\
1.047 & 4.136 \\
1.107 & 4.381 \\
1.170 & 4.631 \\
1.227 & 4.876 \\
1.291 & 5.123 \\
1.348 & 5.371 \\
1.406 & 5.613 \\
1.467 & 5.864 \\
1.522 & 6.109 \\
1.578 & 6.356 \\
1.631 & 6.604 \\
1.685 & 6.846 \\
1.738 & 7.094 \\
1.785 & 7.345 \\
1.837 & 7.589 \\
1.882 & 7.837 \\
1.928 & 8.084 \\
1.965 & 8.332 \\
1.996 & 8.579 \\
2.032 & 8.824 \\
2.059 & 9.069 \\
2.089 & 9.317 \\
2.120 & 9.564 \\
2.149 & 9.812 \\
2.179 & 10.055 \\
2.208 & 10.302 \\
2.236 & 10.549 \\
2.265 & 10.797 \\
2.294 & 11.042 \\
2.324 & 11.291 \\
2.351 & 11.538 \\
2.381 & 11.784 \\
2.408 & 12.029 \\
& 12.274 \\
2.439 & 12.546 \\
\hline & 12.771 \\
\hline
\end{tabular}


Shot 1155

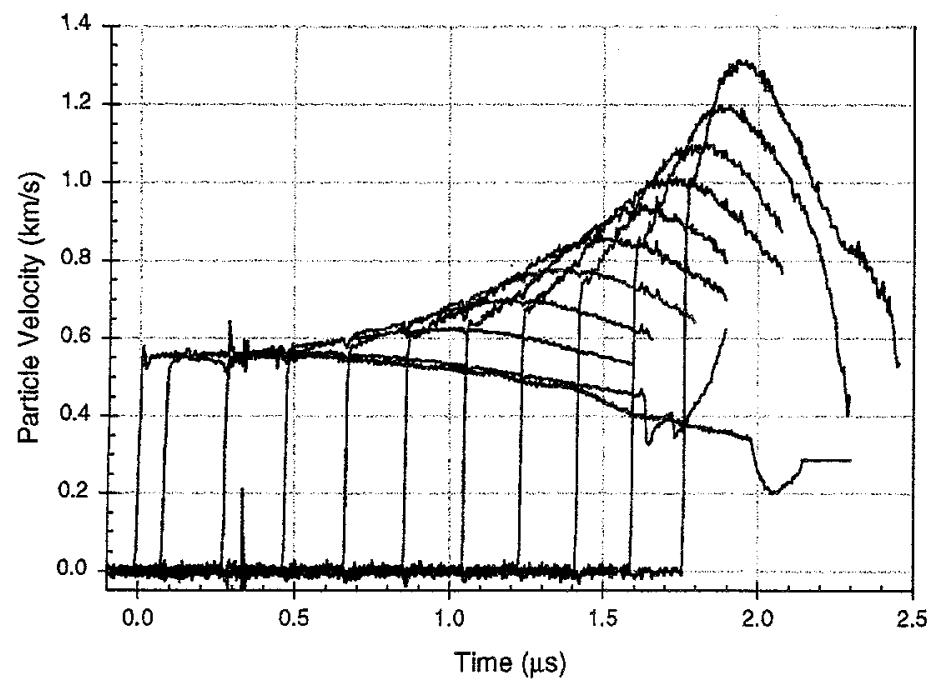

Figure A19. Particle velocity wave profiles from Shot 1155. The input is 3.92 $\mathrm{GPa}$ and was created by impacting Vistal on the PBX 9501 at $0.663 \mathrm{~km} / \mathrm{s}$. The PBX 9501 is of type $B$.

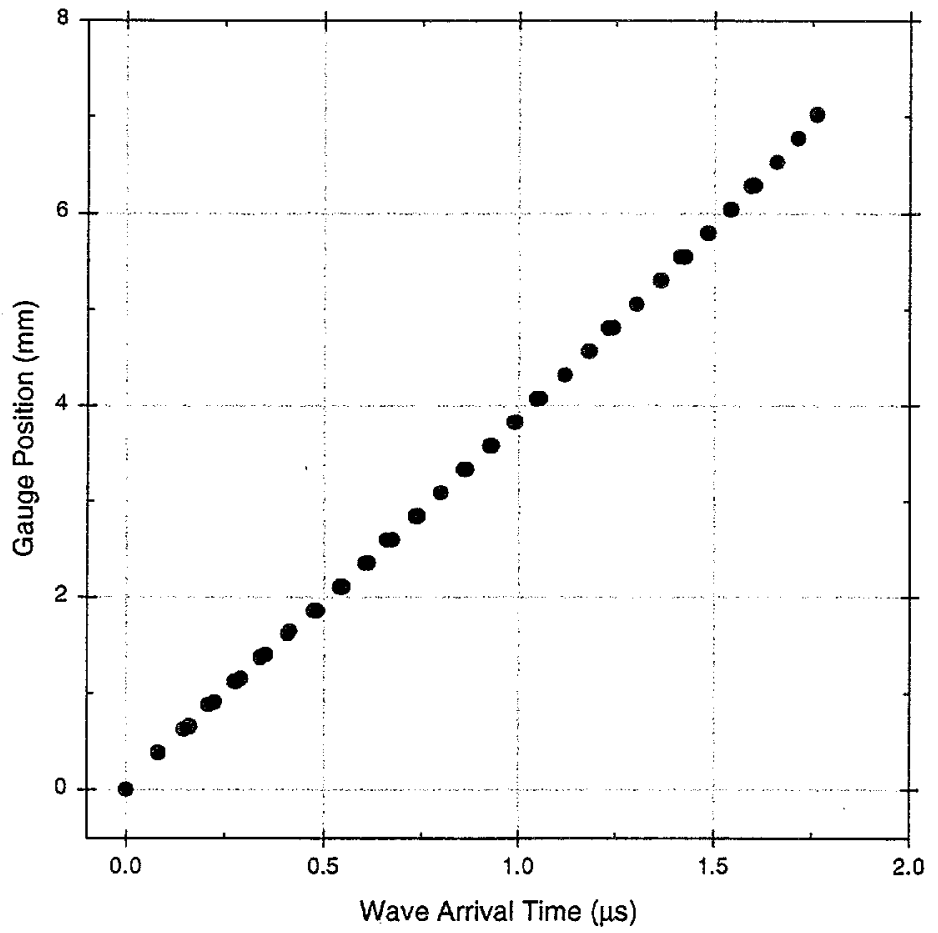

Figure A20. $x-t$ plot for Shot 1155 . This Shot had two shock trackers, both of which broke early. Green points are from the particle velocity and stirrup gauge elements. Red points are from one of the shock trackers and blue points are from the other shock tracker.
Table A10. $t-x$ data for Shot 1155

\begin{tabular}{ll}
$t-\mu s$ & $x-$ mm \\
\hline 0.000 & 0.000 \\
0.082 & 0.382 \\
0.278 & 1.121 \\
0.474 & 1.858 \\
0.660 & 2.595 \\
0.858 & 3.331 \\
1.046 & 4.068 \\
1.230 & 4.802 \\
1.414 & 5.541 \\
1.594 & 6.280 \\
1.762 & 7.018 \\
0.082 & 0.384 \\
0.146 & 0.630 \\
0.208 & 0.878 \\
0.274 & 1.122 \\
0.340 & 1.368 \\
0.408 & 1.610 \\
0.474 & 1.859 \\
0.540 & 2.105 \\
0.604 & 2.350 \\
0.670 & 2.599 \\
0.734 & 2.844 \\
0.798 & 3.089 \\
0.862 & 3.334 \\
0.924 & 3.580 \\
0.988 & 3.825 \\
1.052 & 4.072 \\
1.118 & 4.319 \\
1.180 & 4.564 \\
1.240 & 4.808 \\
1.302 & 5.052 \\
1.362 & 5.300 \\
1.422 & 5.545 \\
1.482 & 5.792 \\
1.540 & 6.039 \\
1.600 & 6.285 \\
0.160 & 0.658 \\
0.224 & 0.906 \\
0.290 & 1.151 \\
0.352 & 1.398 \\
0.414 & 1.642 \\
0.482 & 1.860 \\
0.548 & 2.104 \\
0.612 & 2.351 \\
0.800 & 2.596 \\
& 3.317 \\
0.932 & 3.089 \\
\hline
\end{tabular}


Shot 1150

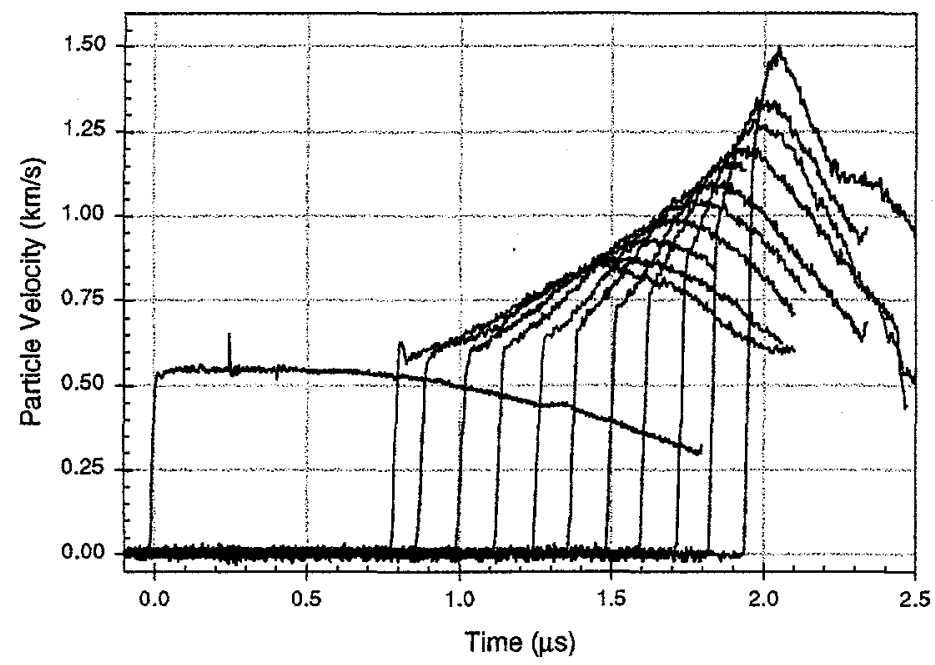

Figure A21. Particle velocity wave profiles from Shot 1150. The input is 3.90 $\mathrm{GPa}$ and was created by impacting Vistal on the PBX 9501 at $0.653 \mathrm{~km} / \mathrm{s}$. The PBX 9501 is of type C.

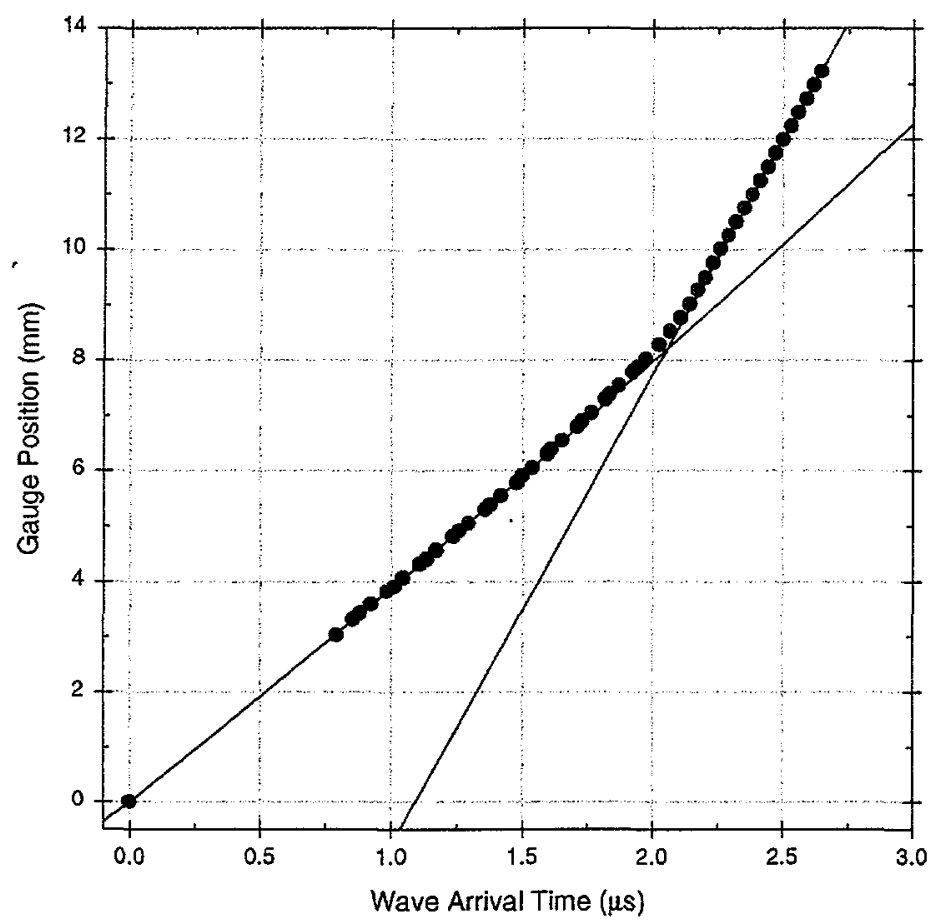

Figure A22. $x-t$ plot for Shot 1150 . Green points are from the particle velocity and stirrup gauge elements. Red points are from the shock tracker. Black points are in a region that is fully detonating.
Table A11, $t-x$ data for Shot 1150

\begin{tabular}{rr}
$t-\mu s$ & $x-\mathrm{mm}$ \\
\hline 0.000 & 0.000 \\
0.792 & 3.025 \\
0.880 & 3.409 \\
1.010 & 3.904 \\
1.132 & 4.400 \\
1.259 & 4.909 \\
1.377 & 5.390 \\
1.499 & 5.901 \\
1.610 & 6.378 \\
1.728 & 6.890 \\
1.834 & 7.367 \\
1.945 & 7.881 \\
0.854 & 3.311 \\
0.921 & 3.572 \\
0.981 & 3.821 \\
1.044 & 4.068 \\
1.107 & 4.316 \\
1.170 & 4.566 \\
1.233 & 4.811 \\
1.294 & 5.059 \\
1.357 & 5.305 \\
1.417 & 5.552 \\
1.478 & 5.783 \\
1.537 & 6.047 \\
1.596 & 6.295 \\
1.652 & 6.546 \\
1.710 & 6.790 \\
1.766 & 7.038 \\
1.819 & 7.285 \\
1.872 & 7.532 \\
1.923 & 7.775 \\
1.973 & 8.024 \\
2.023 & 8.276 \\
2.064 & 8.523 \\
2.106 & 8.767 \\
2.141 & 9.014 \\
2.172 & 9.265 \\
2.201 & 9.491 \\
2.230 & 9.757 \\
2.259 & 10.006 \\
2.291 & 10.253 \\
2.320 & 10.495 \\
2.351 & 10.744 \\
2.382 & 10.992 \\
2.411 & 11.240 \\
2.442 & 11.484 \\
& 12.71919 \\
& 11.734 \\
2.532 & 11.980 \\
\hline
\end{tabular}




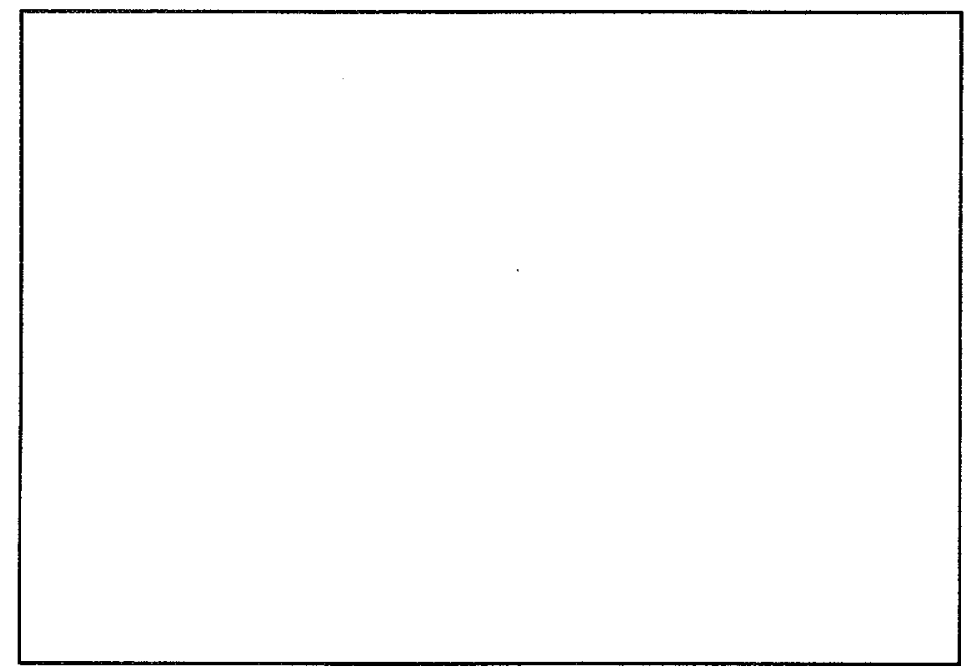

\begin{tabular}{rr}
$t-\mu \mathrm{s}$ & $x-\mathrm{mm}$ \\
\hline 0.000 & 0.000 \\
0.800 & 3.075 \\
0.922 & 3.454 \\
0.986 & 3.726 \\
1.050 & 3.972 \\
1.110 & 4.220 \\
1.176 & 4.470 \\
1.236 & 4.715 \\
1.300 & 4.965 \\
1.360 & 5.213 \\
1.424 & 5.464 \\
1.484 & 5.707 \\
1.548 & 5.914 \\
1.608 & 6.203 \\
1.674 & 6.454 \\
1.732 & 6.701 \\
1.794 & 6.948 \\
1.852 & 7.196 \\
1.912 & 7.444 \\
1.974 & 7.693 \\
2.030 & 7.852 \\
2.088 & 8.185 \\
2.142 & 8.374 \\
2.198 & 8.685 \\
2.252 & 8.932 \\
2.304 & 9.182 \\
2.354 & 9.340 \\
2.406 & 9.657 \\
2.454 & 9.907 \\
2.496 & 10.150 \\
2.536 & 10.399 \\
2.570 & 10.643 \\
2.600 & 10.890 \\
2.628 & 11.142 \\
2.658 & 11.390 \\
2.686 & 11.634 \\
2.716 & 11.885 \\
2.744 & 12.132 \\
2.772 & 12.378 \\
2.800 & 12.631 \\
2.830 & 12.876 \\
2.860 & 13.127
\end{tabular}

Figure A23. Particle velocity wave profiles from Shot 1179 were not obtained. The input is $3.68 \mathrm{GPa}$ and was created by impacting $z$ - cut sapphire on the PBX 9501 at $0.620 \mathrm{~km} / \mathrm{s}$. The PBX 9501 is of type W76.

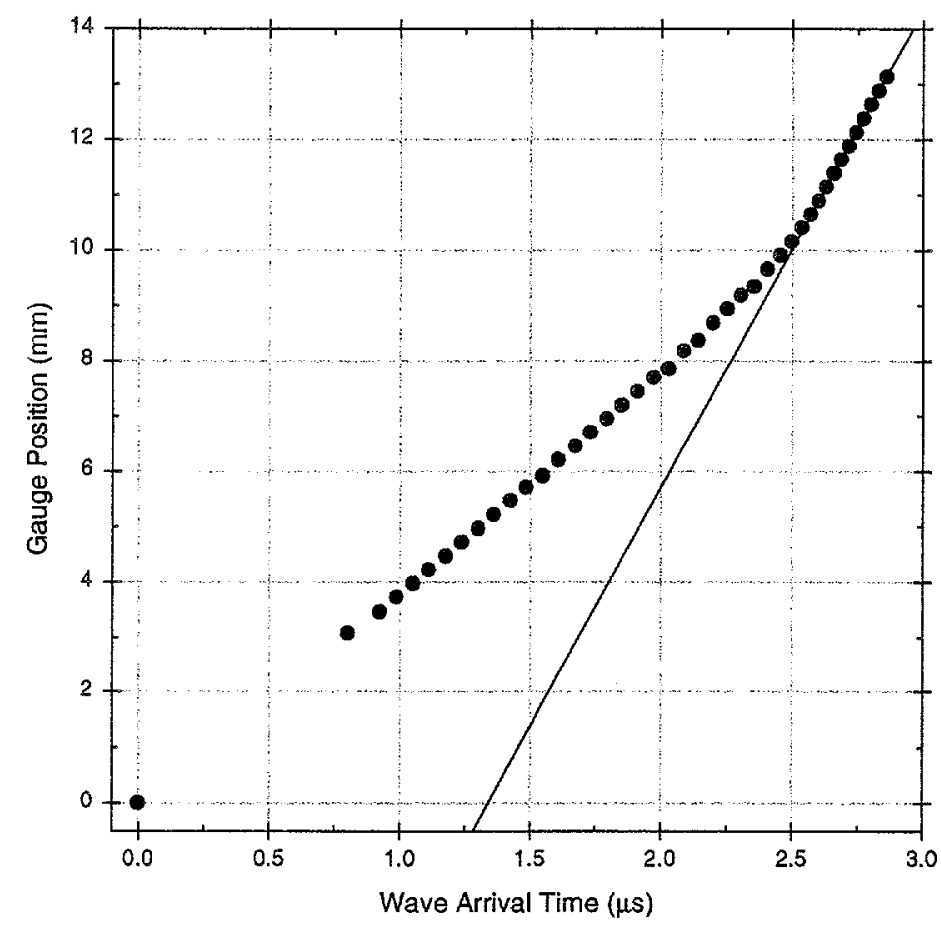

Figure A24. $x$ - $t$ plot for Shot 1179. Red points are from the shock tracker. Black points are from the two stirrup gauges (which gave arrival times only) and from the region that is fully detonating. 
Shot 1178

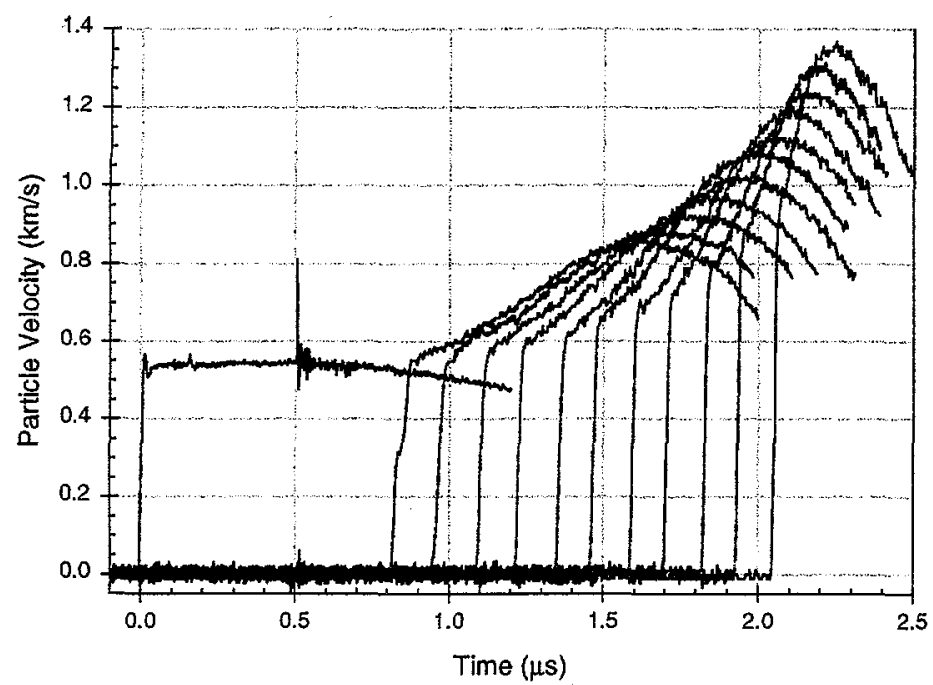

Figure A25. Particle velocity wave profiles from Shot 1178. The input is 3.82 GPa and was created by impacting z-cut sapphire on the PBX 9501 at $0.638 \mathrm{~km} / \mathrm{s}$. The PBX 9501 is of type W78.

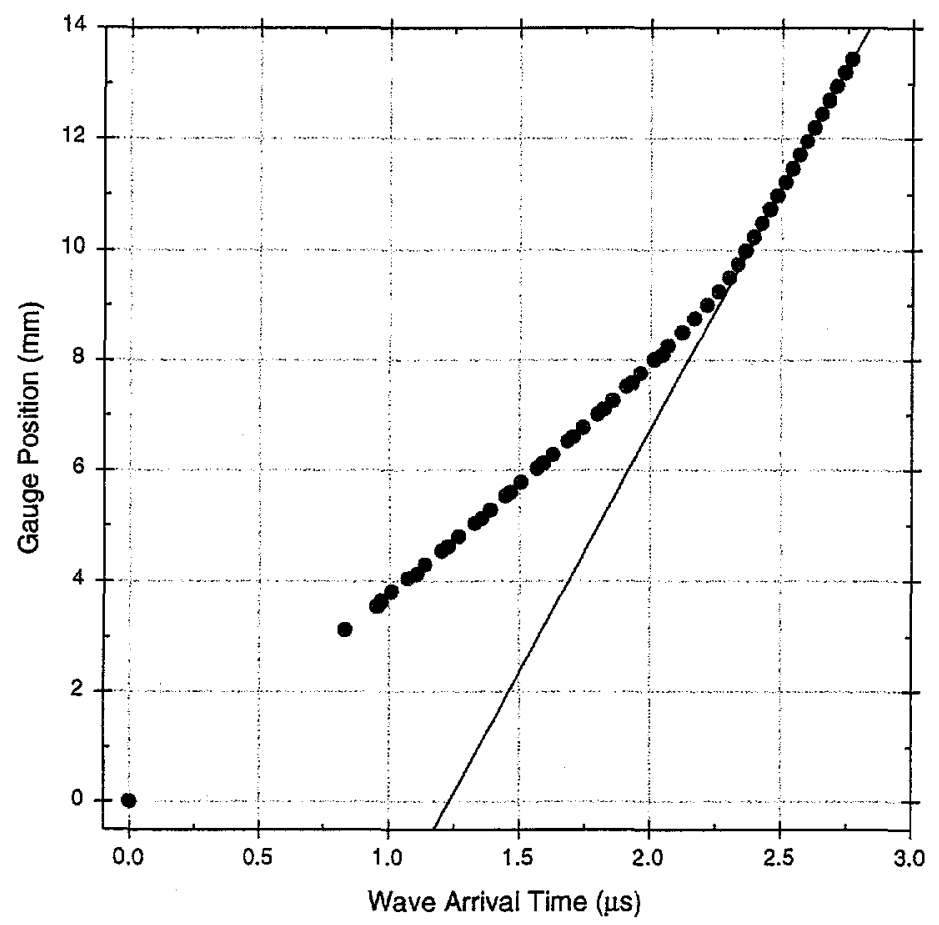

Figure A26. $x$ - $t$ plot for Shot 1178. Red points are from the shock tracker. Blue and green points are from the particle velocity gauges. Black points are from the two stirrup gauges and from the region that is fully detonating.
Table A13. $t-x$ data for Shot 1178

\begin{tabular}{|c|c|}
\hline$t-\mu s$ & $x-\mathrm{mm}$ \\
\hline 0.000 & 0.000 \\
\hline 0.830 & 3.114 \\
\hline 0.971 & 3.630 \\
\hline 1.105 & 4.119 \\
\hline 1.227 & 4.618 \\
\hline 1.357 & 5.126 \\
\hline 1.467 & 5.604 \\
\hline 1.593 & 6.115 \\
\hline 1.707 & 6.591 \\
\hline 1.825 & 7.103 \\
\hline 1.935 & 7.579 \\
\hline 2.049 & 8.092 \\
\hline 0.954 & 3.534 \\
\hline 1.008 & 3.801 \\
\hline 1.070 & 4.047 \\
\hline 1.136 & 4.298 \\
\hline 1.202 & 4.543 \\
\hline 1.266 & 4.791 \\
\hline 1.328 & 5.035 \\
\hline 1.388 & 5.282 \\
\hline 1.448 & 5.530 \\
\hline 1.508 & 5.777 \\
\hline 1.568 & 6.025 \\
\hline 1.630 & 6.272 \\
\hline 1.686 & 6.519 \\
\hline 1.744 & 6.766 \\
\hline 1.802 & 7.008 \\
\hline 1.858 & 7.257 \\
\hline 1.912 & 7.508 \\
\hline 1.966 & 7.753 \\
\hline 2.018 & 8.000 \\
\hline 2.070 & 8.249 \\
\hline 2.122 & 8.494 \\
\hline 2. 168 & 8.742 \\
\hline 2.216 & 8.988 \\
\hline 2.260 & 9.233 \\
\hline 2.300 & 9.482 \\
\hline 2.332 & 9.728 \\
\hline 2.362 & 9.974 \\
\hline 2.394 & 10.220 \\
\hline 2.424 & 10.469 \\
\hline 2.456 & 10.718 \\
\hline 2.484 & 10.965 \\
\hline 2.514 & 11.210 \\
\hline 2.542 & 11.459 \\
\hline 2.570 & 11.704 \\
\hline 2.598 & 11.952 \\
\hline 2.626 & 12.196 \\
\hline 2.654 & 12.446 \\
\hline 2.682 & 12.693 \\
\hline 2.710 & 12.939 \\
\hline 2.740 & 13.189 \\
\hline
\end{tabular}


Shot 1075

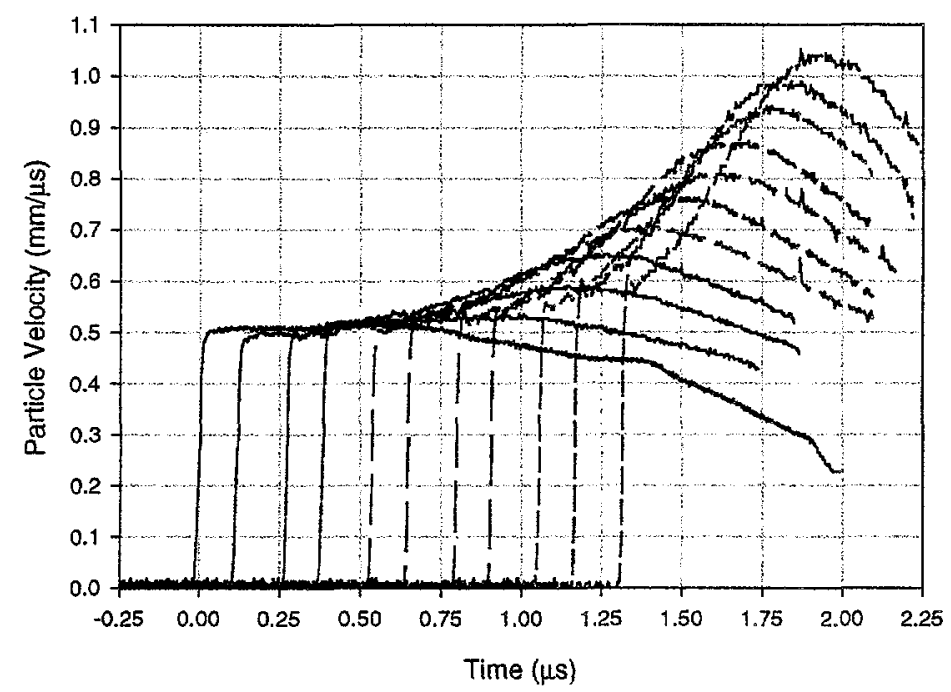

Figure A27. Particle velocity wave profiles from Shot 1075. The input is 3.32 $\mathrm{GPa}$ and was created by impacting Vistal on the PBX 9501 at $0.586 \mathrm{~km} / \mathrm{s}$. The PBX 9501 is of type A.

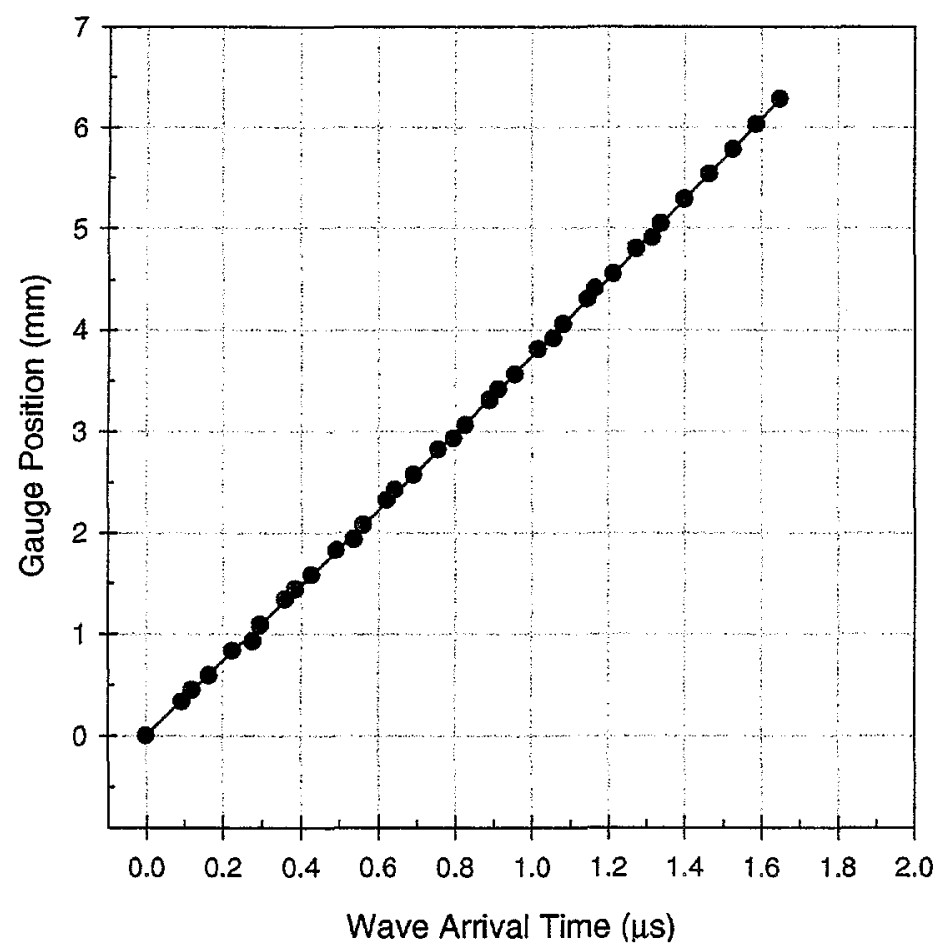

Figure A28. $x-t$ plot for Shot 1075. Red points are from the shock tracker and green points are from the particle velocity gauges.
Table A14. $t-x$ data for Shot 1075

\begin{tabular}{ll}
$t-\mu s$ & $x-\mathrm{mm}$ \\
\hline 0.000 & 0.000 \\
0.120 & 0.450 \\
0.276 & 0.930 \\
0.384 & 1.437 \\
0.536 & 1.937 \\
0.644 & 2.428 \\
0.796 & 2.929 \\
0.912 & 3.414 \\
1.056 & 3.918 \\
1.164 & 4.408 \\
1.316 & 4.907 \\
0.094 & 0.331 \\
0.164 & 0.596 \\
0.224 & 0.840 \\
0.294 & 1.087 \\
0.358 & 1.338 \\
0.426 & 1.579 \\
0.490 & 1.829 \\
0.560 & 2.079 \\
0.622 & 2.326 \\
0.692 & 2.572 \\
0.756 & 2.818 \\
0.826 & 3.064 \\
0.890 & 3.313 \\
0.956 & 3.561 \\
1.016 & 3.811 \\
1.082 & 4.057 \\
1.146 & 4.306 \\
1.212 & 4.544 \\
1.274 & 4.800 \\
1.338 & 5.047 \\
1.400 & 5.290 \\
1.464 & 5.538 \\
1.526 & 5.783 \\
1.586 & 6.034 \\
1.648 & 6.283
\end{tabular}




\section{Shot 1163}

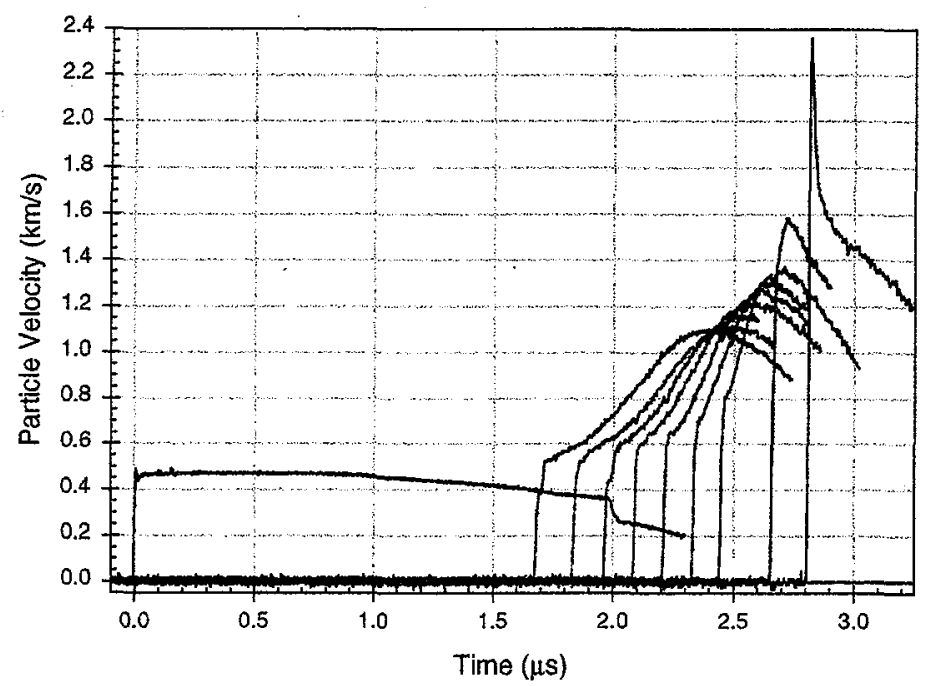

Figure A29. Particle velocity wave profiles from Shot 1163. The input is 3.07 $\mathrm{GPa}$ and was created by impacting Vistal on the PBX 9501 at $0.552 \mathrm{~km} / \mathrm{s}$. The PBX 9501 is of type A.

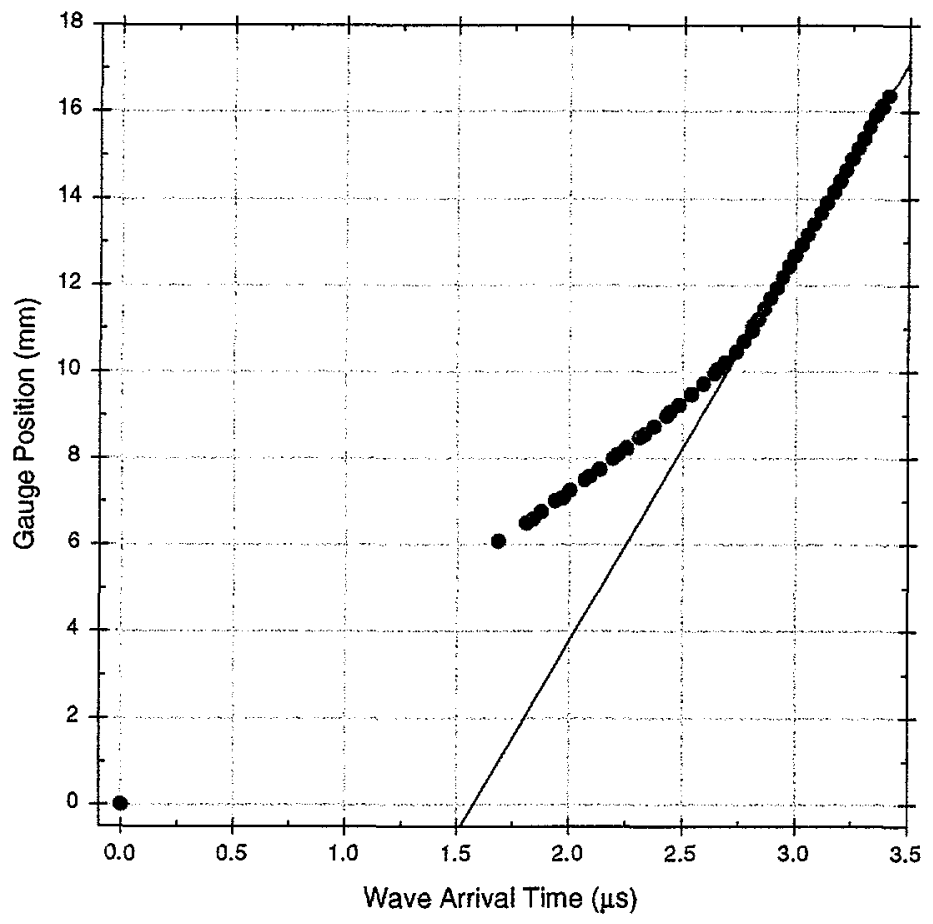

Figure A30. $x-t$ plot for Shot 1163. Red points are from the shock tracker, blue and green points are from the particle velocity gauges. Black points are from the detonating region.
Table A15. $t-x$ data for Shot 1163

\begin{tabular}{rr}
$t-\mu \mathrm{s}$ & $x-\mathrm{mm}$ \\
\hline \hline 0.000 & 0.000 \\
1.682 & 6.081 \\
1.838 & 6.588 \\
1.970 & 7.079 \\
2.090 & 7.574 \\
2.214 & 8.084 \\
2.334 & 8.561 \\
2.446 & 9.073 \\
2.658 & 10.059 \\
2.806 & 11.045 \\
1.806 & 6.490 \\
1.874 & 6.756 \\
1.936 & 7.002 \\
2.002 & 7.248 \\
2.066 & 7.494 \\
2.134 & 7.741 \\
2.192 & 7.989 \\
2.254 & 8.233 \\
2.312 & 8.482 \\
2.376 & 8.729 \\
2.430 & 8.974 \\
2.486 & 9.224 \\
2.540 & 9.472 \\
2.594 & 9.715 \\
2.642 & 9.961 \\
2.690 & 10.211 \\
2.738 & 10.457 \\
2.772 & 10.704 \\
2.806 & 10.951 \\
2.832 & 11.197 \\
2.858 & 11.444 \\
2.886 & 11.693 \\
2.914 & 11.936 \\
2.940 & 12.182 \\
2.968 & 12.430 \\
2.996 & 12.676 \\
3.024 & 12.923 \\
3.052 & 13.165 \\
3.080 & 13.415 \\
3.110 & 13.663 \\
3.138 & 13.909 \\
3.168 & 14.157 \\
3.196 & 14.403 \\
3.222 & 14.649 \\
3.250 & 14.912 \\
3.276 & 15.159 \\
3.302 & 15.388 \\
3.328 & 15.651 \\
3.354 & 15.900 \\
3.384 & 16.121 \\
3.412 & 16.371
\end{tabular}


Shot 1171

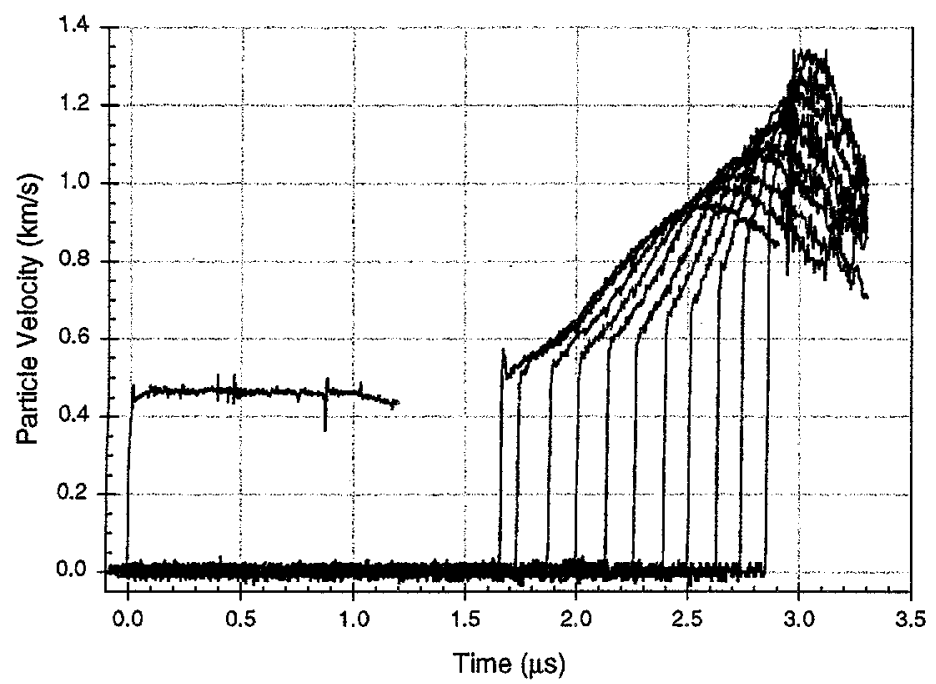

Figure A31. Particle velocity wave profiles from Shot 1171 . The input is 3.09 $\mathrm{GPa}$ and was created by impacting z-cut quartz on the PBX 9501 at $0.656 \mathrm{~km} / \mathrm{s}$. The PBX 9501 is of type B.

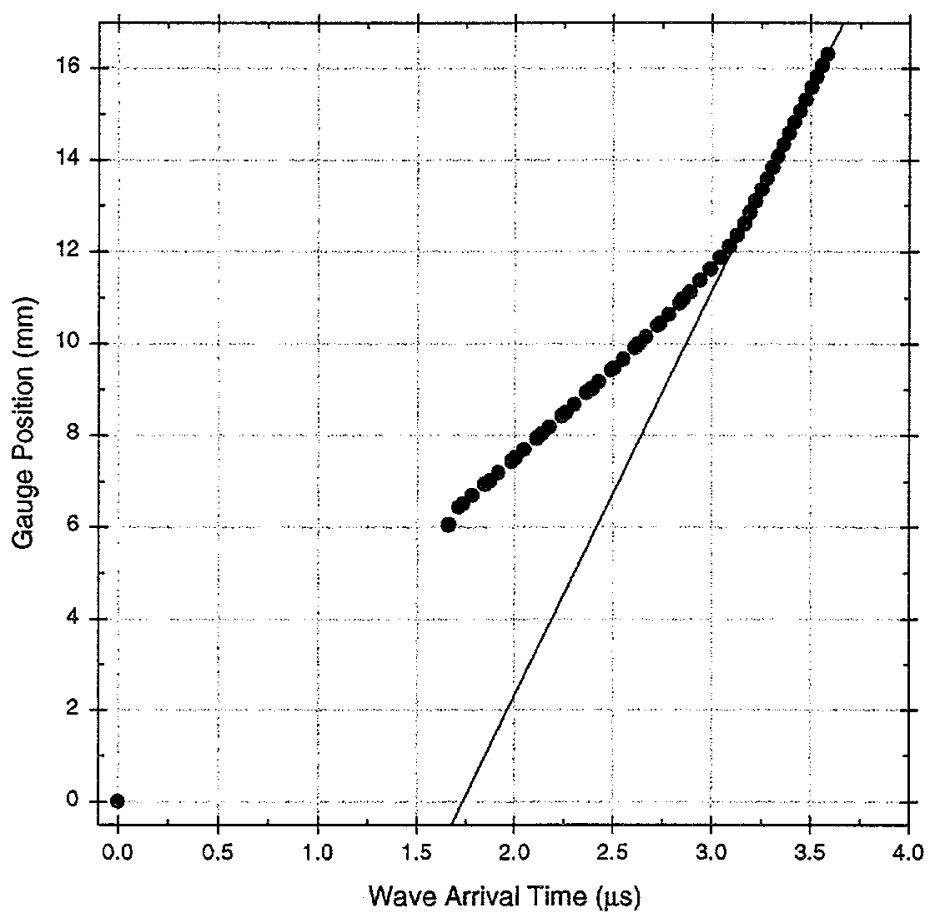

Figure A32. $x-t$ plot for Shot 1171. Red points are from the shock tracker, blue and green points are from the particle velocity gauges. The first two black points are from the stirrup gauges and the last black points are in the detonating region.
Table A16. $t-x$ data for Shot 1171

\begin{tabular}{rr}
$t-\mu s$ & $x-\mathrm{mm}$ \\
\hline 0.000 & 0.000 \\
1.660 & 6.043 \\
1.735 & 6.504 \\
1.874 & 7.010 \\
2.003 & 7.498 \\
2.138 & 8.022 \\
2.263 & 8.488 \\
2.394 & 9.008 \\
2.503 & 9.460 \\
2.630 & 9.996 \\
2.739 & 10.443 \\
2.854 & 10.982 \\
1.713 & 6.422 \\
1.782 & 6.688 \\
1.847 & 6.935 \\
1.914 & 7.183 \\
1.981 & 7.429 \\
2.046 & 7.678 \\
2.111 & 7.923 \\
2.176 & 8.170 \\
2.239 & 8.417 \\
2.302 & 8.664 \\
2.363 & 8.910 \\
2.426 & 9.158 \\
2.489 & 9.405 \\
2.550 & 9.650 \\
2.609 & 9.896 \\
2.666 & 10.145 \\
2.726 & 10.391 \\
2.783 & 10.635 \\
2.838 & 10.882 \\
2.891 & 11.127 \\
2.942 & 11.377 \\
2.995 & 11.622 \\
3.042 & 11.871 \\
3.087 & 12.117 \\
3.128 & 12.361 \\
3.530 & 15.810 \\
3.165 & 12.609 \\
3.194 & 12.858 \\
3.221 & 13.104 \\
3.252 & 13.349 \\
3.279 & 13.594 \\
3.308 & 13.843 \\
3.335 & 14.089 \\
& 14.334 \\
3.460 & 14.582 \\
\hline
\end{tabular}


Shot 1146

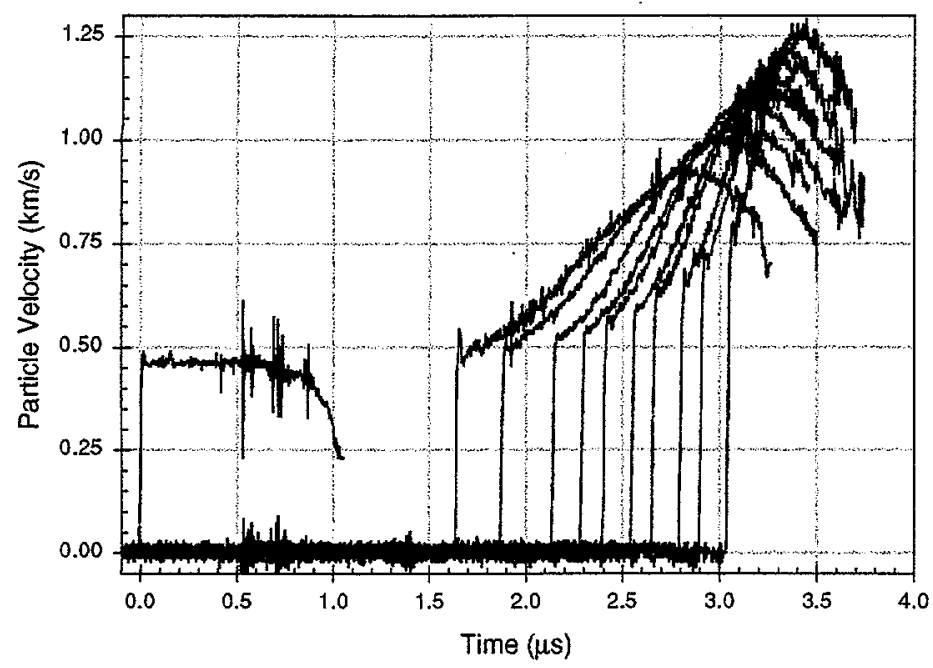

Figure A33. Particle velocity wave profiles from Shot 1146 . The input is 3.10 $\mathrm{GPa}$ and was created by impacting z-cut quartz on the PBX 9501 at $0.652 \mathrm{~km} / \mathrm{s}$. The PBX 9501 is of type C.

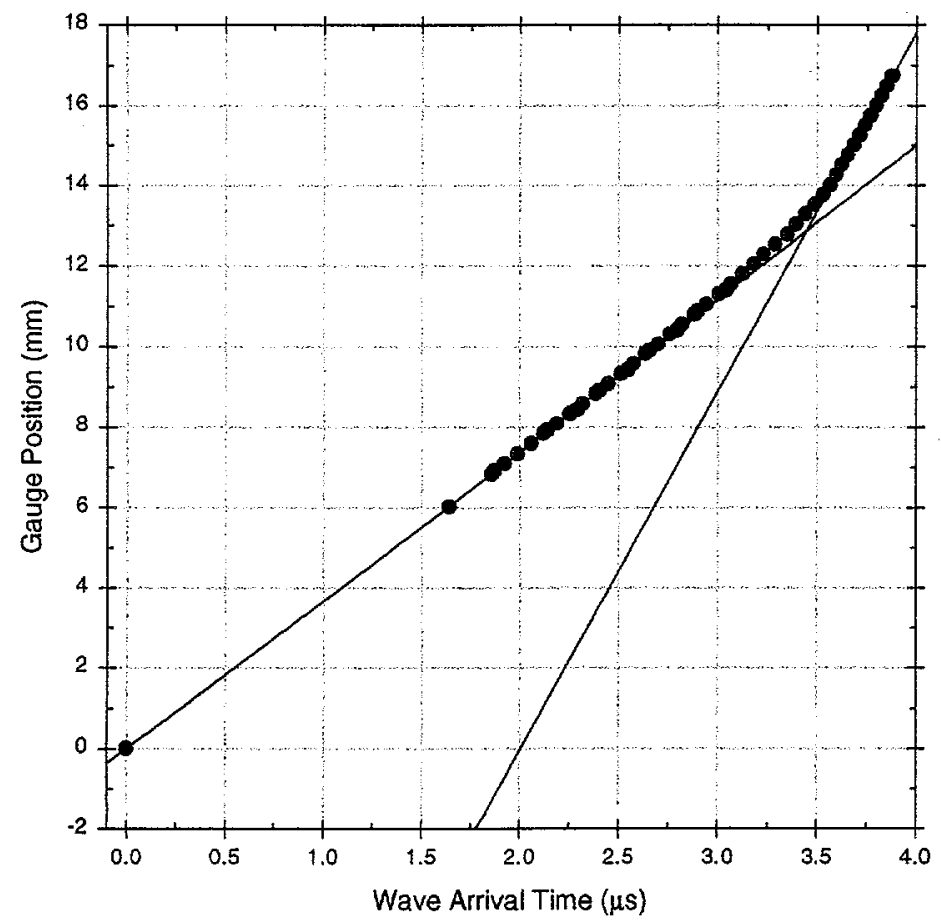

Figure A34. $x$-t plot for Shot 1146. Red points are from the shock tracker and green points are from the particle velocity gauges. The last black points are in the detonating region.
Table A17, $t-x$ data for Shot 1146

\begin{tabular}{rr}
$t-\mu s$ & $x-\mathrm{mm}$ \\
\hline \hline 0.000 & 0.000 \\
1.640 & 6.014 \\
1.872 & 6.931 \\
2.140 & 7.921 \\
2.288 & 8.432 \\
2.404 & 8.915 \\
2.548 & 9.420 \\
2.656 & 9.902 \\
2.796 & 10.412 \\
2.900 & 10.890 \\
3.040 & 11.399 \\
1.856 & 6.827 \\
1.922 & 7.094 \\
1.989 & 7.366 \\
2.056 & 7.585 \\
2.120 & 7.833 \\
2.188 & 8.081 \\
2.254 & 8.330 \\
2.318 & 8.577 \\
2.384 & 8.825 \\
2.448 & 9.075 \\
2.512 & 9.321 \\
2.575 & 9.565 \\
2.636 & 9.815 \\
2.700 & 10.059 \\
2.760 & 10.311 \\
2.822 & 10.553 \\
2.883 & 10.801 \\
2.943 & 11.038 \\
3.005 & 11.298 \\
3.066 & 11.541 \\
3.125 & 11.791 \\
3.180 & 12.039 \\
3.230 & 12.287 \\
3.288 & 12.535 \\
3.350 & 12.777 \\
3.392 & 13.023 \\
3.440 & 13.279 \\
3.486 & 13.523 \\
3.530 & 13.767 \\
3.566 & 14.009 \\
3.596 & 14.263 \\
3.624 & 14.514 \\
3.654 & 14.763 \\
3.684 & 15.008 \\
3.716 & 15.250 \\
3.742 & 15.502 \\
3.768 & 15.739 \\
3.798 & 15.996 \\
3.824 & 16.241 \\
3.852 & 16.492 \\
3.880 & 16.735
\end{tabular}


Shot 1147

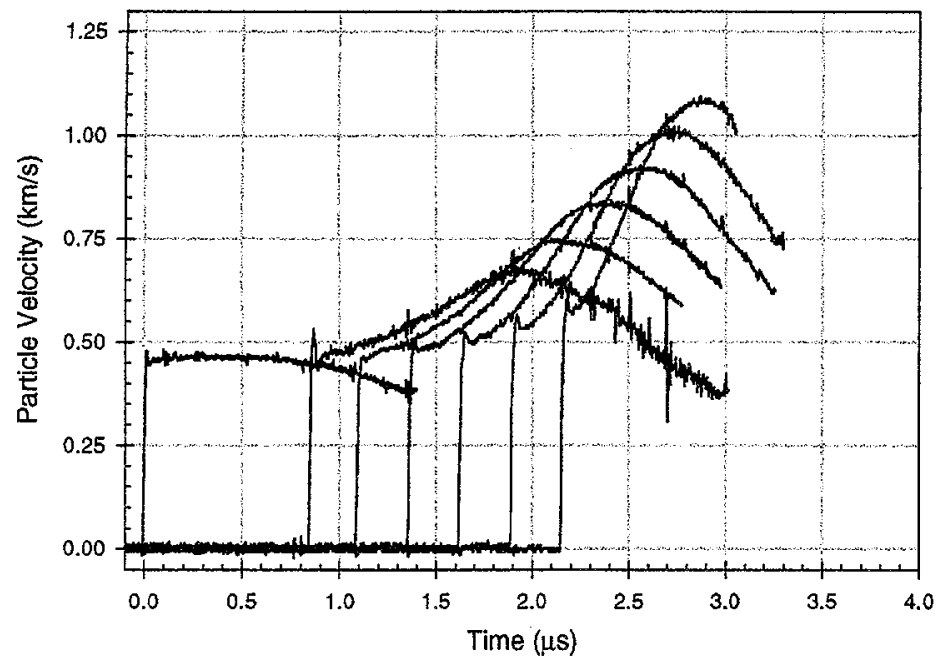

Figure A35. Particle velocity wave profiles from Shot 1147. The input is 3.10 $\mathrm{GPa}$ and was created by impacting $\mathrm{z}-\mathrm{cut}$ quartz on the PBX 9501 at $0.651 \mathrm{~km} / \mathrm{s}$. The PBX 9501 is of type C. Only 7 of the twelve gauges worked, however arrival times were obtained from the other 5 gauges.

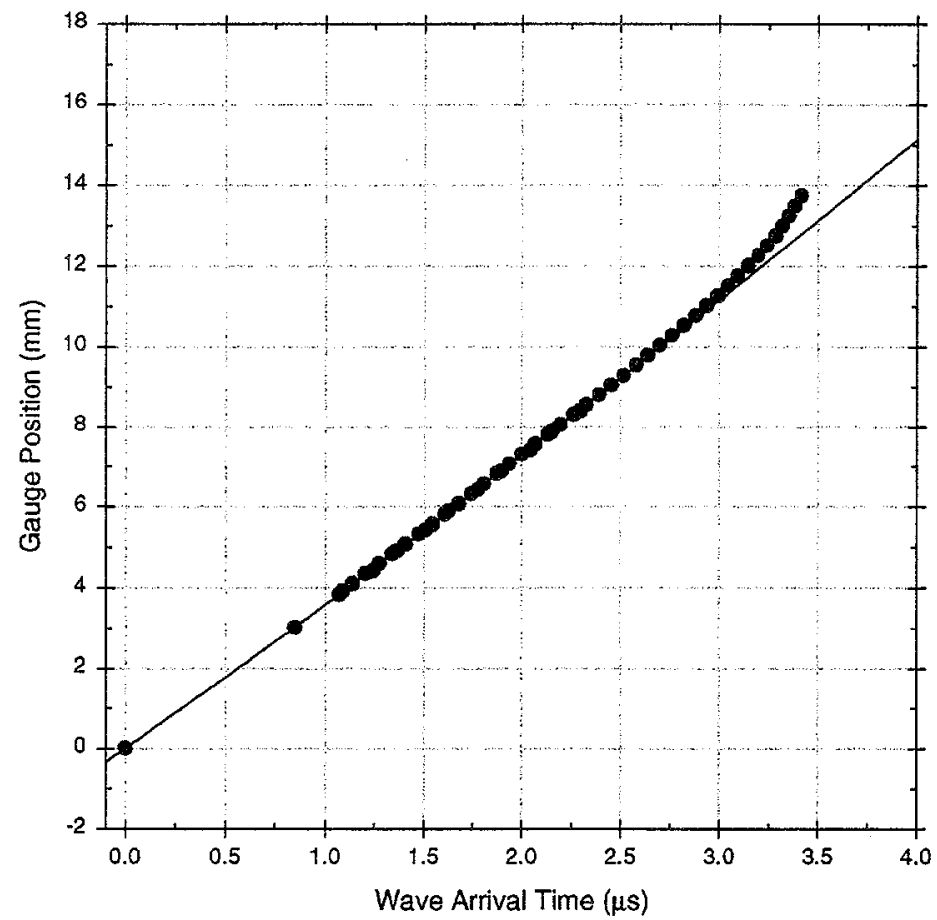

Figure A36. $x-t$ plot for Shot 1147. Red points are from the shock tracker and green points are from the particle velocity gauges.
Table A18. $t-x$ data for Shot 1147

\begin{tabular}{rr}
$t-\mu \mathrm{s}$ & $x-\mathrm{mm}$ \\
\hline 0.000 & 0.000 \\
0.846 & 3.013 \\
1.090 & 3.918 \\
1.242 & 4.413 \\
1.362 & 4.909 \\
1.506 & 5.423 \\
1.626 & 5.899 \\
1.774 & 6.413 \\
1.894 & 6.884 \\
2.042 & 7.401 \\
2.154 & 7.876 \\
2.298 & 8.390 \\
1.070 & 3.826 \\
1.136 & 4.093 \\
1.204 & 4.344 \\
1.272 & 4.591 \\
1.338 & 4.835 \\
1.406 & 5.083 \\
1.472 & 5.331 \\
1.542 & 5.572 \\
1.606 & 5.824 \\
1.676 & 6.072 \\
1.740 & 6.317 \\
1.806 & 6.563 \\
1.870 & 6.816 \\
1.936 & 7.062 \\
2.000 & 7.308 \\
2.068 & 7.556 \\
2.132 & 7.802 \\
2.196 & 8.052 \\
2.264 & 8.299 \\
2.328 & 8.544 \\
2.392 & 8.791 \\
2.454 & 9.040 \\
2.516 & 9.280 \\
2.580 & 9.534 \\
2.640 & 9.778 \\
2.700 & 10.031 \\
2.762 & 10.277 \\
2.822 & 10.525 \\
2.882 & 10.770 \\
2.938 & 11.017 \\
2.994 & 11.260 \\
3.046 & 11.510 \\
3.096 & 11.758 \\
3.148 & 12.002 \\
3.198 & 12.253 \\
3.242 & 12.499 \\
3.286 & 12.745 \\
3.320 & 12.993 \\
3.382 & 13.240 \\
& 13.484
\end{tabular}


Shot 1165

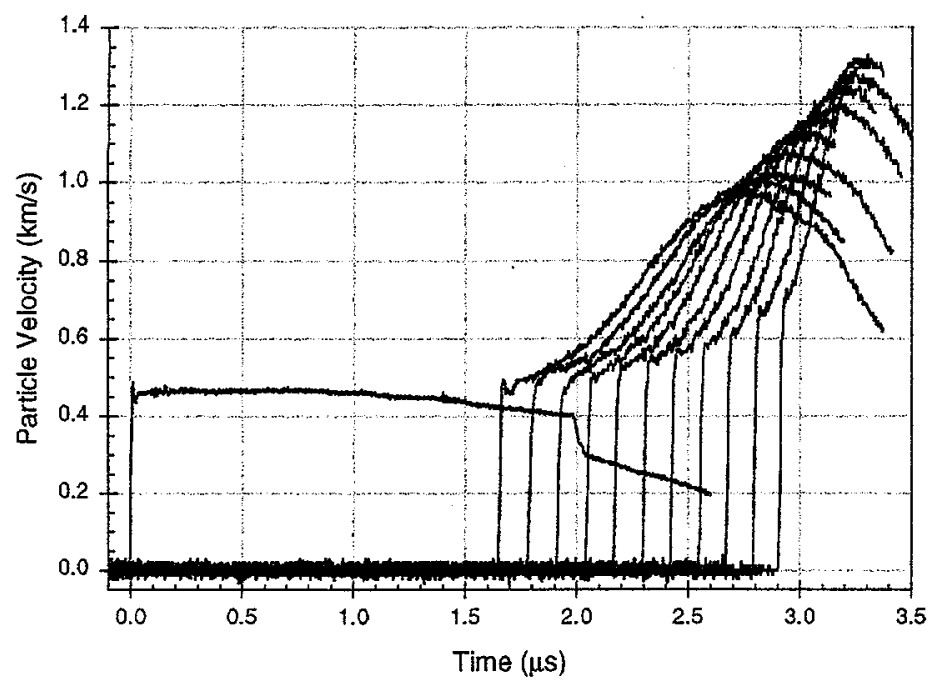

Figure A37. Particle velocity wave profiles from Shot 1165 . The input is 3.13 GPa and was created by impacting Vistal on the PBX 9501 at $0.550 \mathrm{~km} / \mathrm{s}$. The PBX 9501 is of type W76.

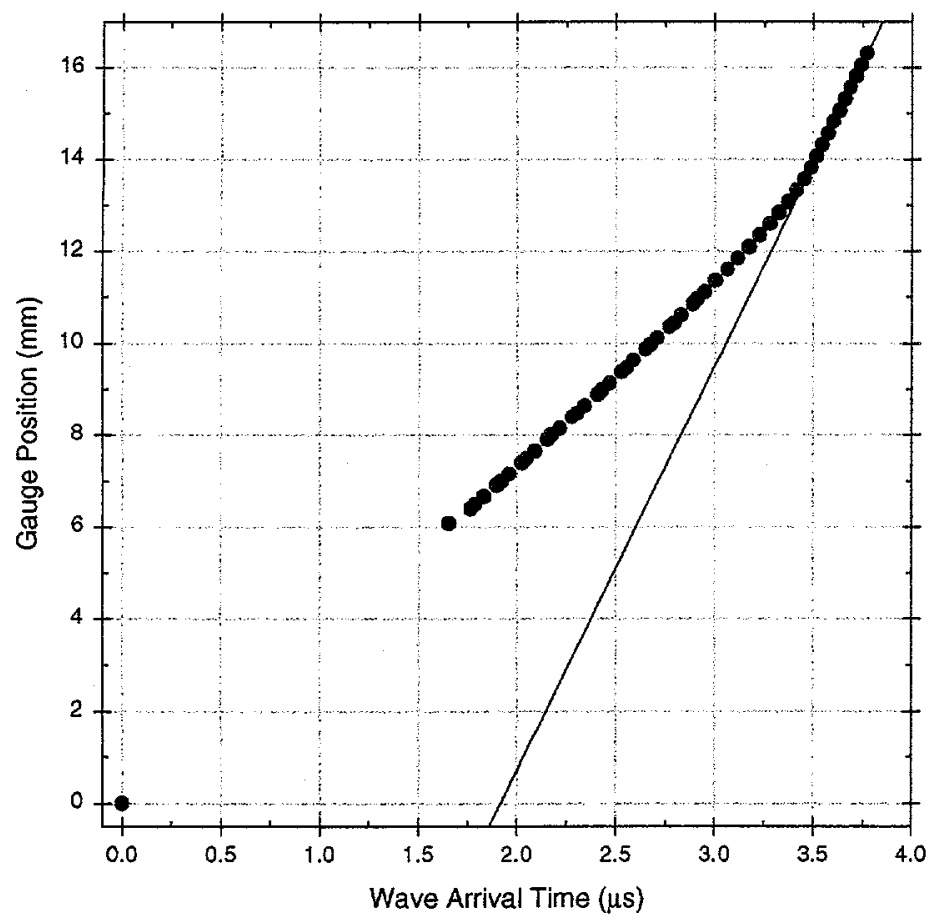

Figure A38. $x$ - $t$ plot for Shot 1165. Red points are from the shock tracker, and blue and green points are from the particle velocity gauges. The first two black points are from the stirrup particle velocity gauges and the last black points are in the detonating region.
Table A19. $t-x$ data for Shot 1165

\begin{tabular}{rr}
$t-\mu \mathrm{s}$ & $x-\mathrm{mm}$ \\
\hline 0.000 & 0.000 \\
1.654 & 6.076 \\
1.788 & 6.491 \\
1.919 & 6.984 \\
2.047 & 7.480 \\
2.171 & 7.933 \\
2.303 & 8.465 \\
2.427 & 8.979 \\
2.555 & 9.455 \\
2.674 & 9.965 \\
2.795 & 10.437 \\
2.910 & 10.952 \\
1.765 & 6.391 \\
1.832 & 6.655 \\
1.897 & 6.908 \\
1.960 & 7.154 \\
2.025 & 7.399 \\
2.089 & 7.645 \\
2.152 & 7.894 \\
2.215 & 8.140 \\
2.278 & 8.385 \\
2.339 & 8.632 \\
2.406 & 8.880 \\
2.467 & 9.127 \\
2.528 & 9.372 \\
2.587 & 9.620 \\
2.650 & 9.865 \\
2.711 & 10.114 \\
2.772 & 10.360 \\
2.831 & 10.607 \\
2.890 & 10.853 \\
2.951 & 11.100 \\
3.004 & 11.348 \\
3.065 & 11.594 \\
3.118 & 11.840 \\
3.174 & 12.087 \\
3.227 & 12.335 \\
3.280 & 12.580 \\
3.327 & 12.829 \\
3.374 & 13.072 \\
3.415 & 13.321 \\
3.456 & 13.567 \\
3.489 & 13.811 \\
3.516 & 14.061 \\
3.545 & 14.307 \\
3.576 & 14.555 \\
3.634 & 14.822 \\
3.663 & 15.062 \\
3.314 \\
3.5 .50 & 15.558 \\
\hline
\end{tabular}


Shot 1177

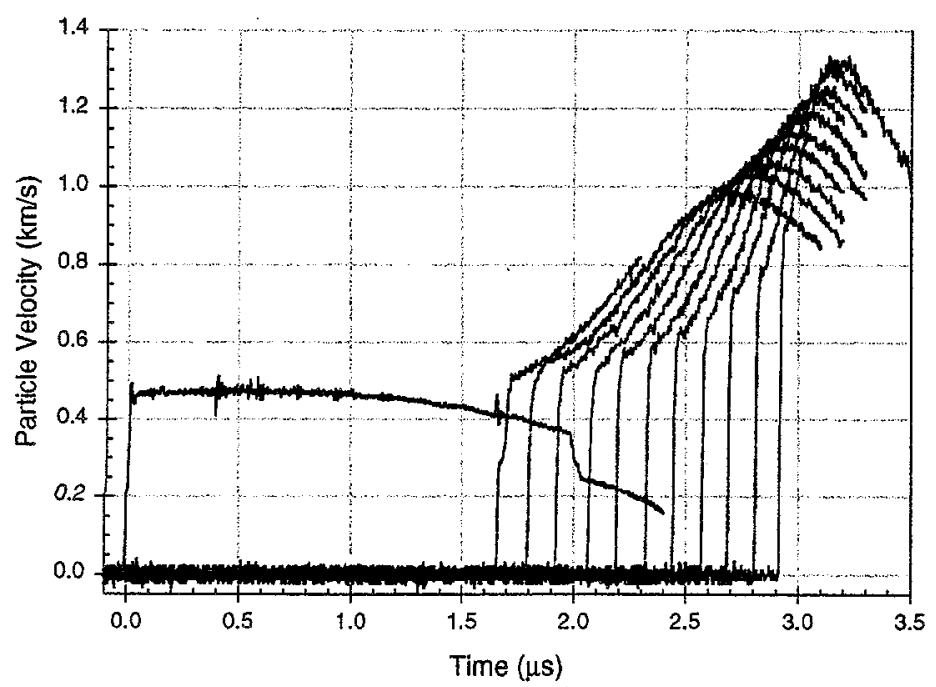

Figure A39. Particle velocity wave profiles from Shot 1177. The input is 3.14 $\mathrm{GPa}$ and was created by impacting Vistal on the PBX 9501 at $0.552 \mathrm{~km} / \mathrm{s}$. The PBX 9501 is of type W78.

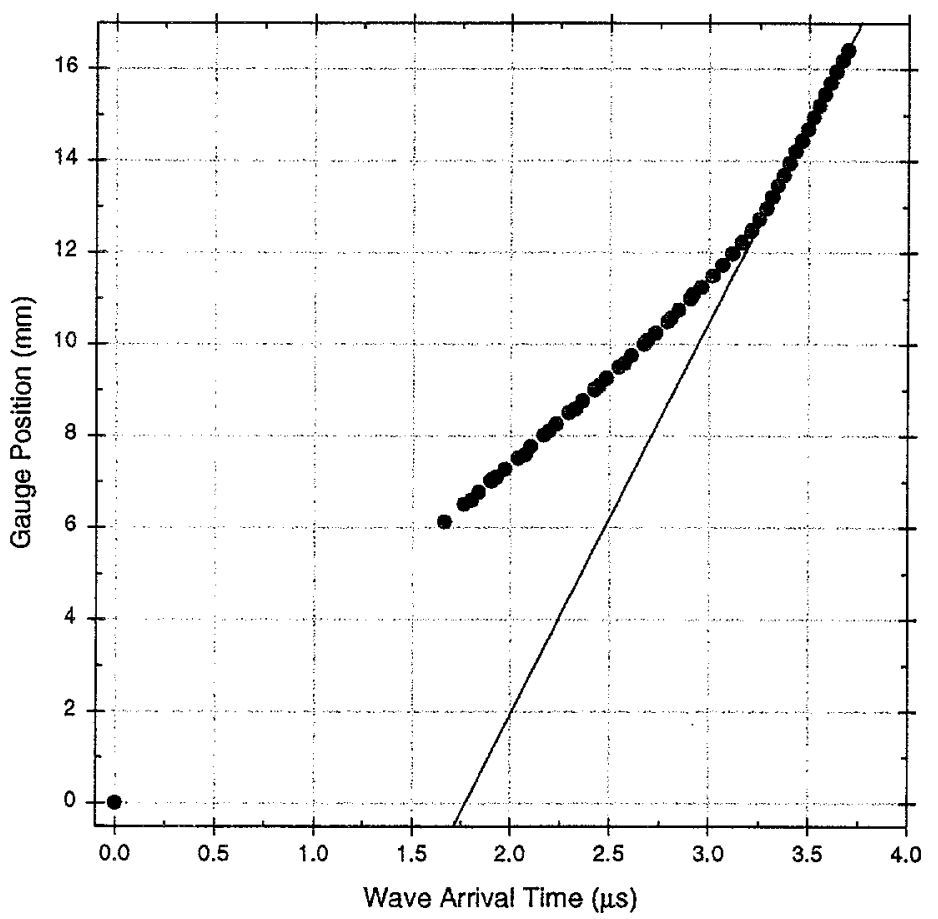

Figure A40. $x-t$ plot for Shot 1177. Red points are from the shock tracker, and blue and green points are from the particle velocity gauges. The first two black points are from the stirrup particle velocity gauges and the last black points are in the detonating region.
Table A20. $t$ - $x$ data for Shot 1177

\begin{tabular}{rr}
$t-\mu \mathrm{s}$ & $x-\mathrm{mm}$ \\
\hline 0.000 & 0.000 \\
1.662 & 6.120 \\
1.802 & 6.593 \\
1.926 & 7.090 \\
2.074 & 7.583 \\
2.194 & 8.102 \\
2.326 & 8.576 \\
2.446 & 9.095 \\
2.574 & 9.569 \\
2.690 & 10.087 \\
2.810 & 10.561 \\
2.918 & 11.080 \\
1.762 & 6.498 \\
1.836 & 6.765 \\
1.900 & 7.015 \\
1.970 & 7.261 \\
2.038 & 7.511 \\
2.100 & 7.757 \\
2.166 & 8.006 \\
2.230 & 8.256 \\
2.294 & 8.502 \\
2.360 & 8.752 \\
2.422 & 9.001 \\
2.482 & 9.246 \\
2.546 & 9.495 \\
2.608 & 9.744 \\
2.670 & 9.993 \\
2.730 & 10.240 \\
2.790 & 10.487 \\
2.846 & 10.736 \\
2.906 & 10.985 \\
2.960 & 11.235 \\
3.016 & 11.482 \\
3.066 & 11.728 \\
3.116 & 11.975 \\
3.164 & 12.224 \\
3.210 & 12.475 \\
3.250 & 12.722 \\
3.286 & 12.968 \\
3.314 & 13.217 \\
3.344 & 13.465 \\
3.374 & 13.694 \\
3.402 & 13.951 \\
3.434 & 14.207 \\
3.464 & 14.435 \\
3.496 & 14.692 \\
3.524 & 14.948 \\
3.552 & 15.198 \\
3.668 & 15.446 \\
& 15.694 \\
\hline & 16.940 \\
&
\end{tabular}

